\title{
Exposing and Overcoming Limitations of Clinical Laboratory Tests in COVID-19 by Adding Immunological Parameters
}

\author{
Running title: Overcoming Limitations of Clinical Laboratory Tests in COVID-19
}

\section{Authors}

Adrián Sánchez-Montalvá, MD, $\mathrm{PhD}^{1,2,3 *}$, Daniel Álvarez-Sierra $\mathrm{PhD}^{4 *}$, Mónica Martínez Gallo ${ }^{4,5,6}$ $\mathrm{PhD}$, Janire Perurena-Prieto BSc ${ }^{4,6}$, Iria Arrese-Muñoz BSc ${ }^{5}$, Juan Carlos Ruiz Rodríguez MD ${ }^{7,8}$, Juan Espinosa-Pereiro MD ${ }^{1,2}$, Pau Bosch-Nicolau MD ${ }^{1,2}$, Xavier Martínez-Gómez MD ${ }^{9,10,11}$, Andrés Anton $\mathrm{PhD}^{12,13,14}$, Ferran Martínez-Valle MD, PhD ${ }^{3,15,16}$, Mar Riveiro-Barciela MD, $\mathrm{PhD}^{3,16,17,18}$, Albert Blanco-Grau BSc ${ }^{19}$, Francisco Rodríguez-Frias $\mathrm{PhD}^{17,19}$, Pol Castellano-Escuder $\mathrm{PhD}^{20}$, Elisabet Poyato Canton $\mathrm{BSc}^{21}$, Jordi Bas Minguet $\mathrm{PhD}^{21}$, Eva Martínez-Cáceres $\mathrm{MD}^{6,23,24}$, Alex Sánchez-Pla $\mathrm{PhD}^{20,22}$, Coral Zurera Egea BSc ${ }^{23}$, Aina Teniente Serra $\mathrm{PhD}^{6,23,24}$, Manuel Hernández González $\mathrm{PhD}^{4,5,6^{* *}}$, Ricardo Pujol-Borrell $\mathrm{MD}, \mathrm{PhD}^{4,5,6^{* *}}$ and the Hospital Vall d'Hebron COVID19 Immune Profile Group.

${ }^{1}$ Infectious Disease Department, Hospital Universitari Vall Hebron, Barcelona, Spain

${ }^{2}$ International Health Programme Institut Català de la Salut, Vall Hebron Research Institute (VHIR), Campus Vall Hebron, Barcelona, Spain.

${ }^{3}$ Department of Medicine, Universitat Autònoma Barcelona, Campus Vall Hebron, Barcelona, Spain

${ }^{4}$ Translational Immunology Research Group, Vall Hebron Research Institute (VHIR), Campus Vall Hebron, Barcelona, Spain.

${ }^{5}$ Immunology Department, Hospital Universitari Vall Hebron, Barcelona, Spain

${ }^{6}$ Department of Cell Biology, Physiology, and Immunology, Universitat Autònoma Barcelona, Campus Vall Hebron, Barcelona, Spain.

${ }^{7}$ Intensive Medicine Department, Hospital Universitari Vall Hebron, Barcelona, Spain.

${ }^{8}$ Organ Dysfunction and Resuscitation Research Group, Vall Hebron Research Institute (VHIR), Campus Vall Hebron, Barcelona, Spain.

${ }^{9}$ Epidemiology and Public Health Department, Hospital Universitari Vall Hebron, Campus Vall Hebron, Barcelona, Spain

${ }^{10}$ Epidemiology and Public Health Research, Group, Vall Hebron Research Institute (VHIR), Campus Vall Hebron, Barcelona, Spain.

${ }^{11}$ Department of Pediatrics, Obstetrics and Gynecology, Epidemiology and Pub Health, Universitat Autònoma Barcelona, Barcelona, Spain.

${ }^{12}$ Microbiology Department, Hospital Universitari Vall Hebron, Barcelona, Spain.

${ }^{13}$ Microbiology Research Group, Vall Hebron Research Institute (VHIR), Campus Vall Hebron, Barcelona, Spain

${ }^{14}$ Department of Genetics and Microbiology, Autonomous University of Barcelona, Campus Vall Hebron, Barcelona, Spain.

${ }^{15}$ Internal Medicine Department, Hospital Universitari Vall Hebron, Barcelona, Spain

${ }^{16}$ Systemic Disease Research Group, Valle Hebron Research Institute (VHIR), Campus Vall Hebron, Barcelona, Spain.

${ }^{17}$ Liver Disease Research Group, Valle Hebron Research Institute (VHIR), Campus Vall Hebron, Barcelona, Spain.

${ }^{18}$ CIBERehd - Instituto de Salud Carlos III, Campus Vall Hebron, Barcelona, Spain

${ }^{19}$ Clinical Laboratory Department, Hospital Universitari Vall Hebron, Barcelona, Spain

${ }^{20}$ Bioinformatics and Statistics Group, University of Barcelona, Barcelona, Spain

${ }^{21}$ Immunology Division, Bellvitge University Hospital, Hospitalet de Llobregat, Barcelona, Spain

${ }^{22}$ Statistics and Bioinformatics Unit, Vall Hebron Research Institute (VHIR), Campus Vall Hebron,

Barcelona Spain,

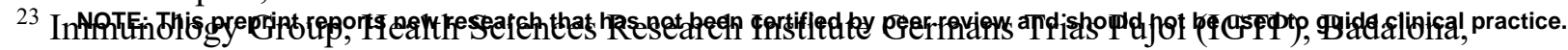

Barcelona, Spain 
medRxiv preprint doi: https://doi.org/10.1101/2022.01.29.22270016; this version posted February $2,2022$. The copyright holder for this preprint (which was not certified by peer review) is the author/funder, who has granted medRxiv a license to display the preprint in All rights reserved. No reuse allowed without permission.

${ }^{24}$ Immunology Department, Hospital Universitari Germans Trias Pujol, Badalona (Barcelona), Spain

Campus Vall Hebron postal address: Passeig Vall d'Hebron 119-129, 08035 Barcelona, Spain.

The Immunology Group at Vall d'Hebron Hospital are part of the Universitat Autònoma de Barcelona - Focis Center of Excellence (www.focisnet.org)

*These authors share first authorship

** These authors contributed equally to this work and share last authorship

Correspondence:

Ricardo Pujol-Borrell MD, $\mathrm{PhD}$

Vall d'Hebron Institute of Oncology

Campus Vall Hebron

Natzaret 115-117, 08035, Barcelona, Spain

Tel. +34932543450 Ext. 8682

Email: Ricardo.pujol@uab.cat

This study was funded by Instituto de Salud Carlos III, Madrid, Spain, grants COV20/00416, Cov20/00654 and COV20/00388 to R.P-B, ATS and JBM respectively and co-financed by the European Regional Development Fund (ERDF). DÁ-S is recipient of a doctoral fellowship from the Vall d'Hebron Research Institute, Barcelona, Spain. ASM was supported by a postdoctoral grant "Juan Rodés" (JR18/00022) from Instituto de Salud Carlos III through the Ministry of Economy and Competitiveness, Spain 
medRxiv preprint doi: https://doi.org/10.1101/2022.01.29.22270016; this version posted February 2,2022 . The copyright holder for this preprint (which was not certified by peer review) is the author/funder, who has granted medRxiv a license to display the preprint in

All rights reserved. No reuse allowed without permission.

\begin{abstract}
Background: Almost two years since the onset of the COVID-19 pandemic no predictive algorithm has been generally adopted, nor new tests identified to improve the prediction and management of SARS-CoV-2 infection.

Methods: Retrospective observational analysis of the predictive performance of clinical parameters and laboratory tests in hospitalised patients with COVID-19. Outcomes were 28-day survival and maximal severity in a cohort of 1,579 patients and two validation cohorts of 598 and 434 patients. A pilot study conducted in a patient subgroup measured 17 cytokines and 27 lymphocyte phenotypes to explore additional predictive laboratory tests.
\end{abstract}

Findings: 1) Despite a strong association of 22 clinical and laboratory variables with the outcomes, their joint prediction power was limited due to redundancy. 2) Eight variables: age, comorbidity index, oxygen saturation to fraction of inspired oxygen ratio, neutrophil-lymphocyte ratio, Creactive protein, aspartate aminotransferase/alanine aminotransferase ratio, fibrinogen, and glomerular filtration rate captured most of the statistical predictive power. 3) The interpretation of clinical and laboratory variables was improved by grouping them in categories. 4) Age and organ damage-related tests were the best predictors of survival, and inflammatory-related tests were the best predictors of severity. 5) The pilot study identified several immunological tests (including chemokine ligand 10, chemokine ligand 2, and interleukin 1 receptor antagonist), that performed better than currently used tests.

Conclusions: Currently used tests for clinical management of COVID-19 patients are of limited value due to redundancy, as all measure aspects of two major processes: inflammation, and organ damage. There are no independent predictors based on the quality of the nascent adaptive immune response. Understanding the limitations of current tests would improve their interpretation and simplify clinical management protocols. A systematic search for better biomarkers is urgent and feasible. 
medRxiv preprint doi: https://doi.org/10.1101/2022.01.29.22270016; this version posted February 2,2022 . The copyright holder for this

preprint (which was not certified by peer review) is the author/funder, who has granted medRxiv a license to display the preprint in perpetuity.

All rights reserved. No reuse allowed without permission.

\section{INTRODUCTION}

Two years after the onset of the coronavirus disease (COVID-19) pandemic, the clinical, laboratory, and imaging features of patients with severe acute respiratory syndrome coronavirus 2 (SARS$\mathrm{CoV}-2$ ) infection have been widely described[1-5]. The wide clinical spectrum of COVID-19 became obvious during the first wave, and although the effect of inoculum size should be considered [6,7], variation has been mainly attributed to host factors, as variants of concern only appeared later [8]. The analysis of the first wave has obvious advantages for the identification of host factors and their biomarkers. Among host factors that affect the severity of illness, age, sex, genetic background, immunological status and prior immunity to coronaviruses[9] have been evaluated. Gene mutations of the interferon (IFN) pathway play a clear role in a small proportion of cases[10], and polymorphisms of several genes associated with immune response have been identified in genome-wide association studies[11,12]; however, to date, the genotypes that convey a risk of severe COVID-19 have not been defined in a way that is practically applicable for prediction in clinical practice.

Reports originating from the analysis of electronic health records have confirmed the predictive value of clinical laboratory tests usually associated with poor outcomes in other infections (i.e., blood cell counts, acute-phase reactants [APRs], and coagulation factors)[13-21] but none of the proposed predictive algorithms combining demographic, clinical, and laboratory data have been widely adopted. In small case series, the state of the immune system in COVID-19 patients has been analysed using the latest tools[22-28] leading to the detection of deep perturbations in the immune system. However, inferences of the effect of these perturbations in the efficiency of the immune response and their clinical consequences are not simple and, to date, no new predictive tests have been validated or added to the clinical laboratory toolbox for COVID-19 management.

We report a retrospective analysis of data from a cohort of 1,579 consecutive patients treated at the Vall d'Hebron University Hospital (HUVH) during the first wave of COVID-19 in Barcelona. We validated the main conclusions by comparison with cohorts from two other academic hospitals that belong to the same healthcare provider (the Catalan Institute of Health [ICS]) in Catalonia, Spain.

We conducted this retrospective observational study assuming that the predictive power of clinical laboratory tests had not been fully exploited, with the main objective of improving their interpretation. A secondary objective was to explore the predictive value of a selection of robust immunological tests that might identify an early dysregulated immune response associated with severe COVID-19.

\section{PATIENTS AND METHODS}

The database of the HUVH cohort was obtained by merging data sets from the Infectious Disease, Epidemiology and Clinical Laboratory departments. Consecutive patients aged $\geq 18$ years with a SARS-CoV-2 positive polymerase chain reaction (PCR) from any respiratory sample, hospitalised in HUVH between 10 March and 29 April 2020 were included in the study (see Tables 1 and 1S). This COVID-19 HUVH cohort consisted of 1,579 patients (Fig 1). All patient medical records included the number of symptoms, days from symptom onset (DFSO), initial assessment of vital signs, comorbidities, length of hospital stay (LOS), intensive care unit (ICU) admission, oxygen supplementation and supportive ventilation requirements, outcome during the hospitalisation and results from clinical laboratory tests. Data were censored on the date of discharge, death, or 28 days after admission, whichever occurred first. The outcome of all patients discharged before the 28th day was ascertained through a review of the primary care electronic health record notes. 


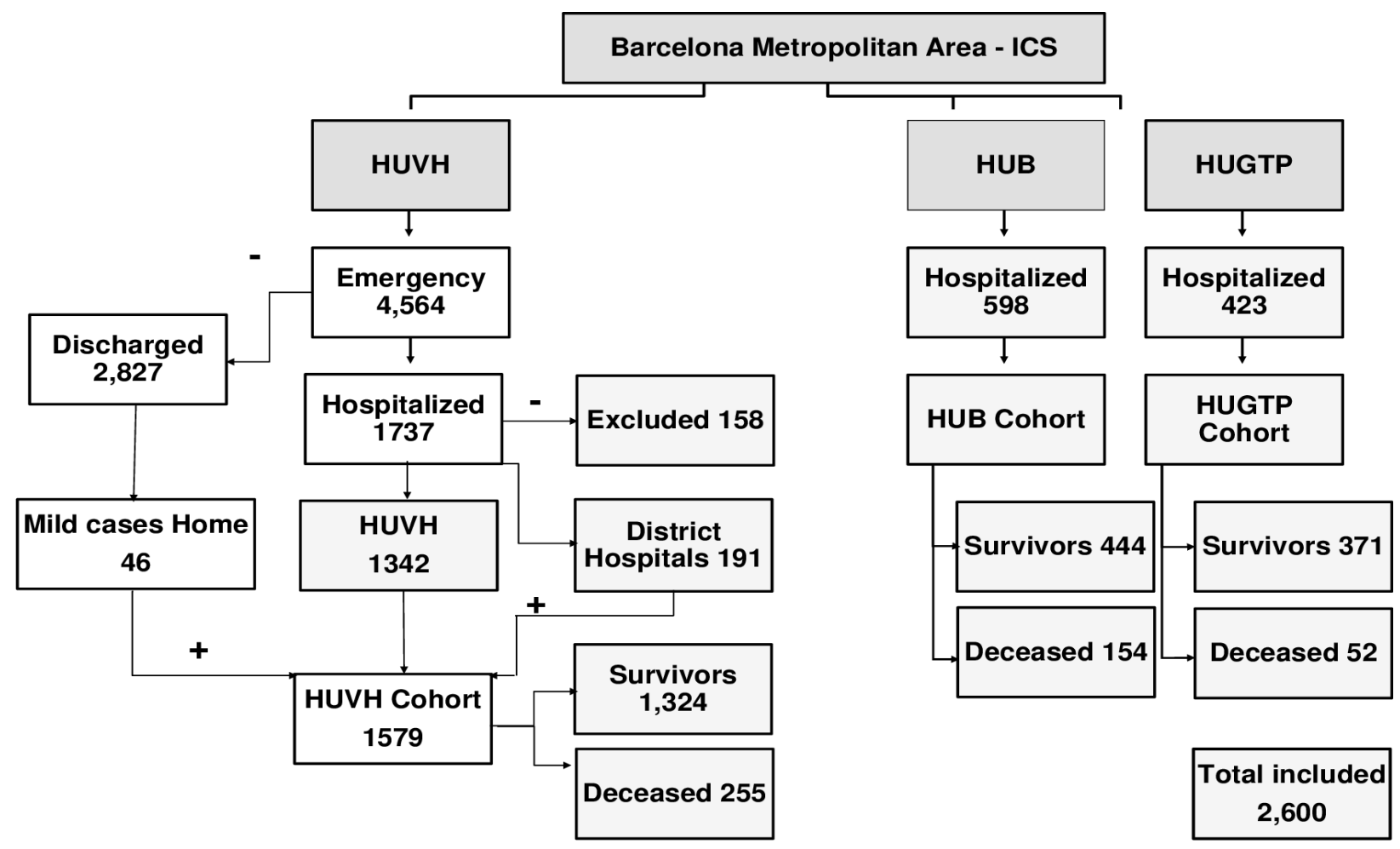

Fig 1. Selection of patients for the cohorts from Vall d'Hebron University Hospital (HUVH), Bellvitge University Hospital (HUB), and Germans Trias i Pujol University Hospital (HUGTP). All patients were confirmed by polymerase chain reaction (PCR) to have coronavirus disease (COVID-19). The details of the excluded patients are provided in Table 1S. The data from HUVH corresponds to patients who were admitted to the emergency division between 10 March and 29 April 2020; to HUGTP between 17 March and 12 May 2020; and to HUB between 16 March and 23 September 2020. The number of deceased patients corresponds to the 28-day follow-up period. The HUB and HUGTP cohorts include only hospitalised patients.

Comorbidities were classified as 1) cardiovascular disease and/or hypertension, 2) chronic lung disease, 3) diabetes, 4) neurological disease, 5) chronic kidney disease, 6) active non-terminal malignancy, 7) obesity, and 8) chronic liver disease. Each comorbidity was assigned value of 1, and a global comorbidity index ( 1 to 8 ) was generated. The clinical severity category was assigned as the maximal score attained during hospitalisation, using a simplified version of the World Health Organization (WHO) 10-point COVID-19 disease clinical progression score[29] as follows: 1) Mild, no activity limitations or not requiring hospitalisation; 2) Moderate, hospitalised, not requiring high-flow oxygen therapy or ventilation support; 3) Severe, hospitalised requiring highflow oxygen therapy or ventilation support; and 4) Deceased, those who died before day 28 of hospitalisation. These categories correspond to the WHO scores 1-3, 4-5, 6-9, and 10, respectively. For some analyses, the mild and moderate categories were combined into a non-severe category, and the severe and deceased categories were combined into a severe category.

The validation cohorts from the Bellvitge University Hospital (HUB) and the Germans Trias i Pujol University Hospital (HUGTP) included 598 and 423 patients, respectively, and, together with the HUVH cohort, at total of 2,600 patients were included in the analysis.

\section{Outcomes}

Final outcomes for comparison included survival vs. death, and maximum clinical severity. For the validation cohorts the only available outcome was survival for 28 days (survivors) and death (deceased). 
medRxiv preprint doi: https://doi.org/10.1101/2022.01.29.22270016; this version posted February 2,2022 . The copyright holder for this preprint (which was not certified by peer review) is the author/funder, who has granted medRxiv a license to display the preprint in

All rights reserved. No reuse allowed without permission.

\section{Clinical laboratory tests}

Detection of SARS-CoV-2 was first performed by an in-house PCR assay with primers and probes from 2019-nCoV CDC PCR panel, using the One-Step RT-PCR kit (Qiagen, Germany). When commercial assays became available, a real-time multiplex RT-PCR assay (Allplex ${ }^{\mathrm{TM}}$ 2019-nCoV Assay, Seegene, South Korea) was used. The laboratory data set at onset included Hemoglobin (Hb), WBC, Neutrophils, Lymphocytes, Monocytes, Eosinophils, Basophils, Platelets, IL-6, CReactive Protein (CRP), Ferritin, LDH, Fibrinogen, D-dimer, Prothrombin time INR, AST, ALT, Bilirubin direct and total, Urea, Creatinine and estimated Glomerular Filtration Rate (eGFR, National Kidney Foundation algorithm.

The clinical laboratories were equipped with Beckman Coulter (Brea, CA, USA) and Roche Diagnostics (Indianapolis, IN, USA) automatic analysers that were integrated with two TECAN (Zug, Switzerland) continuous lines and two automatic cold storage and retrieval units that ensure sample integrity. Interleukin 6 (IL-6) levels were measured in a Elycsis ${ }^{\circledR}$ Cobas analyser (Roche). Samples for assessing the predictive performance of clinical laboratory tests were taken on admission to the hospital; glomerular filtration rate (GFR) was calculated by applying the algorithm of Levey et al.[30]; additional laboratory test data for the 28-day follow-up period were available from 9,475 samples corresponding to 1,079 of the 1,579 patients in the HUVH cohort.

\section{Immunological tests}

The levels of cytokines chemokine ligand 2 (CCL2), chemokine ligand 10 (CXCL10), granulocytemacrophage colony-stimulating factor (GM-CSF), interferon (IFN)-alpha, IFN-gamma, interleukin (IL)-10, IL-12 p70, IL-13, IL-15, IL-17A, IL-1RA, IL-2, IL-4, IL-6, IL-7, and tumour-necrosis factor (TNF), and granzyme B were measured in sera using the ELLA microfluidic platform (Biotechne ${ }^{\circledR}$, Minneapolis, MN, USA); for sCD163 levels an enzyme-linked immunosorbent assay was used (CD163 human kit, Thermo Fisher Societies, Waltham, MA, USA).

The Human Immune Phenotyping Consortium protocol [31,32] was adapted for the study of COVID-19 patients. The antibodies used are shown in Table 2S. Blood was collected in EDTA vacutainer tubes (BD-Plymouth, UK) and processed within 4 hours. A total of $10^{5}$ events were acquired from each sample in most cases, using a NAVIOS EX flow cytometer (Beckman Coulter). Data were analysed with Kaluza Beckman Software v.2.1. Absolute values were generated by loading counts from the haematological analyser (XN-2000; Sysmex, Japan) parallel sample analysis.

\section{Statistical analysis}

Categorical variables were summarised as frequencies and proportions and continuous variables as means, standard deviations, and 95\% confidence intervals (CIs) or medians and interquartile ranges (IQRs), depending on their distribution. Pairwise comparisons used the Mann-Whitney U-test and Kruskal-Wallis test, adjusted for the false-discovery rate (FDR), where indicated (using the Benjamini and Hochberg, or Bonferroni method, as indicated). C-reactive protein (CRP), IL-6, ferritin, and D-dimer values were logarithmically transformed. A threshold of $30 \%$ of laboratory missing data was used as the exclusion criteria for data analyses. The initial oxygen saturation to fraction of inspired oxygen ratio $(\mathrm{SpO} 2 / \mathrm{FiO} 2)$ value while breathing room air was available for a subset of 827 patients. The data from these patients were either analysed separately, or when this parameter was included in a general analysis and resulted in a reduction the number of subjects, this was indicated in the reporting of the results.

Bivariable logistic regression was used to calculate the age-adjusted odd ratios (OR) and effect size ( $\mathrm{Z}$ score) of each variable. Multivariable logistic regression was used to calculate the predictive power of different combinations of variables. Correlation among variables was analysed using the 
medRxiv preprint doi: https://doi.org/10.1101/2022.01.29.22270016; this version posted February 2,2022 . The copyright holder for this preprint (which was not certified by peer review) is the author/funder, who has granted medRxiv a license to display the preprint in

All rights reserved. No reuse allowed without permission.

non-parametric Spearman test. For analysis of follow-up data of the HUVH cohort, locally weighted smoothing (LOESS) was applied to clinical laboratory variables to visualise the relationship between the mean and CI of each variable, time and 28-day outcome, as described by Abers et al.[1]. To assess the performance of each clinical laboratory test, the receiver-operating characteristic (ROC) curve and the corresponding area under the curve (AUC) values were calculated, using age as a variable for comparison. In addition, random forest simulation and principal component analysis (PCA) were performed to further compare the influence of the laboratory and clinical variables on the outcomes in each hospital dataset.

Statistical tests were 2-sided and used a significance threshold of at least $p<0.05$. R, version 4.1.0 (The R Foundation for Statistical Computing, Vienna, Austria) and Prism 9® (GraphPad, San Diego, CA, USA) packages were used for all analyses. Statistical analysis was conducted by the Statistics and Bioinformatics Unit (UEB), Vall d'Hebron Hospital Research Institute, and by coauthors PC-E and RP-B under the supervision of UEB.

\section{Ethical review}

This project was approved by the institutional ethics board of the three institutions (HUVH, HUGTP, and HUB) which waived the requirement for individual informed consent (protocol R(AG)242/2020). In the HUVH cohort, residual sera samples were transferred to the Vall d'Hebron University Hospital Biobank (PT17/0015/0047) part of the Carlos III Institute of Health network of biobanks (Number C.0006012).

\section{RESULTS}

\section{Overall clinical features of HUVH cohort}

The HUVH cohort included 1,579 PCR-confirmed COVID-19 patients with a median age of was 62 years (IQR: 50-75 years), of whom 255 (16.1\%) died during the first 28 days after hospitalisation (Fig 2A). Eight hundred eighty (55.7\%) patients were male. The proportion of males was higher $(58.0 \%)$ among the deceased patients and this proportion was significantly higher than the proportion of males in the Barcelona metropolitan area at the time $(47.5 \%$ male, $p<0.001)$. [33,34] A total of $236(14.9 \%)$ patients were admitted to the ICU with a 28-day case fatality rate of $13.9 \%[35]$. 
medRxiv preprint doi: https://doi.org/10.1101/2022.01.29.22270016; this version posted February 2,2022 . The copyright holder for this preprint (which was not certified by peer review) is the author/funder, who has granted medRxiv a license to display the preprint in perpetuity.

All rights reserved. No reuse allowed without permission.

A

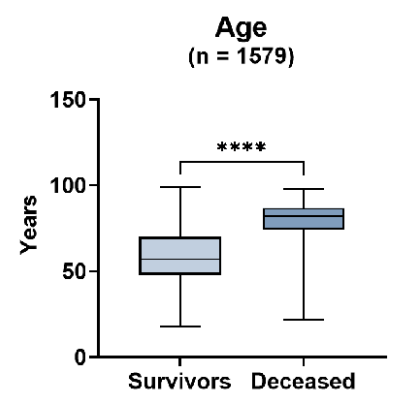

B

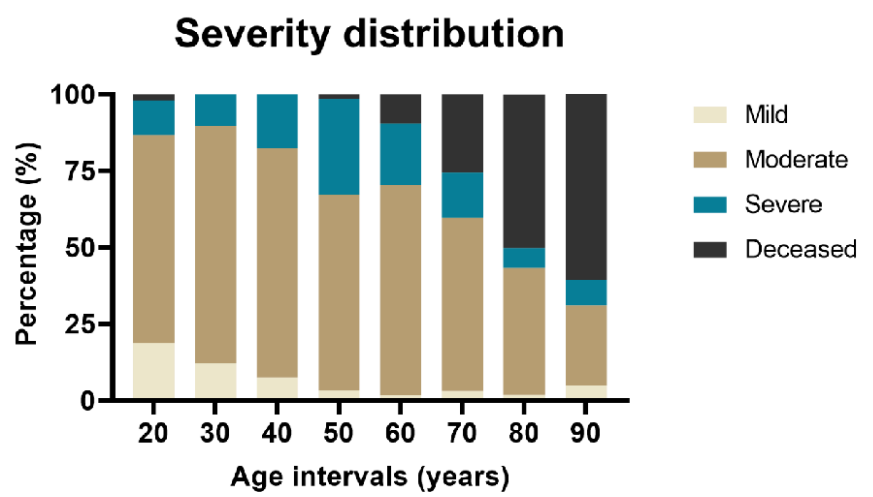

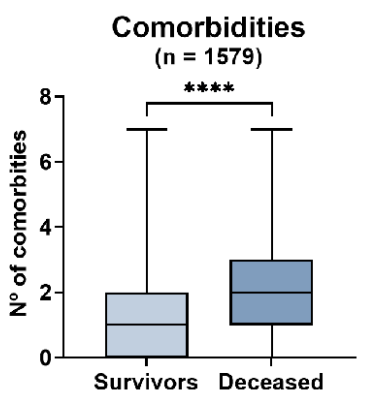

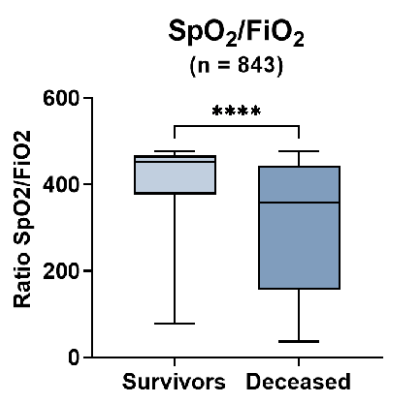

\section{C}

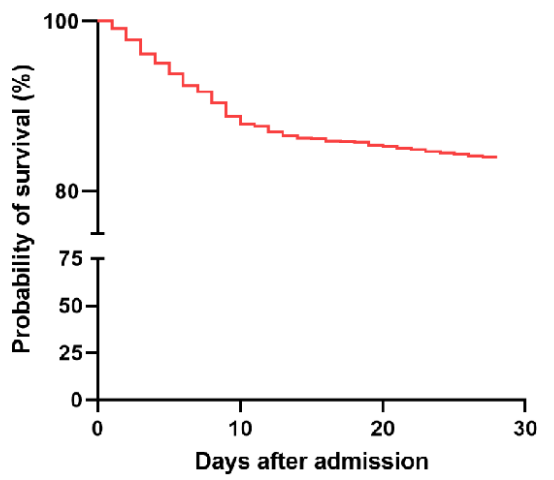

Fig 2. The structure and outcomes of the Vall d'Hebron University Hospital cohort. (A) Left panel, age distribution of the survivors and that of the deceased is markedly different (median [IQR]: 62 years [50-75 years] vs. 82 years [7487 years], $\mathrm{p}<0.001$ ) as are comorbidities (central panel) and $\mathrm{SpO}_{2} / \mathrm{FiO}_{2}$ (right panel). (B) Distribution of the patients in the HUVH cohort among the four severity categories, based on the World Health Organization criteria (described in the Material and Methods section). The number of patients in the mild category is small $(\mathrm{n}=71)$ as only patients with bilateral pneumonia or severe associated pathologies were hospitalised during this period of the pandemic. (C) Survival after admission: this graph highlights mortality during the initial 10 days, with a high number of patients older than 80 years dying in the initial 3-4 days (see text "Overall Clinical Features of HUVH cohort"). HUVH, Vall d'Hebron University Hospital.

The presenting symptoms are shown in Table 1. Of note, digestive symptoms were more frequent in survivors $(31.1 \%$ vs. $20.0 \%, \mathrm{p}<0.001)$. Cardiovascular and/or hypertension, chronic lung disease, diabetes, neurological disease, chronic kidney disease, and active non-terminal malignancy were associated to decreased 28-day survival, but not chronic liver disease nor obesity. The comorbidity index was significantly higher in deceased patients and patients with severe disease than in survivors and patients with non-severe disease. Each comorbidity added $10 \%$ mortality risk up to an index of 4 (Table 3S) 
Table 1. Summary of the clinical and demographic features of HUVH cohort

\begin{tabular}{|c|c|c|c|c|c|c|c|c|}
\hline & & \multicolumn{4}{|c|}{ Survivors vs deceased } & \multicolumn{3}{|c|}{ Non-severe vs severe } \\
\hline & & $\begin{array}{l}\text { Patients } \\
\text { n (\%) }\end{array}$ & $\begin{array}{c}\text { Survivors } \\
\mathrm{n}(\%)\end{array}$ & $\begin{array}{c}\text { Deceased } \\
\mathrm{n}(\%)\end{array}$ & $p$-value & $\begin{array}{c}\text { Non-severe } \\
\mathrm{n}(\%)\end{array}$ & $\begin{array}{c}\text { Severe } \\
\mathrm{n}(\%)\end{array}$ & $p$-value \\
\hline All & & $1579(100)$ & $1324(83.9)$ & $255(16.1)$ & NA & $1040(63.8)$ & $539(34.1)$ & NA \\
\hline Female & & $699(44.3)$ & $592(44.7)$ & $107(42.0)$ & \multirow{2}{*}{0.449} & $491(47.2)$ & $208(38.6)$ & \multirow{2}{*}{0.001} \\
\hline Male & & $880(55.7)$ & $732(55.3)$ & $148(58.0)$ & & $549(52.8)$ & $331(61.4)$ & \\
\hline \multirow[t]{2}{*}{ ICU } & & $236(14.9)$ & $203(15.3)$ & $33(13.9)$ & 0.4 & $1(0.1)$ & $235(43.6)$ & $1.612 E-126$ \\
\hline & & Median (IQR) & Median (IQR) & Median (IQR) & $p$-value & Median (IQR) & $\begin{array}{l}\text { Median } \\
\text { (IQR) }\end{array}$ & $p$-value \\
\hline Age, years & & $62(50-75)$ & $57(48-70)$ & $82(74-87)$ & $7.26 \mathrm{E}-81$ & $58(47-71)$ & $70(54-82)$ & $2.4872 \mathrm{E}-29$ \\
\hline DFSO & & $7(4-9)$ & $7(5-10)$ & $5(2-7)$ & $9.40 \mathrm{E}-19$ & $7(5-10)$ & $6(3-8)$ & $2.9561 \mathrm{E}-14$ \\
\hline LOS & & $7(2-20)$ & $7(2-24)$ & $7(4-11)$ & 0.4226 & $5(2-10)$ & $14(6-36)$ & $1.5748 \mathrm{E}-44$ \\
\hline Disease duration, days & & $15.0(10-28)$ & $15(10-34)$ & $12(9-18)$ & $4.45 \mathrm{E}-11$ & $13(9-21)$ & $22(11-43)$ & $1.4952 \mathrm{E}-17$ \\
\hline Clinical Presentation & & n (\%) & $\mathrm{n}(\%)$ & $\mathrm{n}(\%)$ & $p$-value & $\mathrm{n}(\%)$ & $\mathrm{n}(\%)$ & $p$-value \\
\hline General & Fever & $1314(83.2)$ & $1132(85.4)$ & $199(75.3)$ & 0.040 & $886(85.2)$ & $438(81.3)$ & 0.051 \\
\hline \multirow[t]{3}{*}{ Respiratory } & Upper respiratory symptoms (only) & $94(5.9)$ & $85(6.5)$ & $9(3.4)$ & 0.063 & $69(6.5)$ & $25(4.6)$ & 0.118 \\
\hline & Lower respiratory symptoms & $1351(85.6)$ & $1148(86.7)$ & $203(79.6)$ & 0.020 & $892(85.8)$ & $459(85.2)$ & 0.763 \\
\hline & Pneumonia & $1524(96.5)$ & $1271(96.0)$ & $253(99.2)$ & 0.008 & $989(95.1)$ & $535(99.3)$ & $3.62 \mathrm{E}-06$ \\
\hline Digestive & All & $491(31.1)$ & $440(33.2)$ & $51(20.0)$ & $1.182 \mathrm{E}-05$ & $353(33.9)$ & $138(25.6)$ & $7.11 \mathrm{E}-04$ \\
\hline \multirow[t]{9}{*}{ Comorbidities } & & $\mathrm{n}(\%)$ & $\mathrm{n}(\%)$ & $\mathrm{n}(\%)$ & $p$-value & $\mathrm{n}(\%)$ & $\mathrm{n}(\%)$ & $p$-value \\
\hline & Cardiovascular \& hypertension & $712(45.1)$ & $508(38.4)$ & $204(80.0)$ & $8.534 \mathrm{E}-37$ & $394(37.9)$ & $318(59.0)$ & $1.463 \mathrm{E}-15$ \\
\hline & Chronic lung disease & $278(17.6)$ & $198(15.0)$ & $80(31.4)$ & 5.134E-09 & $145(13.9)$ & $133(24.7)$ & 2.143E-07 \\
\hline & Diabetes & $293(1850.0)$ & $223(16.8)$ & $70(28.3)$ & $1.90 \mathrm{E}-05$ & $170(16.3)$ & $123(22.8)$ & 0.002 \\
\hline & Neurological disease & $227(14.4)$ & $156(11.8)$ & $71(27.8)$ & $1.29 \mathrm{E}-09$ & $121(11.6)$ & $106(19.7)$ & $2.89 \mathrm{E}-05$ \\
\hline & Chronic kidney disease & $134(8.5)$ & $79(6)$ & $55(21.6)$ & $1.03 \mathrm{E}-13$ & $55(5.3)$ & $79(14.7)$ & $9.101 E-10$ \\
\hline & Active non-terminal malignancy & $113(7.2)$ & $62(4.7)$ & $51(20.0)$ & $1.10 \mathrm{E}-15$ & $41(3.9)$ & $72(13.4)$ & 4.197E-11 \\
\hline & Obesity & $261(16.5)$ & $227(17.3)$ & $34(12.8)$ & 0.85 & $145(13.9)$ & $116(21.5)$ & $2.00 \mathrm{E}-04$ \\
\hline & Chronic liver disease & $61(3.9)$ & $48(3.7)$ & $13(4.9)$ & 0.139 & $37(3.6)$ & $24(4.5)$ & 0.409 \\
\hline \multirow[t]{2}{*}{ Comorbidity index* } & & Median (IQR) & Median (IQR) & Median (IQR) & $p$-value & Median (IQR) & $\begin{array}{l}\text { Median } \\
\text { (IQR) }\end{array}$ & $p$-value \\
\hline & & $1(0-2)$ & $2(1-3)$ & $2(1-3)$ & $2.2961 \mathrm{E}-38$ & $1(0-2)$ & $2(1-3)$ & $1.0118 \mathrm{E}-26$ \\
\hline
\end{tabular}

* The breakdown of patients by comorbidity index is in Table 1S.

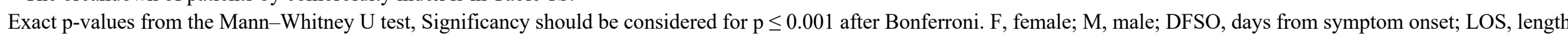
of stay; significant $\mathrm{p}$ values in bolt. 
medRxiv preprint doi: https://doi.org/10.1101/2022.01.29.22270016; this version posted February 2,2022 . The copyright holder for this preprint (which was not certified by peer review) is the author/funder, who has granted medRxiv a license to display the preprint in

All rights reserved. No reuse allowed without permission.

The distribution of disease severity was as follows, 71 (4.5\%), 969 (61.4\%), 284 (17.9\%), and 255 (16.1\%) in the mild, moderate, severe, and deceased categories, respectively. The age of patients increased with increasing disease severity category, except between the moderate and severe disease groups (Fig 2B and Table 4S). The LOS increased with disease severity for the three initial disease severity categories but was shorter among the deceased because $24.9 \%$ of the deceased patients died during the initial 4 days of hospitalisation (Fig 2C). The median disease duration was 18 days (IQR: 10-18 days) and was progressively longer with increasing disease severity (Table 5S). Age had a strong effect on mortality: for patients in the age groups 50-59, 60-69, 70-79, 8089 and $>90$ years, with 28 -day case fatality rates of $1.82 \%, 10.9 \%, 26.4 \%, 49.7 \%$ and $60.6 \%$ respectively.

In the dichotomous disease severity grouping, there were 1,040 and 539 patients in the non-severe and severe categories, respectively. Deceased patients accounted for $43.7 \%$ of the severe category. The disease severity was significantly associated with age, DFSO, LOS, disease duration, and comorbidities other than chronic liver disease. Disease severity was greater in males than in females, but after adjusting for multiple comparisons the statistical significance was moderate compared with the other statistically significant associations (exact $p=0.001$, after Bonferroni's correction $\mathrm{p}=0.03)$ (Table 1).

\section{Predictive power of current clinical laboratory test}

The exploratory statistical analysis of the HUVH cohort revealed that, despite the strong association of 22 of the 30 variables with 28-day outcomes (Fig 3 and Tables 2 and 5S), the predictive power of the combined variables was limited and appeared to rely disproportionally on age, a non-laboratory variable (Table 3). Further analyses described in the supplementary section "Sequence of statistical biomarker analyses" were undertaken to determine the reason of this limitation, as summarised below. 


\section{Severity based analysis}
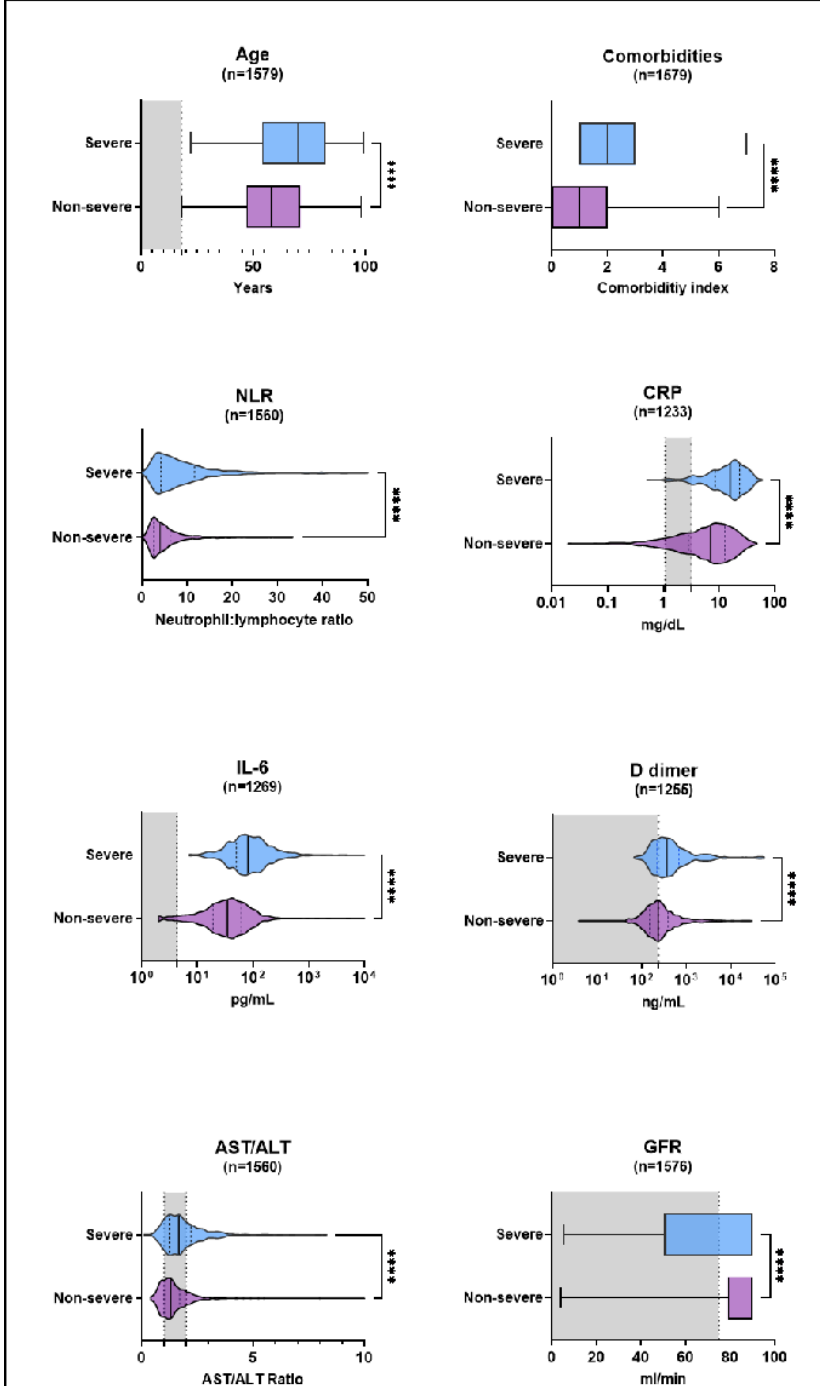

\section{Survival based analysis}
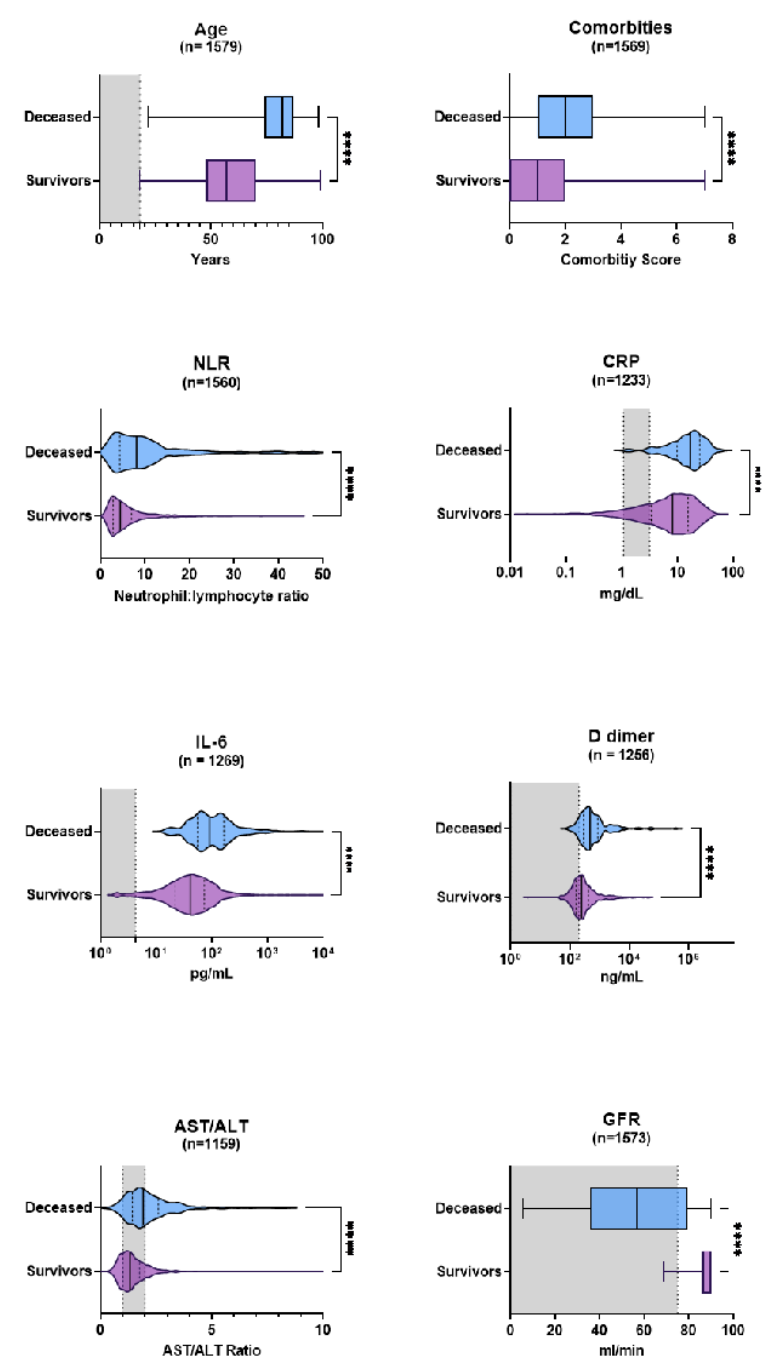

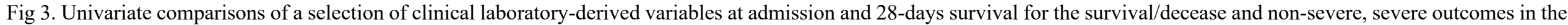

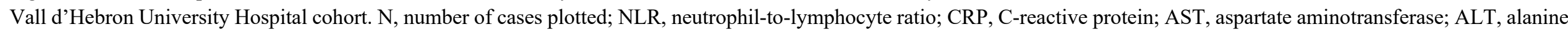

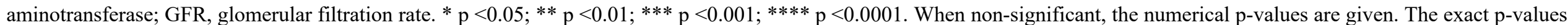
are given in Table 2 . The distribution of age and GFR are markedly different in the severity and survival analysis. 
Table 2. Pairwise comparison of biomarkers for decease and severity outcomes, HUVH cohort

\begin{tabular}{|c|c|c|c|c|c|c|c|}
\hline Patients, Median (IQR) & $\begin{array}{c}\text { Total }(n= \\
1579)\end{array}$ & Survivors $(n=1324)$ & $\begin{array}{l}\text { Non-survivors }(n= \\
\text { 255) }\end{array}$ & $\begin{array}{c}p \text {-value } \\
\text { (exact) }\end{array}$ & $\begin{array}{c}\text { Non-Severe }(n= \\
1324)\end{array}$ & $\begin{array}{c}\text { Severe and } \\
\text { deceased }(n= \\
255)\end{array}$ & $\begin{array}{c}p \text {-value } \\
\text { (exact) }\end{array}$ \\
\hline Age, years, median and IQR & $62(50-75)$ & $57(48-70)$ & $82(74-87)$ & $7.26 \mathrm{E}-81$ & $58(47-71)$ & $70(54-82)$ & $2.49 \mathrm{E}-29$ \\
\hline Comorbidities & $1(0-2)$ & $2(1-3)$ & $2(1-3)$ & $2.30 \mathrm{E}-38$ & $1(0-2)$ & $2(1-3)$ & 1.0118E-26 \\
\hline \multicolumn{8}{|c|}{ INFLAMMATION RELATED BIOMARKERS (IFRB) } \\
\hline \multicolumn{8}{|l|}{ Blood (normal range) } \\
\hline $\mathrm{Hb}(12-15 \mathrm{~g} / \mathrm{dL})$ & $13.5(12.3-14.5)$ & $13.7(10.7-11.9)$ & $12.6(11.4-13.8)$ & $4.95 \mathrm{E}-15$ & $13.7(12.5-14.6)$ & $13.1(12.0-14.3)$ & 5.64E-09 \\
\hline WBC $\left(4-1110^{9} / \mathrm{L}\right)$ & $6.5(5.0-8.8)$ & $6.5(5.0-8.2)$ & $7.5(5.32-10)$ & $1.51 \mathrm{E}-05$ & $6.36(4.95-8.10)$ & $7.39(5.29-10.4)$ & $1.26 \mathrm{E}-10$ \\
\hline Neutrophils, \% (40-80) & $76.1(68-83.2)$ & $74.8(68.3-81.0)$ & $82.9(75.4-87.9)$ & $1.07 \mathrm{E}-20$ & $73.3(65.9-79.8)$ & $82.4(74.3-87.6)$ & $6.07 \mathrm{E}-39$ \\
\hline Neutrophils (2-7 109/L) & $4.8(3.5-6.7)$ & $4.7(3.4-7.6)$ & $6.1(3.9-8.6)$ & $7.18 \mathrm{E}-10$ & $4.56(3.33-6.23)$ & $5.92(4.01-8.68)$ & 1.63E-19 \\
\hline Lymphocytes, \% (20-50) & $16(10.5-23)$ & $17(12-24)$ & $10(7.2-17.0)$ & $1.07 \mathrm{E}-23$ & $18.1(12.8-24.8)$ & $11.6(7.50-18.2)$ & $8.34 \mathrm{E}-41$ \\
\hline Lymphocytes $\left(1.2-3.510^{9} / \mathrm{L}\right)$ & $1(0.7-1.4)$ & $1.1(0.8-1.4)$ & $0.7(0.6-1.0)$ & $3.69 \mathrm{E}-22$ & $1.11(0.82-1.50)$ & $0.85(0.60)$ & $1.80 \mathrm{E}-28$ \\
\hline Monocytes, \% (2-10) & $6.7(4.8-8.8)$ & $6.8(5.0-8.8)$ & $5.4(3.6-7.80)$ & $1.01 \mathrm{E}-10$ & $7.20(5.50-9-20)$ & $5.40(3.70-7.80)$ & $1.92 \mathrm{E}-24$ \\
\hline Monocytes $\left(0.1-1 \quad 10^{9} / \mathrm{L}\right)$ & $0.43(0.30-0.59)$ & $0.44(0.31-0.59)$ & $0.39(0.28-0.56)$ & 0.013 & $0.45(0.33-0.61)$ & $0.39(0.28-0.58)$ & $1.02 \mathrm{E}-05$ \\
\hline Eosinophils, \% (0.0-5.0) & $0.0(0-0.3)$ & $0.00(0.00-0.10)$ & $0(0.00-0.00)$ & $4.40 \mathrm{E}-07$ & $0.1(0.00-0.40)$ & $0.00(0.00-0.10)$ & $1.87 \mathrm{E}-14$ \\
\hline Eosinophils $\left(0.0-0.510^{9} / \mathrm{L}\right)$ & $0.00(0.00-0.01)$ & $0.0(0-0.01)$ & $0(0.00-0.00)$ & 0.006 & $0.0(0-0.03)$ & $0(0.00-0.01)$ & $9.7144 \mathrm{E}-12$ \\
\hline Basophils $(0.0-0.2 \mathrm{E} 9 / \mathrm{L})$ & $0(0.01-0.03)$ & $0.0(0.01-0.03)$ & $0.02(0.01-0.03)$ & 0.454 & $0.02(0.01-0.02)$ & $0.02(0.01-0.03)$ & 0.1591 \\
\hline Neutrophil-Lymphocyte ratio & $4.8(3.0-7.0)$ & $4.4(3.2-6.7)$ & $7.7(4.3-12.2)$ & $1.39 \mathrm{E}-21$ & $4.07(2.68-4.21)$ & $7.07(4.21-11.7)$ & 4.71E-39 \\
\hline Platelets $\left(140-40010^{9} / \mathrm{L}\right)$ & $197(154-251)$ & $202(170-286)$ & $174(133-227)$ & $2.87 \mathrm{E}-07$ & $292(159-254)$ & $190(143-190)$ & $2.63 \mathrm{E}-04$ \\
\hline \multicolumn{8}{|l|}{ APR and related parameters } \\
\hline CRP $(0.03-0.5 \mathrm{mg} / \mathrm{dL})$ & $8.9(3.8-16.6)$ & $8.1(3.8-15.5)$ & $17.9(10.2-24.5)$ & $2.05 \mathrm{E}-19$ & $7.07(2.57-12.58)$ & $15.8(8.51-23.44)$ & $5.99 \mathrm{E}-43$ \\
\hline IL-6 $(0.0-4.3 \mathrm{pg} / \mathrm{mL})$ & $45.1(23.6-80.0)$ & $41.41(24.7-85.9)$ & $90.5(55.3-162.8)$ & $1.88 \mathrm{E}-24$ & $34.6(19.0-61.65)$ & $81.2(50.1-138.0)$ & $1.01 \mathrm{E}-55$ \\
\hline Ferritin $(25-400 \mathrm{ng} / \mathrm{mL})$ & $539(282.5-1011.5)$ & $527(155.5-709.5)$ & $671(355-1153)$ & 0.04 & $467(251 .-891.2)$ & $724(426 .-1348)$. & $1.06 \mathrm{E}-12$ \\
\hline \multicolumn{8}{|l|}{ Coagulation } \\
\hline Fibrinogen $(2.39-6.1 \mathrm{~g} / \mathrm{L})$ & $5.1(4.4-6)$ & $5.2(4.4-5.7)$ & $4.9(4.2-5.9)$ & 0.04 & $5.06(4.42-5.86)$ & $5.31(4.45-6.15)$ & 0.0129 \\
\hline D-dimer $(0-243 \mathrm{ng} / \mathrm{mL})$ & $263(168-463.5)$ & $248.5(197.8-591.0)$ & $477(292.5-860.8)$ & $4.65 \mathrm{E}-16$ & $234(151-389)$ & $371(223-692)$ & $3.80 \mathrm{E}-20$ \\
\hline Prothrombin time, INR $(0.7-1.3)$ & $1.1(1.0-1.2)$ & $1.1(1.0-1.2)$ & $1.1(1.1-1.3)$ & $9.32 \mathrm{E}-08$ & $1.09(1.02-1.17)$ & $1.11(1.04-1.23)$ & $1.25 \mathrm{E}-05$ \\
\hline \multicolumn{8}{|c|}{ ORGAN DAMAGE RELATED BIOMARKERS (ODRB) } \\
\hline $\mathrm{SpO} 2 / \mathrm{FiO} 2$ & $448(354-462)$ & $452(377-465)$ & $358(156-443)$ & $5.55 \mathrm{E}-22$ & $457(438-467)$ & $369(230-448)$ & $8.58 \mathrm{E}-44$ \\
\hline \multicolumn{8}{|l|}{ Liver function tests } \\
\hline AST (12-50 IU/L) & $40(30-60)$ & $39(26.0-49.5)$ & $44.5(31-68)$ & 0.01 & $38(28-55)$ & $45(33-68)$ & $6.55 \mathrm{E}-11$ \\
\hline AST/ALT $(<1.5)$ & $1.39(1.06-1.88)$ & $1.3(1.0-1.8)$ & $1.9(1.4-2.6)$ & $6.06 \mathrm{E}-31$ & $1.3(1-1.71)$ & $1.67(1.24-2.21)$ & $2.97 \mathrm{E}-24$ \\
\hline Bilirubin, Direct $(0.1-0.57 \mathrm{mg} / \mathrm{dL})$ & $0.30(0.24-0.38)$ & $0.30(0.24-0.37)$ & $0.35(0.27-0.46)$ & $8.37 \mathrm{E}-05$ & $0.29(0.24-0.36)$ & $0.32(0.26-0.43)$ & $1.34 \mathrm{E}-05$ \\
\hline Bilirubin, Total $(0.3-1.2 \mathrm{mg} / \mathrm{dL})$ & $0.57(0.45-0.74)$ & $0.57(0.44-0.73)$ & $0.63(0.47-0.85)$ & 0.03 & $0.56(0.45-0.73)$ & $0.58(0.44-0.81)$ & 0.185 \\
\hline \multicolumn{8}{|l|}{ Kidney function tests } \\
\hline Urea $(17-42 \mathrm{mg} / \mathrm{dL})$ & $35(25-51)$ & $32(24.0-55.0)$ & $58(42-87)$ & $8.77 \mathrm{E}-47$ & $31(24-44)$ & $46(31.8-72.3)$ & 2.23E-31 \\
\hline Creatinine $(0,67-1.17 \mathrm{mg} / \mathrm{dL})$ & $0.80(0.60-0.97)$ & $0.79(0.65-0.94)$ & $1.01(0.78-1.36)$ & $2.20 \mathrm{E}-20$ & $0.79(0.64-0.95)$ & $0.92(0.74-1.29)$ & $2.48 \mathrm{E}-23$ \\
\hline $\operatorname{GFR}\left(>75 \mathrm{~mL} / \mathrm{min} / 1,73 \mathrm{~m}^{2}\right)$ & $88.5(67.8-90.0)$ & $90.0(76.4-90.0)$ & $56.9(35.9-79.5)$ & $2.37 \mathrm{E}-101$ & $90(78.9-90)$ & $76.3(50.3-90)$ & $1.42 \mathrm{E}-37$ \\
\hline
\end{tabular}

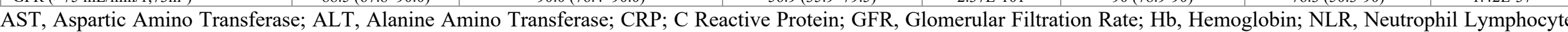
Ratio; NC, not calculated, $\mathrm{SpO} 2 / \mathrm{FiO} 2$, Oxygen saturation to fraction of inspired oxygen ratio; WBC, White Blood cell Count. 
medRxiv preprint doi: https://doi.org/10.1101/2022.01.29.22270016; this version posted February 2, 2022. The copyright holder for this preprint (which was not certified by peer review) is the author/funder, who has granted medRxiv a license to display the preprint in perpetuity.

All rights reserved. No reuse allowed without permission.

Table 3. Classification tables from multiple logistic regression including different sets of variables for survival vs decease or severe vs non-severe as outcome.

\begin{tabular}{|l|r|r|r|r|r|}
\hline \multicolumn{7}{|l|}{ Predicted outcome, 19 clinical and laboratory variables* for survival versus decease } \\
\hline Classification table & Predicted survival & Predicted decease & Total & \% Correctly classified \\
\hline Observed Survival & 357 & 8 & 365 & 97.81 \\
\hline Observed Decease & 21 & 25 & 46 & $\mathbf{5 4 . 3 5}$ \\
\hline Total & 378 & 33 & 411 & 92.94 \\
\hline
\end{tabular}

Predicted outcome, 19 clinical and laboratory variables* severe versus non-severe

\begin{tabular}{|l|r|r|r|r|}
\hline Classification table & Predicted non-severe & Predicted severe & Total & \% Correctly classified \\
\hline Observed non-severe & 244 & 26 & 270 & 90.37 \\
\hline Observed severe & 64 & 77 & 141 & $\mathbf{5 4 . 6 1}$ \\
\hline Total & 308 & 103 & 411 & 78.10 \\
\hline
\end{tabular}

Predicted outcome, 16 non-clinical variables** for survival versus decease

\begin{tabular}{|l|r|r|r|r|}
\hline Classification table & Predicted survival & Predicted decease & Total & \% Correctly classified \\
\hline Observed survival & 356 & 9 & 365 & 97.53 \\
\hline Observed decease & 30 & 16 & 46 & $\mathbf{3 4 . 7 8}$ \\
\hline Total & 386 & 25 & 411 & 90.51 \\
\hline
\end{tabular}

Predicted outcome, 16 non-clinical variables** for severe versus non-severe

\begin{tabular}{|c|c|c|c|c|}
\hline Classification table & Predicted non-severe & Predicted severe & Total & $\%$ Correctly classified \\
\hline Observed non-severe & 245 & 25 & 270 & 90.74 \\
\hline Observed severe & 59 & 82 & 141 & 58.16 \\
\hline Total & 304 & 107 & 411 & 79.56 \\
\hline \multicolumn{5}{|c|}{ Predicted outcome, 15 non-clinical variables for survival versus decease (no SpO2/FiO2)*** } \\
\hline Classification table & Predicted survival & Predicted decease & Total & $\%$ Correctly classified \\
\hline Observed survival & 897 & 9 & 906 & 99.01 \\
\hline Observed decease & 68 & 20 & 88 & 22.73 \\
\hline Total & 965 & 29 & 994 & 92.25 \\
\hline
\end{tabular}

Predicted outcome, 15 non-clinical variables for severe versus non-severe (no SpO2/FiO2)****

\begin{tabular}{|l|r|r|r|r|}
\hline Classification table & Predicted non-severe & Predicted severe & Total & \% Correctly classified \\
\hline Observed non-severe & 691 & 49 & 740 & 93.38 \\
\hline Observed severe & 162 & 92 & 254 & $\mathbf{3 6 . 2 2}$ \\
\hline Total & 853 & 141 & 994 & 78.77 \\
\hline
\end{tabular}

*The 19 variables included were age, gender, comorbidity index, SpO2/FiO2, Hb, Neutrophil \%, Lymph \%, monocyte $\%$, eosinophils \%, NLR, Platelets, CRP, IL-6, D-dímer, ferritin, fibrinogen, prothrombin time INR, AST/ALT ratio and GFR. ** The 16 variables included were the same minus for age, sex, and comorbidities. *** The 15 variables were the same minus for age, sex, comorbidities and, $\mathrm{SpO} 2 / \mathrm{FiO} 2$.

Classification tables using different sets of variables show that, the despite good ROC curves and overall high proportion of correctly classified cases, their power in predicting poor outcomes, either decease or severe disease, is under the $60 \%$. Prediction it is very dependent on age and, among biomarkers, on $\mathrm{SpO} 2 / \mathrm{FiO} 2$ as seen comparing the different tables using 17 and 16 non-clinical 
medRxiv preprint doi: https://doi.org/10.1101/2022.01.29.22270016; this version posted February 2,2022 . The copyright holder for this

preprint (which was not certified by peer review) is the author/funder, who has granted medRxiv a license to display the preprint in

All rights reserved. No reuse allowed without permission.

variables. It should be noticed that laboratory variables, even without $\mathrm{SpO} 2 / \mathrm{FiO} 2$, are better for predicting severity than decease. When $\mathrm{SpO} 2 / \mathrm{FiO} 2$ is excluded (16 variables) the \% of correctly classified drops even if the number of observations was increase to the double. Analyses with the reduced set of eight variables i.e., age, comorbidities, SpO2/FiO2, NLR, CRP, AST/ALT, fibrinogen and GFR, gave similar results confirming the redundancy of the variables (data not shown). For more details see tables in xlsx format, "multiple logistic regression by decease" and "multiple logistic regression".

\section{Improving the interpretation of biomarkers}

The white blood cell differential counts showed marked imbalance due to an approximately $250 \%$ reduction in the lymphocyte count and a $20-30 \%$ increase in the neutrophil count. At the individual level, the reduction of lymphocytes was disproportionate to the increase in neutrophils.

The APRs had a broad range of variation e.g., >10,000 and 50-fold for IL-6 and CRP, respectively, and in most patients the values were out of the normal range, while the aspartate aminotransferase/alanine aminotransferase (AST/ALT) ratio and kidney function test results were only moderately altered and often remained within the normal range.

Multiple correlation (Fig 4), univariate age-adjusted logistic regression (Table 4), multivariable logistic regression analyses (Table 3 ) and examining their respective shifts from the normal range (Table 6S), suggested that these variables could be classified into three broad categories, clinicodemographic (CD), including age, sex and the comorbidity index; inflammation related biomarkers (IFRB) including blood cell counts, levels of APRs, and coagulation factors; and organ damagerelated biomarkers (ODRB), including liver and kidney function tests and $\mathrm{SpO}_{2} / \mathrm{FiO}_{2}$. These analyses revealed that the neutrophil-lymphocyte ratio (NLR) and the AST/ALT ratio captured most of the predictive value of lymphocyte and neutrophils variations and of liver function test variations, respectively, and that $\mathrm{SpO}_{2} / \mathrm{FiO}_{2}$ conveyed much of the predictive power of the ODRBs (see supplementary text "Sequence of statistical biomarker analysis") 


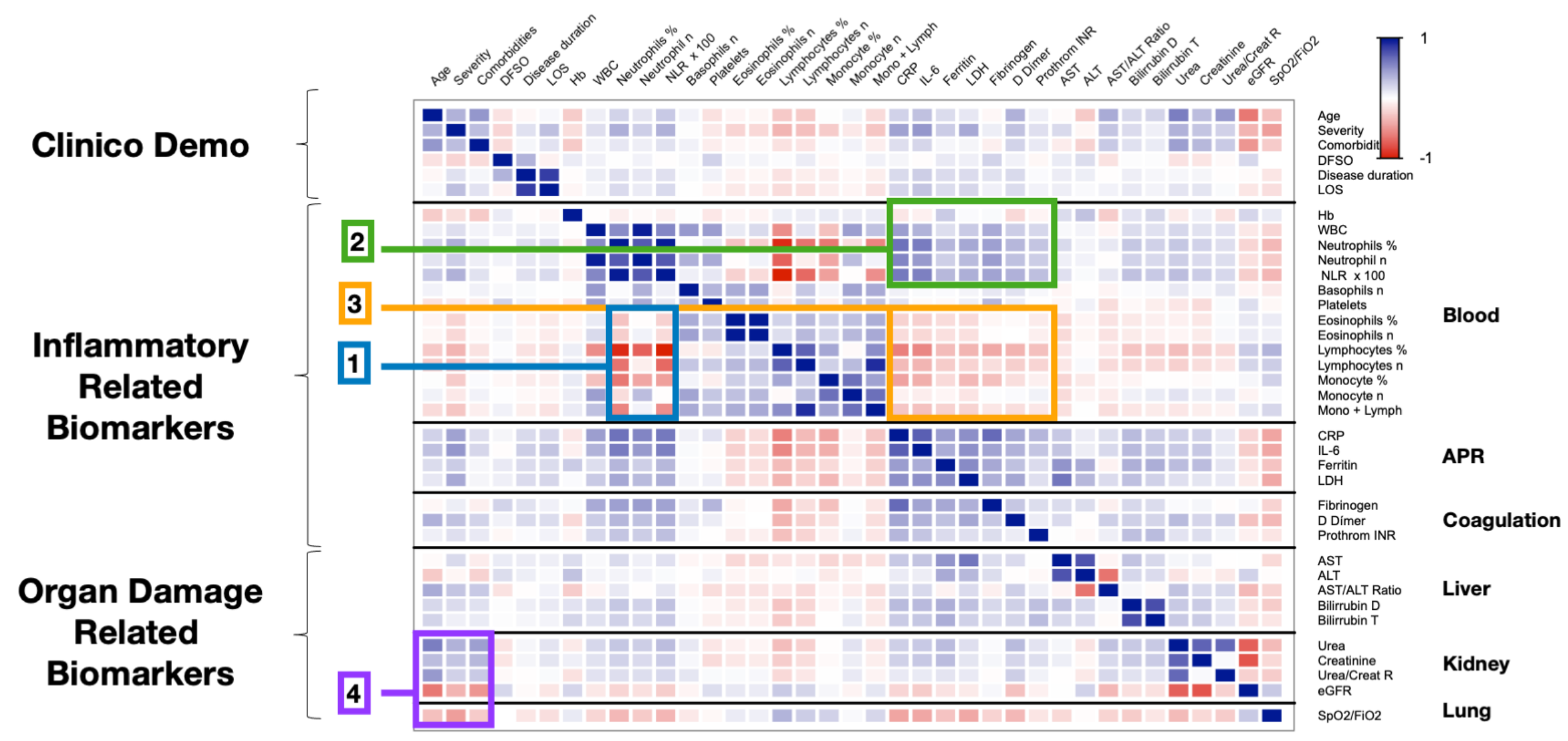

Fig 4. Overall correlograms of selected data on demographics and clinical laboratory variables that were organised in categories. [1] The blue rectangle highlights the negative correlation between neutrophils and the cluster of lymphocytes, monocytes, and eosinophils. [2] The green rectangle highlights the blood cell variables that correlate positively with the acute-phase reactants (APRs) and coagulation factors. [3] The orange rectangle highlights the negative correlation between lymphocytes, monocytes, and eosinophils with APRs and coagulation factors. [4] The magenta rectangle highlights the correlations between kidney function and the disease severity, comorbidities, $\mathrm{SpO}_{2} / \mathrm{FiO}_{2}$, and disease duration. The cells following the diagonal highlights the seven families of variables: demographics/clinical, myeloid cells, lymphocytes/mononuclear cells, APRs, coagulation, liver function test, and kidney function test, which show the expected strong correlations among themselves. The thick lines between rows separate the main categories. APR, acute-phase reactants; $\mathrm{SpO}_{2} / \mathrm{FiO}_{2}$, oxygen saturation/fraction of inspired oxygen; DFSO, days from symptom onset; LOS, length of stay; NLR, neutrophil-to-lymphocyte ratio; CRP, C-reactive protein; AST, aspartate aminotransferase; ALT, alanine aminotransferase; eGFR, estimated glomerular filtration rate. 
medRxiv preprint doi: https://doi.org/10.1101/2022.01.29.22270016; this version posted February 2,2022 . The copyright holder for this preprint (which was not certified by peer review) is the author/funder, who has granted medRxiv a license to display the preprint in perpetuity.

All rights reserved. No reuse allowed without permission.

Table 4. Univariate age adjusted logistic regression for 28-days survival/decease and non-severe/severe outcomes

\begin{tabular}{|c|c|c|c|c|c|c|c|c|c|c|}
\hline \multicolumn{6}{|c|}{ 28d decease outcome age adjusted } & \multicolumn{5}{|c|}{28 maximal severity age adjusted } \\
\hline Variables & $\begin{array}{l}\text { Odds } \\
\text { Ratio }\end{array}$ & CI & $\begin{array}{c}Z \\
\text { value }\end{array}$ & $\operatorname{Pr}(>|\mathbf{z}|)$ & $Z$ value Rank & Odds Ratio & CI & $Z$ value & $\operatorname{Pr}(>|z|)$ & $Z$ value Rank \\
\hline IL-6 (pg/mL) & 2.59 & $2.06-3.31$ & 7.84 & $<0.001$ & 1 & 12.24 & $8.24-18.56$ & 12.10 & $<0.001$ & 1 \\
\hline $\mathrm{CRP}(\mathrm{mg} / \mathrm{dL})$ & 3.20 & $2.38-4.41$ & 7.40 & $<0.001$ & 2 & 9.55 & $6.47-14.40$ & 11.06 & $<0.001$ & 2 \\
\hline $\mathrm{SpO} 2 / \mathrm{FiO} 2$ ratio & 0.99 & $0.99-1.00$ & 7.05 & $<0.001$ & 3 & 0.99 & $0.98-0.99$ & 10.17 & 0.001 & 4 \\
\hline Neutrophils (\%) & 1.06 & $1.04-1.08$ & 6.38 & $<0.001$ & 4 & 1.19 & $1.14-1.23$ & 10.76 & $<0.001$ & 3 \\
\hline NLR $\times 100$ & 1.08 & $1.06-1.11$ & 6.33 & $<0.001$ & 5 & 1.13 & $1.10--1.16$ & 9.87 & 0.001 & 5 \\
\hline Monocytes (\%) & 0.86 & $0.81-0.90$ & 6.20 & $<0.001$ & 6 & 0.86 & $0.83-0.89$ & 7.89 & $<0.001$ & 8 \\
\hline Neutrophils $\left(10^{9} / \mathrm{L}\right)$ & 1.14 & $1.09-1.19$ & 5.74 & $<0.001$ & 7 & 1.19 & $1.14-1.23$ & 8.86 & $<0.001$ & 7 \\
\hline GFR $\left(\mathrm{mL} / 1.73 \mathrm{~m}^{2}\right)$ & 0.98 & $0.97-0.99$ & 5.44 & $<0.001$ & 8 & 0.98 & $0.97-0.98$ & 6.94 & $<0.001$ & 11 \\
\hline Lymphocytes (\%) & 0.95 & $0.92-0.97$ & 5.04 & $<0.001$ & 9 & 1.03 & $1.03-1.04$ & 9.79 & $<0.001$ & 6 \\
\hline WBC $\left(10^{9} / \mathrm{L}\right)$ & 1.11 & $1.06-1.16$ & 4.82 & $<0.001$ & 10 & 1.14 & $1.01-1.18$ & 7.29 & $<0.001$ & 9 \\
\hline AST/ALT ratio & 1.49 & $1.26-176$ & 4.74 & $<0.001$ & 11 & 1.53 & $1.32-1.80$ & 5.47 & $<0.002$ & 13 \\
\hline $\mathrm{D}$ dimer $(\mathrm{ng} / \mathrm{mL})$ & 1.51 & $1.26-1.83$ & 4.35 & $<0.001$ & 12 & 2.60 & $1.92-3.56$ & 6.05 & $<0.001$ & 12 \\
\hline Creatinine $(\mathrm{mg} / \mathrm{dL})$ & 1.32 & $1.14-1.53$ & 3.68 & $<0.001$ & 13 & 1.39 & $1.20-1.65$ & 4.02 & $<0.001$ & 16 \\
\hline Lymphocytes $\left(10^{9} / \mathrm{L}\right)$ & 0.51 & $0.35-0.73$ & 3.61 & $<0.001$ & 14 & 0.41 & $0.32-0.52$ & 6.95 & $<0.001$ & 10 \\
\hline Ferritin (ng/mL) & 1.43 & $1.12-1.85$ & 2.85 & 0.004 & 15 & 1.00 & $1.000-1.001$ & 5.42 & $<0.001$ & 14 \\
\hline Eosinophils (\%) & 0.63 & $0.45-0.85$ & 2.79 & 0.005 & 16 & 0.62 & $0.49-0.76$ & 4.35 & $<0.001$ & 15 \\
\hline $\mathrm{Hb}(\mathrm{g} / \mathrm{dL})$ & 0.89 & $0.81-0.98$ & 2.41 & 0.016 & 17 & 1.12 & $1.04-1.19$ & 3.23 & 0.001 & 17 \\
\hline Eosinophils $\left(10^{9} / \mathrm{L}\right)$ & 0.02 & $0.00-0.62$ & 2.07 & 0.039 & 18 & 0.04 & $0.003-0.360$ & 2.67 & 0.007 & 18 \\
\hline Monocytes $\left(10^{9} / \mathrm{L}\right)$ & 0.72 & $0.45-1.07$ & NA & 0.127 & NA & 0.74 & $0.51-1.04$ & 1.66 & 0.097 & 20 \\
\hline Platelets $\left(10^{9} / \mathrm{L}\right)$ & 1.00 & $1.00-1.00$ & NA & 0.203 & NA & 1.00 & $0.997-1.000$ & 1.80 & 0.070 & 19 \\
\hline
\end{tabular}

AST, Aspartic Amino Transferase; ALT, Alanine Amino Transferase; CRP; C Reactive Protein; GFR, Glomerular Filtration Rate; Hb, Hemoglobin; NLR, Neutrophil Lymphocyte Ratio; NC, not calculated, WBC, White Blood cell Count.

Applying this classification to assess variable performance using ROC curve analysis (Table 5) showed that the $\mathrm{CD}$ and ODRB variables performed moderately better for predicting survival, while the IFRB variables were better for predicting disease severity and in distinguishing between moderate and severe disease (Fig 5A and Table 3). The strong influence of age was more evident in the analysis of survival curves (using Youden index as cut-off, Table 5) in which the hazard ratio (HR) for age under or above 60 years was 32, while the next highest HR was GFR with HR of 9.3. The predictors of disease severity in descending order were age, GFR, urea, IL-6, D-dimer, and comorbidities (Fig 5B). The predictive power of both the ODRB and IFRB variables was maintained in the logistic regression analysis after adjusting for age (Table 4) or reduced by ROC analysis of age interval stratified values (Table 7S). However, the random forest simulation further confirmed that age was the single best predictor of outcome, and that the combination of all variables was only partially additive (Table $8 \mathrm{~S}$ ). 
medRxiv preprint doi: https://doi.org/10.1101/2022.01.29.22270016; this version posted February 2,2022 . The copyright holder for this preprint (which was not certified by peer review) is the author/funder, who has granted medRxiv a license to display the preprint in perpetuity.

All rights reserved. No reuse allowed without permission.

Table 5. ROC curve analysis as for clinical laboratory test performance comparison for survival/decease and non-severe/severe outcomes.

\begin{tabular}{|c|c|c|c|c|}
\hline \multicolumn{5}{|c|}{ Decease Outcome } \\
\hline Variable & AUC & $\mathrm{CI}$ & $p$ & $\begin{array}{c}\text { YOUDEN for } \\
\text { Hazard Ratios cut off }\end{array}$ \\
\hline Age & 0.87 & $0.85-0.89$ & 0.001 & $>60.50$ \\
\hline Comorbidities & 0.75 & $0.72-0.78$ & $5.95 \mathrm{E}-25$ & $>1.50$ \\
\hline GFR & 0.80 & $0.77-0.83$ & $2.45 \mathrm{E}-53$ & $<87.30$ \\
\hline IL-6 & 0.77 & $0.73-0.81$ & $5.24 \mathrm{E}-26$ & $>50.50$ \\
\hline AST/ALT & 0.73 & $0.69-0.77$ & $6.08 \mathrm{E}-31$ & $>1.64$ \\
\hline $\mathrm{SpO} 2 / \mathrm{FiO} 2$ & 0.73 & $0.70-0.78$ & $1.79 \mathrm{E}-43$ & $<439.50$ \\
\hline CRP & 0.73 & $0.70-0.78$ & $1.44 \mathrm{E}-20$ & $>11.13$ \\
\hline D-dimer & 0.73 & $0.69-0.77$ & 7.42E-20 & $>353.00$ \\
\hline Creatinine & 0.71 & $0.67-0.74$ & $4.35 \mathrm{E}-25$ & $>1.12$ \\
\hline Lymphocyte \% & 0.69 & $0.65-0.73$ & $1.18 \mathrm{E}-21$ & $<12.05$ \\
\hline NLR & 0.69 & $0.65-0.73$ & $1.33 \mathrm{E}-21$ & $>6.85$ \\
\hline Neutrophil \% & 0.69 & $0.65-0.73$ & $1.61 \mathrm{E}-43$ & $>82.15$ \\
\hline $\mathrm{Hb}$ & 0.65 & $0.62-0.69$ & $5.67 \mathrm{E}-09$ & $<13.45$ \\
\hline Monocytes & 0.63 & $0.59-0.67$ & $5.05 \mathrm{E}-11$ & $<6.65$ \\
\hline Prothrombin time (INR) & 0.61 & $0.56-0.65$ & $1.37 \mathrm{E}-07$ & $>1.21$ \\
\hline Platelets & 0.60 & $0.56-0.64$ & 9.94E-07 & $<162.50$ \\
\hline Eosinophils \% & 0.59 & $0.55-0.62$ & $1.32 \mathrm{E}-5$ & $<0.15$ \\
\hline Ferritin & 0.57 & $0.51-0.62$ & 0.019 & $>668.00$ \\
\hline \multicolumn{5}{|c|}{ Severity outcome } \\
\hline IL6 & 0.78 & $0.75-0.80$ & $8.65 \mathrm{E}-56$ & $\mathrm{NC}$ \\
\hline $\mathrm{SpO} 2 / \mathrm{FiO} 2$ & 0.77 & $0.74-0.81$ & $1.79 \mathrm{E}-43$ & $\mathrm{NC}$ \\
\hline CRP & 0.75 & $0.71-0.77$ & $5.77 \mathrm{E}-43$ & $\mathrm{NC}$ \\
\hline NLR & 0.71 & $0.68-0.73$ & $1.74 \mathrm{E}-41$ & $\mathrm{NC}$ \\
\hline GFR & 0.69 & $0.65-0.71$ & $1.69 \mathrm{E}-33$ & $\mathrm{NC}$ \\
\hline Age & 0.67 & $0.64-0.70$ & $2.55 \mathrm{E}-29$ & $\mathrm{NC}$ \\
\hline D-dimer & 0.67 & $0.63-0.69$ & $2.63 \mathrm{E}-20$ & $\mathrm{NC}$ \\
\hline Monocytes \% & 0.66 & $0.62-0.68$ & $1.92 \mathrm{E}-24$ & $\mathrm{NC}$ \\
\hline AST/ALT & 0.66 & $0.62-0.68$ & $2.97 \mathrm{E}-24$ & $\mathrm{NC}$ \\
\hline Comorbidity & 0.65 & $0.62-0.68$ & $5.95 \mathrm{E}-25$ & $\mathrm{NC}$ \\
\hline Ferritin & 0.64 & $0.60-0.67$ & $1.08 \mathrm{E}-12$ & $\mathrm{NC}$ \\
\hline Eosinophils \% & 0.61 & $0.57-0.63$ & $3.14 \mathrm{E}-12$ & $\mathrm{NC}$ \\
\hline $\mathrm{Hb}$ & 0.59 & $0.55-0.62$ & $5.67 \mathrm{E}-09$ & $\mathrm{NC}$ \\
\hline Monocytes n & 0.57 & $0.53-0.59$ & $1.02 \mathrm{E}-05$ & $\mathrm{NC}$ \\
\hline
\end{tabular}

AST, Aspartic Amino Transferase; ALT, Alanine Amino Transferase; CRP; C Reactive Protein; GFR, Glomerular Filtration Rate; Hb, Hemoglobin; NLR, Neutrophil Lymphocyte Ratio; NC, not calculated. 
medRxiv preprint doi: https://doi.org/10.1101/2022.01.29.22270016; this version posted February 2,2022 . The copyright holder for this preprint (which was not certified by peer review) is the author/funder, who has granted medRxiv a license to display the preprint in All rights reserved. No reuse allowed without permission.

A

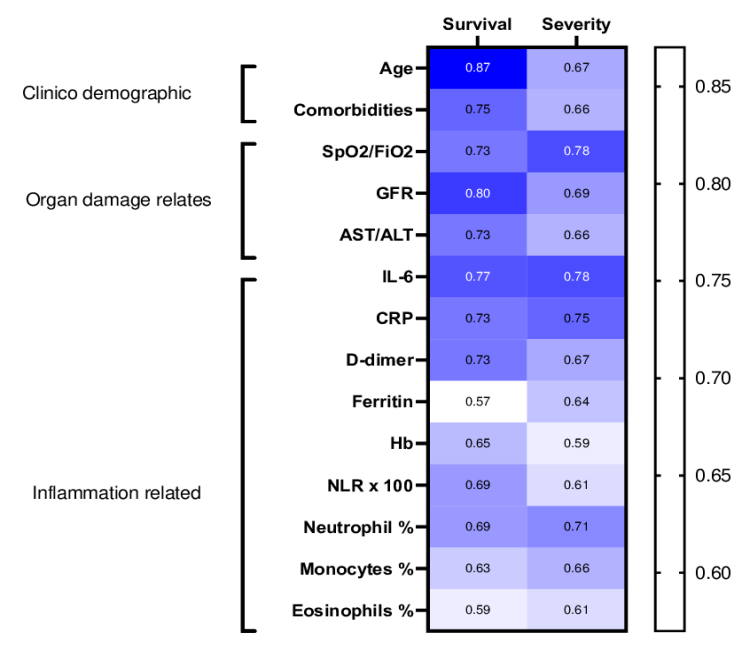

B

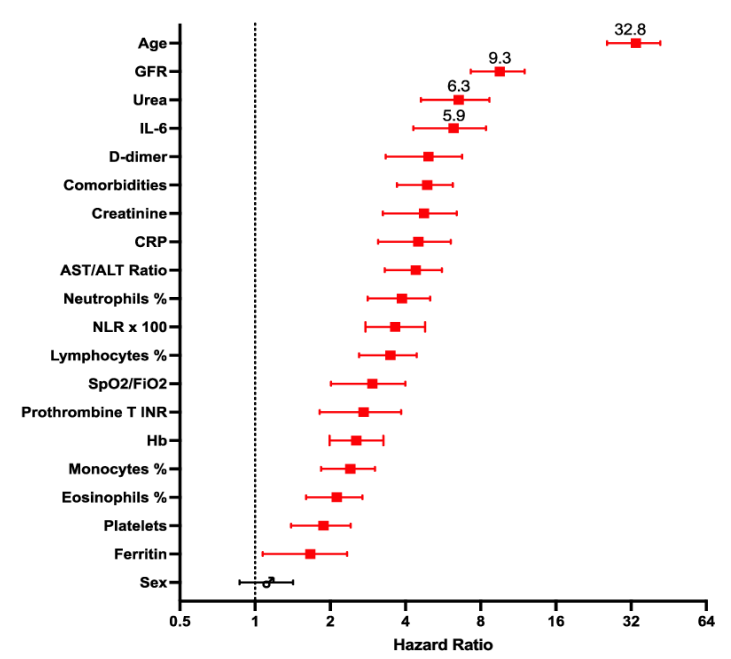

Fig 5. Relative weight of different variables in prediction. (A) Heatmap summarising the values under the curve (AUC) generated by applying clinical laboratory performance test to each the main variables; the performance was assessed by survival/decease and for non-severity/severity outcomes. (B) Hazard ratios corresponding to survival curves for Youden index cut-off. Red, significant values. SpO2/FiO2, oxygen saturation/fraction of inspired oxygen; GFR, glomerular filtration rate, NLR, neutrophil-to-lymphocyte ratio; CRP, C-reactive protein; AST, aspartate aminotransferase; ALT, alanine aminotransferase; $\mathrm{Hb}$, haemoglobin. The $\mathrm{r}$ - and $\mathrm{p}$-values of the data represented in the heatmap are in xlsx format files in the supplementary material "Correlation of variables, r-values" and "Correlation of variables, p-values.

\section{Predictive power of variables during hospitalisation}

The analysis of the 7,586-follow-up observations showed that association of biomarkers with survival varied during the 28 days of follow-up. The Kaplan-Meier survival curves of most IFRB variables for predicting survival remained separated during the first few days of hospitalisation with maximum separation around day 5 (Fig 6). Interpretation of the values in patients with longer hospital stays was difficult due to the decreasing sample size and complications arising from medical interventions. The survival curves for ODRBs, GFRs and AST/ALT ratio maintained their separation for most of the follow-up period. 


\section{IFRB}
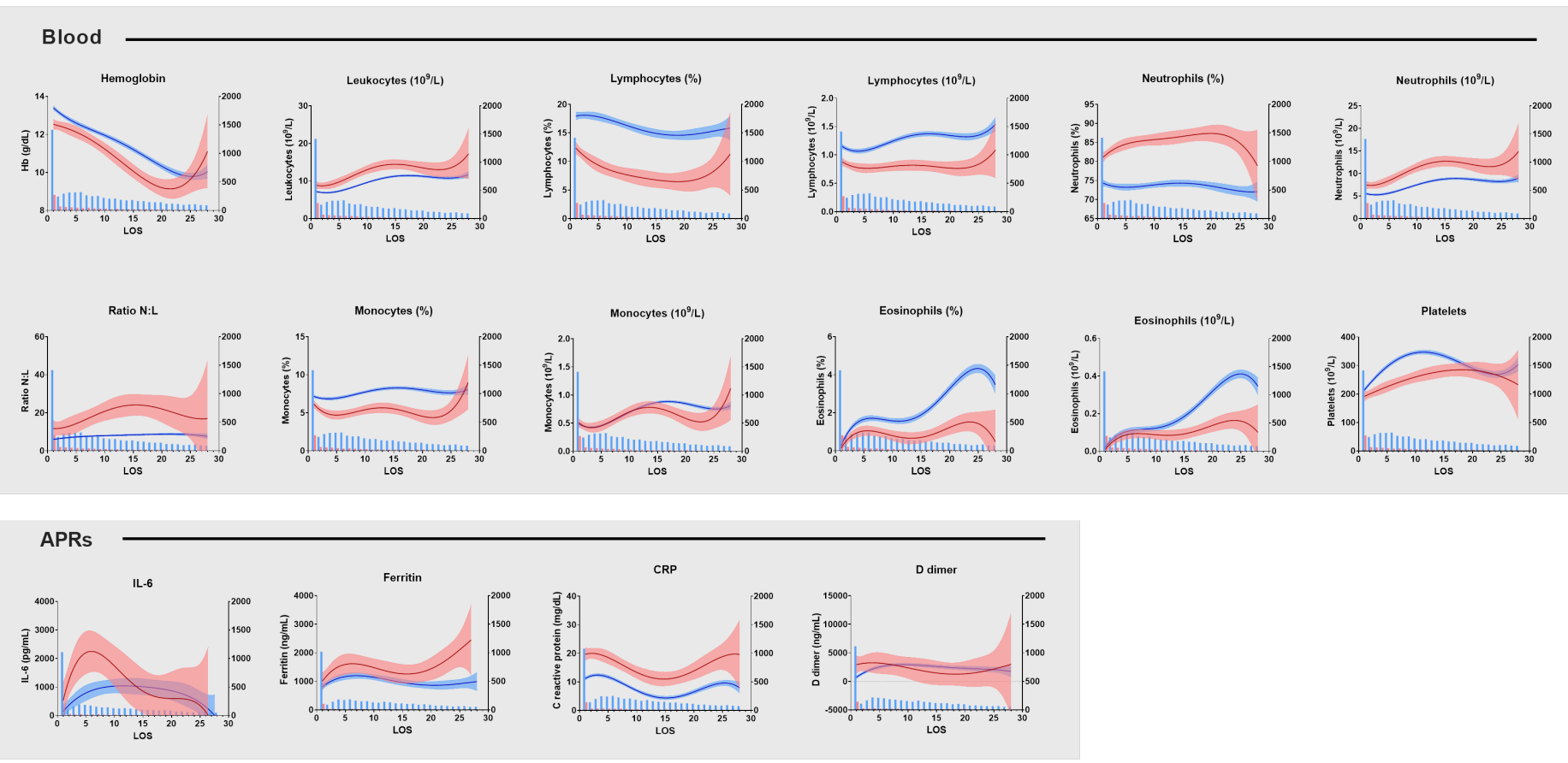

\section{ODRB}

Liver and kidney tests

$$
\text { ASTIALT ratio }
$$
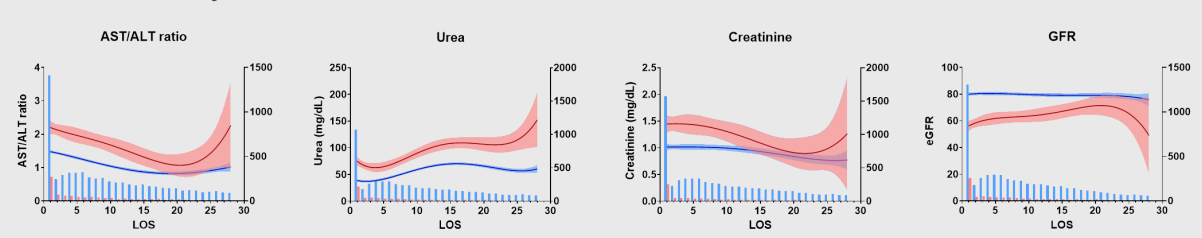

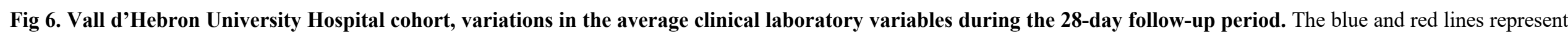

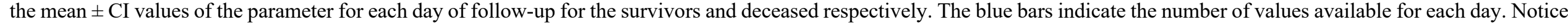

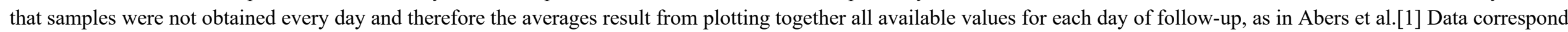

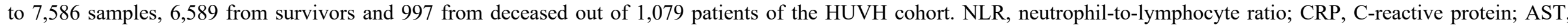

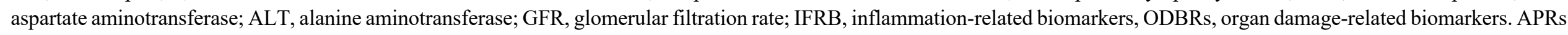
acute-phase reactants. 
medRxiv preprint doi: https://doi.org/10.1101/2022.01.29.22270016; this version posted February 2,2022 . The copyright holder for this preprint (which was not certified by peer review) is the author/funder, who has granted medRxiv a license to display the preprint in perpetuity.

All rights reserved. No reuse allowed without permission.

\section{Selection of a core panel of clinical laboratory tests}

At present in HUVH, as in many hospitals, approximately 30 clinical laboratory variables and $\mathrm{SpO} 2 / \mathrm{FiO} 2$ are routinely measured in COVID-19 patients as part of the work-up on admission. Correlation analysis and multivariable logistic regression showed that these variables had a high level of multicollinearity (Table 3), which was confirmed by random forest simulation and PCA (Fig 4 and 4S, Table 8S). Using repeated analysis and progressively excluding variables, a reduced set of eight variables: age, comorbidity index, $\mathrm{SpO} 2 / \mathrm{FiO} 2$, haemoglobin, NLR, CRP, AST/ALT ratio, and GFR, were found to capture the prediction power of all variables (see supplementary material, "Sequence of statistical biomarkers analyses: complexity reduction" and tables "Repeated multivariable logistic regression deceased" and "Repeated multivariable logistic binary severity" among the supplementary Excel tables). As age and comorbidities are non-time-varying only six of the eight variables are required for clinical management. These results do not imply, however, that IL-6, ferritin, lactate dehydrogenase, triglycerides, procalcitonin, D-dimer, and coagulation tests do not provide valuable information in clinical practice depending on the context.

\section{Results of the two validation cohort analyses}

The comparison among the three cohorts confirmed the prognostic power of the main IFRB and ODRB variables, even though the statistical ranking of their positions varied between cohorts (Table 6, and Figs 7 and 8). In addition, biomarker performance as predictors of outcome was maintained in the three cohorts in the random forest simulations (Table 9S).

Table 6. Pairwise comparison of demographic and clinical laboratory biomarkers in the exploratory (HUVH) and the two validation cohorts (HUGTP and HUB).

\begin{tabular}{|c|c|c|c|c|c|c|}
\hline Patients & $\begin{array}{l}\text { Cohort HUVH } \\
(n=1579)\end{array}$ & $\begin{array}{l}\text { Cohort HUB } \\
\quad(n=598)\end{array}$ & $\begin{array}{c}\text { Cohort } \\
\text { HUGTP } \\
(n=423)\end{array}$ & $\begin{array}{c}\text { HUVH vs. } \\
\text { HUB } \\
(p \text {-value })\end{array}$ & $\begin{array}{c}\text { HUVH vs. } \\
\text { HUGTP } \\
(p \text {-value) }\end{array}$ & $\begin{array}{l}\text { HUB vs. } \\
\text { HUGTP } \\
\text { (p-value) }\end{array}$ \\
\hline \multicolumn{7}{|l|}{ Demographics } \\
\hline Age Median (IQR) & $62(50-75)$ & $65(53-74)$ & $62(52-71)$ & 0.07 & 0.94 & 0.03 \\
\hline Females n (\%) & $699(44.2 \%)$ & $208(34.8 \%)$ & $157(37.1 \%)$ & \multirow[t]{2}{*}{$<0.0001$} & \multirow[t]{2}{*}{0.46} & \multirow[t]{2}{*}{0.009} \\
\hline Males n (\%) & $880(55.7 \%)$ & $389(65.2 \%)$ & $266(62.90 \%)$ & & & \\
\hline \multicolumn{7}{|l|}{ Mortality } \\
\hline Global n (\%) & $\begin{array}{l}255 / 1579 \\
(16.14 \%)\end{array}$ & $154 / 598(25.7 \%)$ & $\begin{array}{c}52 / 423 \\
(12.3 \%)\end{array}$ & $<0.0001$ & $<0.0001$ & 0.57 \\
\hline Females n $(\%)$ & 107/699 (15.3\%) & $52 / 208(25.0 \%)$ & 14/157 (8.9\%) & 0.002 & 0.0001 & 0.42 \\
\hline Males n (\%) & $\begin{array}{c}148 / 880 \\
(16.8 \% \%)\end{array}$ & $101 / 389(25.9 \%)$ & $38 / 266(14.3)$ & 0.0002 & 0.3443 & 0.0003 \\
\hline DFSO Median (IQR) & $7(4-10)$ & $11(8-15)$ & $7(4-10)$ & $<0.0001$ & $>0.99$ & $<0.0001$ \\
\hline $\begin{array}{l}\text { Laboratory } \\
\text { variables }\end{array}$ & Median (IQR) & Median (IQR) & Median (IQR) & & & \\
\hline \multicolumn{7}{|l|}{ Blood } \\
\hline $\mathrm{Hb}(\mathrm{g} / \mathrm{dL})$ & $13.5(12.3-14.5)$ & $12.8(11.5-13.9)$ & $\begin{array}{c}13.6(12.5- \\
14.7)\end{array}$ & $<0.0001$ & 0.14 & $<0.0001$ \\
\hline WBC $\left(10^{9} / \mathrm{L}\right)$ & $6.6(5.1-8.8)$ & $7.2(5.3-11.1)$ & $6.9(5.2-9.3)$ & $<0.0001$ & 0.07 & 0.07 \\
\hline Neutrophils, $\%$ & $76.1(68-83.2)$ & $80.4(68.8-87.9)$ & $\begin{array}{c}79.5(71.2- \\
85.4)\end{array}$ & $<0.0001$ & 0.0001 & 0.33 \\
\hline Neutrophils $\left(10^{9} / \mathrm{L}\right)$ & $4.9(3.5-6.9)$ & $5.7(3.6-9.1)$ & $5.2(3.8-7.8)$ & $<0.0001$ & 0.005 & 0.17 \\
\hline Lymphocytes (\%) & $16(10.5-23)$ & $12.7(7.3-20.7)$ & $12.5(8.1-19.1)$ & $<0.0001$ & $<0.0001$ & 0.83 \\
\hline Lymphocytes $\left(10^{9} / \mathrm{L}\right)$ & $1(0.7-1.4)$ & $0.9(0.6-1.3)$ & $0.8(0.6-1.2)$ & $<0.0001$ & $<0.0001$ & 0.09 \\
\hline Monocytes (\%) & $6.7(4.8-8.8)$ & $5.8(3.6-8.9)$ & $6.8(4.9-9.1)$ & $<0.0001$ & 0.29 & $<0.0001$ \\
\hline Monocytes $\left(10^{9} / \mathrm{L}\right)$ & $0.4(0.31-0.6)$ & $0.4(0.3-0.6)$ & $0.5(0.3-0.7)$ & 0.34 & 0.009 & 0.003 \\
\hline Eosinophils (\%) & $0(0-0.3)$ & $0.1(0-0.9)$ & $0.1(0-0.2)$ & $<0.0001$ & 0.47 & 0.006 \\
\hline Eosinophils $\left(10^{9} / \mathrm{L}\right)$ & $0(0-0.02)$ & $0.01(0-0.06)$ & $0(0-0)$ & $<0.0001$ & $<0.0001$ & $<0.0001$ \\
\hline Basophils $\left(10^{9} / \mathrm{L}\right)$ & $0(0.01-0.03)$ & $0.02(0.01-0.03)$ & $0(0-0)$ & 0.06 & $<0.0001$ & $<0.0001$ \\
\hline NLR & $4.8(3.0-7.0)$ & $6.3(3.4-11.8)$ & $6.3(3.7-10.8)$ & $<0.0001$ & $<0.0001$ & 0.93 \\
\hline
\end{tabular}


medRxiv preprint doi: https://doi.org/10.1101/2022.01.29.22270016; this version posted February $2,2022$. The copyright holder for this preprint (which was not certified by peer review) is the author/funder, who has granted medRxiv a license to display the preprint in perpetuity.

All rights reserved. No reuse allowed without permission.

\begin{tabular}{|c|c|c|c|c|c|c|}
\hline Platelets $\left(10^{9} / \mathrm{L}\right)$ & $197(154-251)$ & $234.5(174.3-327.8)$ & $203(160-254)$ & $<0.0001$ & 0.35 & $<0.0001$ \\
\hline \multicolumn{7}{|l|}{ Clinical Chemistry } \\
\hline CRP (mg/dL) & $8.9(3.8-16.6)$ & $8.1(3.5-16.7)$ & $9.5(4.8-16.7)$ & 0.31 & 0.64 & 0.69 \\
\hline IL-6 (pg/mL) & $45.1(23.6-80.0)$ & $53.5(20.4-131.1)$ & $\begin{array}{c}47.1(24.6- \\
92.6)\end{array}$ & 0.01 & 0.21 & 0.21 \\
\hline Ferritin $(\mathrm{ng} / \mathrm{mL})$ & $\begin{array}{c}539(282.5- \\
1011.5)\end{array}$ & $\begin{array}{c}1210.4(617.0- \\
1903.3)\end{array}$ & $\begin{array}{c}614(316.5- \\
1080)\end{array}$ & $<0.0001$ & 0.16 & $<0.0001$ \\
\hline $\begin{array}{l}\text { Triglycerides } \\
(\mathrm{mg} / \mathrm{dL})\end{array}$ & $121(92-161)$ & $173.9(123.5-251.3)$ & NA (NA) & $<0.0001$ & NA & NA \\
\hline LDH (UI/L) & $336(271-421)$ & $330.1(261.3-448.1)$ & $\begin{array}{c}313(224- \\
441.5)\end{array}$ & 0.50 & 0.02 & 0.04 \\
\hline Urea $(\mathrm{mg} / \mathrm{dL})$ & $35(25-51)$ & $39(26.8-58.9)$ & $34.9(25-48.5)$ & 0.009 & 0.17 & 0.009 \\
\hline AST (IU/L) & $40(30-60)$ & $35.4(23.9-58)$ & NA (NA) & $<0.0001$ & NA & NA \\
\hline ALT (IU/L) & $28(19-50)$ & $33.1(19.9-60.5)$ & $30(21-53)$ & $<0.0001$ & 0.008 & 0.11 \\
\hline $\begin{array}{l}\text { Direct bilirubin } \\
(\mathrm{mg} / \mathrm{dL})\end{array}$ & $0.3(0.2-0.4)$ & NA (NA) & NA (NA) & $<0.0001$ & NA & NA \\
\hline $\begin{array}{l}\text { Total bilirubin } \\
(\mathrm{mg} / \mathrm{dL})\end{array}$ & $0.6(0.5-0.7)$ & $0.5(0.4-0.7)$ & $0.6(0.5-0.8)$ & $<0.001$ & 0.03 & $<0.0001$ \\
\hline $\mathrm{D}$ dimer $(\mathrm{ng} / \mathrm{mL})$ & $263(168-463.5)$ & $590(355-2108)$ & $\begin{array}{c}670(415- \\
1188.5)\end{array}$ & $<0.0001$ & $<0.0001$ & 0.69 \\
\hline Fibrinogen $(\mathrm{g} / \mathrm{L})$ & $5.1(4.4-6)$ & $5.8(5.1-6.6)$ & $7.6(6.5-8.8)$ & $<0.0001$ & $<0.0001$ & $<0.0001$ \\
\hline $\begin{array}{l}\text { Prothrombin time } \\
\text { INR }\end{array}$ & $1.1(1.0-1.2)$ & $1.1(1.1-1.2)$ & $1.22(1.1-1.4)$ & $<0.0001$ & $<0.0001$ & $<0.0001$ \\
\hline
\end{tabular}

AST, Aspartic Amino Transferase; ALT, Alanine Amino Transferase; CRP; C Reactive Protein; GFR, Glomerular Filtration Rate; Hb, Hemoglobin; NLR, Neutrophil Lymphocyte Ratio; WBC, White Blood cell Count. 


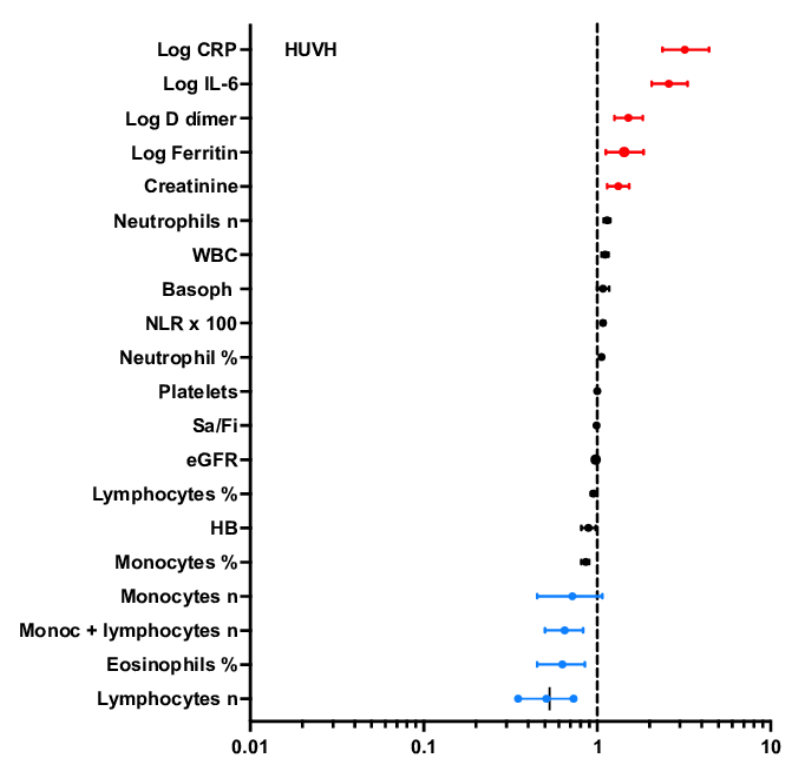

OR

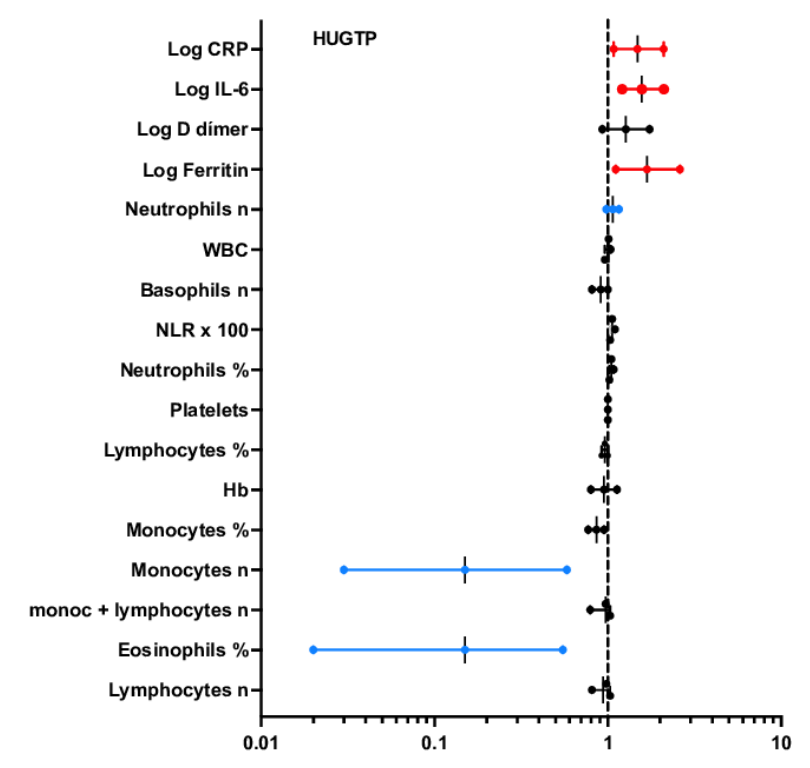

OR

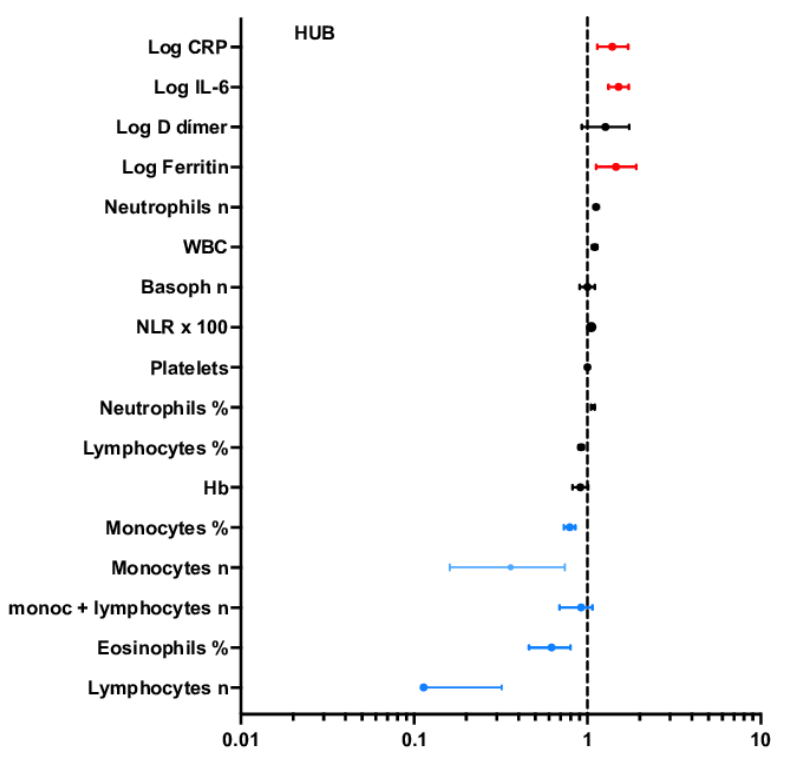

OR

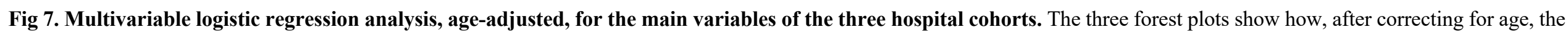

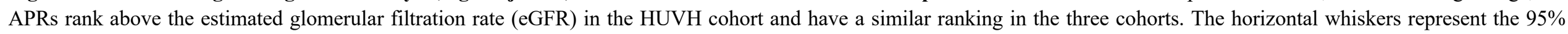

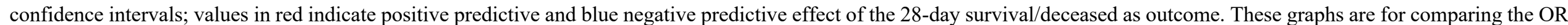

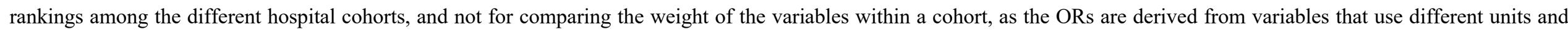

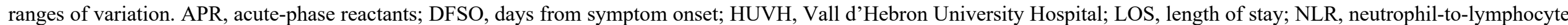

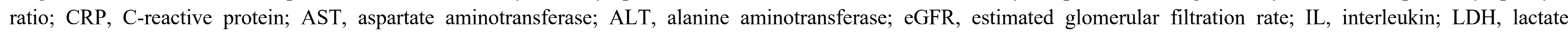
dehydrogenase; $\mathrm{Hb}$, haemoglobin. 
medRxiv preprint doi: https://doi.org/10.1101/2022.01.29.22270016; this version posted February 2,2022 . The copyright holder for this preprint (which was not certified by peer review) is the author/funder, who has granted medRxiv a license to display the preprint in

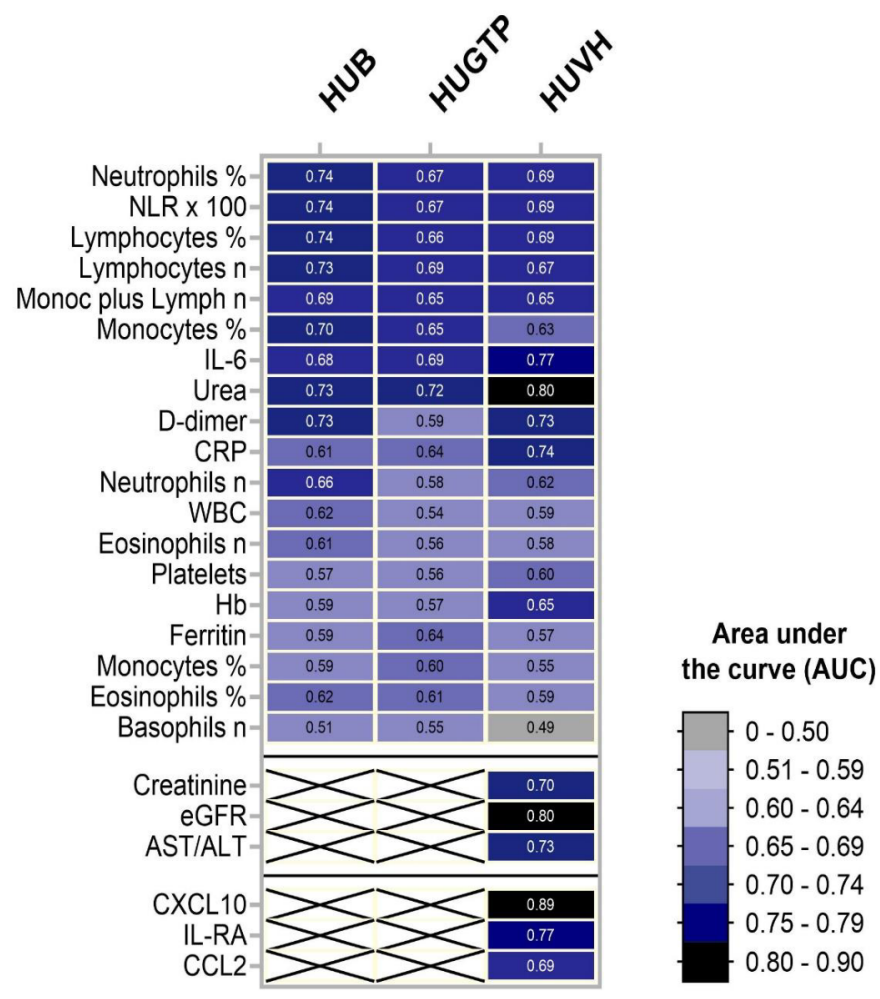

Fig 8. Heatmap of the area under the curve (AUC) of the receiver-operating characteristic curves corresponding to the variables available for the three cohorts. IL-6, CRP, urea, lymphocytes, and neutrophils occupy central positions. At the bottom, the AUC for some variables available only from the HUVH cohort and the AUC values for the three cytokines that perform better in the group of 74 patients who were analysed in the HUVH cohort. The numbers within the cells are the AUC values. APR, acute-phase reactants; Sa/Fi, oxygen saturation/fraction of inspired oxygen; DFSO, days from symptom onset; HUVH, Vall d'Hebron University Hospital; LOS, length of stay; NLR, neutrophil-tolymphocyte ratio; CRP, C-reactive protein; AST, aspartate aminotransferase; ALT, alanine aminotransferase; eGFR, estimated glomerular filtration rate; IL, interleukin; LDH, lactate dehydrogenase; Hb, haemoglobin; ROC, receiveroperating characteristic; AUC, area under the curve.

\section{Predictive ability of immunological variables}

Despite the limited size of the group analysed in the pilot study ( $\mathrm{n}=74$, Table 10S), CXCL10 had the highest $\mathrm{ROC}$ curve (AUC $=0.83$ ) of all variables including age, IFRB and ODRB, and performed better than any of the other variables considered. IL1RA and CCL2 also showed promise as biomarkers (Table 7 and Fig 9).

Table 7. Performance of expanded immunological parameters in the special immunological studies group as assessed by ROC curve analysis and compared with other variables in the same group. 
medRxiv preprint doi: https://doi.org/10.1101/2022.01.29.22270016; this version posted February 2, 2022. The copyright holder for this preprint (which was not certified by peer review) is the author/funder, who has granted medRxiv a license to display the preprint in

\begin{tabular}{|c|c|c|c|c|c|c|c|c|c|c|}
\hline \multicolumn{11}{|c|}{ Survival/decease as outcome } \\
\hline & & & & & & & & & & \\
\hline Variables & AUC & CI & $p$-value & & AUC t1 & CI & $p$-value & AUC t2 & CI & $p$-value \\
\hline Age & 0.55 & $0.42-0.69$ & 0.438 & & & & & & & \\
\hline Clin Lab Biomarkers & & & & Cytokines & & & & & & \\
\hline GFR & 0.55 & $0.46-0.74$ & 0.176 & CXCL10 & 0.83 & $0.74-0.92$ & $2.34 \mathrm{E}-06$ & 0.77 & $0.65-0.88$ & $1.24 \mathrm{E}-04$ \\
\hline IL-6 & 0.60 & $0.66-0.88$ & 0.000 & IL-1RA & 0.77 & $0.60-0.84$ & 0.002 & 0.74 & $0.61-0.85$ & $7.71 \mathrm{E}-04$ \\
\hline $\mathrm{SpO} 2 / \mathrm{FiO} 2$ ratio & 0.77 & $0.70-0.91$ & $<0.001$ & IL-6 & 0.76 & $0.65-0.87$ & $1.903 \mathrm{E}-04$ & 0.83 & $0.73-0.93$ & $2.34 \mathrm{E}-06$ \\
\hline CRP & 0.80 & $0.61-0.86$ & 0.002 & CCL2 & 0.69 & $0.56-0.82$ & 0.006 & 0.81 & $0.69-0.91$ & $1.60 \mathrm{E}-05$ \\
\hline D-dimer & 0.73 & $0.43-0.71$ & 0.353 & IL-10 & 0.67 & $0.54-0.79$ & 0.019 & 0.72 & $0.60-0.84$ & 0.0014 \\
\hline Creatinine & 0.57 & $0.49-0.78$ & 0.069 & IL-15 & 0.67 & $0.54-0.80$ & 0.012 & 0.74 & $0.63-0.85$ & $5.00 \mathrm{E}-04$ \\
\hline Lymphocytes, \% & 0.63 & $0.62-0.86$ & 0.001 & IL-7 & 0.65 & $0.52-0.79$ & 0.027 & 0.73 & $0.62-0.85$ & $8.036 \mathrm{E}-04$ \\
\hline NLR $\times 100$ & 0.74 & $0.63-0.87$ & 0.001 & TNF- $\alpha$ & 0.65 & $0.51-0.79$ & 0.033 & 0.73 & $0.55-0.81$ & 0.008 \\
\hline Neutrophils, \% & 0.75 & $0.66-0.89$ & 0.000 & & & & & & & \\
\hline $\mathrm{Hb}$ & 0.52 & $0.37-0.68$ & 0.775 & & & & & & & \\
\hline Monocytes, \% & 1.00 & $1.00-1.00$ & $<0.001$ & & & & & & & \\
\hline Platelets & 0.52 & $0.38-0.66$ & 0.789 & Flow cytometry & & & & & & \\
\hline Eosinophils, \% & 0.58 & $0.45-0.72$ & 0.263 & $\begin{array}{l}\text { CD3+CD62L+ } \\
\text { Naive T cells (\%) }\end{array}$ & 0.73 & $0.54-0.92$ & 0.032 & NA & NA & NA \\
\hline Ferritin & 0.61 & $0.46-0.76$ & 0.147 & TH17 (n) & 0.67 & $0.45-0.88$ & 0.131 & NA & NA & NA \\
\hline \multicolumn{11}{|c|}{ Non-severe vs severe as outcome } \\
\hline Variables & AUC & CI & $p$-value & & AUC t1 & CI & $p$-value & AUC t2 & CI & $p$-value \\
\hline Age & 0.55 & 0.42 to 0.69 & 0.438 & & & & & & & \\
\hline Clin Lab Biomarkers & & & & Cytokines & & & & & & \\
\hline GFR & 0.60 & 0.45 to 0.74 & 0.180 & CXCL10 & 0.83 & $0.74-0.92$ & $2.340 \mathrm{E}-06$ & 0.77 & $0.65-0.89$ & $1.24 \mathrm{E}-04$ \\
\hline IL-6 & 0.77 & 0.65 to 0.88 & 2.72E-04 & IL-6 & 0.77 & $0.66-0.88$ & $1.903 \mathrm{E}-04$ & 0.83 & $0.73-0.94$ & $2.34 \mathrm{E}-06$ \\
\hline $\mathrm{SpO} 2 / \mathrm{FiO} 2$ ratio & 0.80 & 0.70 to 0.91 & 3.08E-05 & IL1-RA & 0.73 & $0.60-0.84$ & 7.714E-04 & 0.74 & $0.62-0.86$ & 7.71E-04 \\
\hline CRP & 0.73 & 0.61 to 0.86 & 0.002 & IL-15 & 0.72 & $0.55-0.81$ & 0.012 & 0.75 & $0.63-0.86$ & $4.98 \mathrm{E}-04$ \\
\hline D-dimer & 0.57 & 0.43 to 0.71 & 0.353 & CCL-2 & 0.69 & $0.57-0.82$ & 0.065 & 0.81 & $0.69-0.92$ & $1.60 \mathrm{E}-05$ \\
\hline Creatinine & 0.63 & 0.49 to 0.78 & 0.069 & IL-10 & 0.67 & $0.54-0.79$ & 0.019 & 0.73 & $0.61-0.85$ & 0.001 \\
\hline Lymphocytes, \% & 0.74 & 0.62 to 0.86 & 0.001 & TNF-alpha & 0.65 & $0.51-0.79$ & 0.033 & 0.69 & $0.56-0.82$ & 0.008 \\
\hline NLR $\times 100$ & 0.75 & 0.63 to 0.87 & $6.08 \mathrm{E}-04$ & IL-7 & 0.64 & $0.50-0.77$ & 0.051 & 0.74 & $0.62-0.85$ & 8.04E-04 \\
\hline Neutrophils, \% & 0.77 & 0.66 to 0.89 & $1.77 \mathrm{E}-04$ & IL-2 & 0.6 & $0.46-0.73$ & 0.176 & 0.78 & $0.66-0.90$ & $7.23 \mathrm{E}-05$ \\
\hline $\mathrm{Hb}$ & 0.52 & 0.37 to 0.68 & 0.775 & IL-17 & 0.52 & $0.38-0.66$ & 0.777 & 0.70 & $0.57-0.83$ & 0.005 \\
\hline Monocytes, \% & 0.72 & 0.60 to 0.84 & 0.003 & & & & & & & \\
\hline Platelets & 0.52 & 0.38 to 0.66 & 0.789 & Flow cytometry & & & & & & \\
\hline Eosinophils, \% & 0.58 & 0.45 to 0.72 & 0.263 & $\begin{array}{l}\text { CD3+CD62L+ } \\
\text { Naive T }(\%)\end{array}$ & 0.61 & 0.40 to 0.83 & 0.3080 & & & \\
\hline Ferritin & 0.61 & 0.46 to 0.76 & 0.147 & TH17 (n) & 0.57 & 0.34 to 0.79 & 0.5490 & & & \\
\hline
\end{tabular}

Cytokine group of patients, $n=74$, Flowcytometry phenotype group of patients $n=41$, for details see Table 10S.

T1, time 1, initial data, T2 time 2, 2-3 days after onset. CRP; C Reactive Protein; NLR, Neutrophil / Lymphocyte Ratio; GFR, Glomerular Filtration Rate;; Hb, Hemoglobin. P valued in bold, significant. 

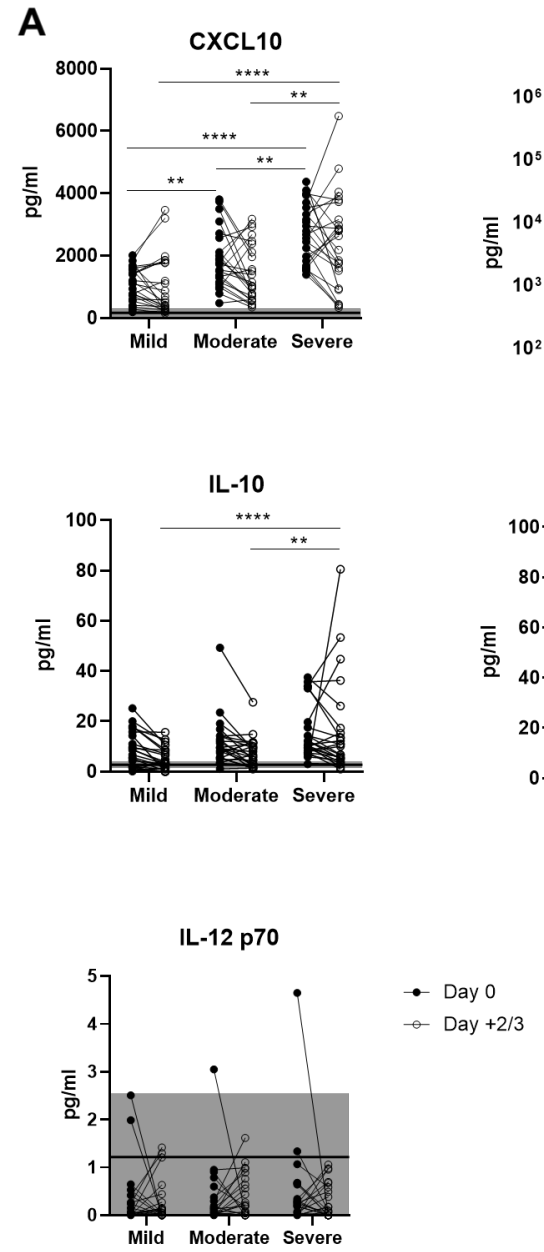

IL-1RA
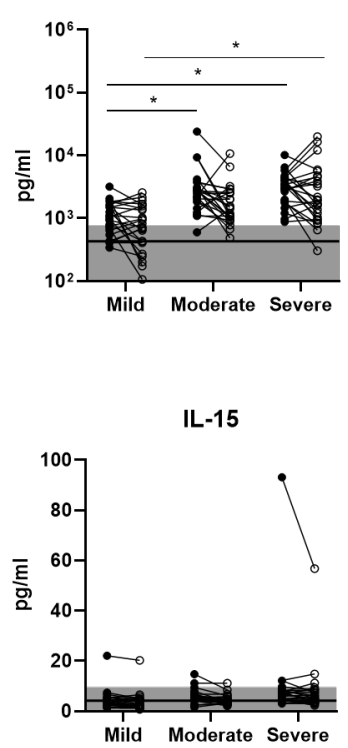
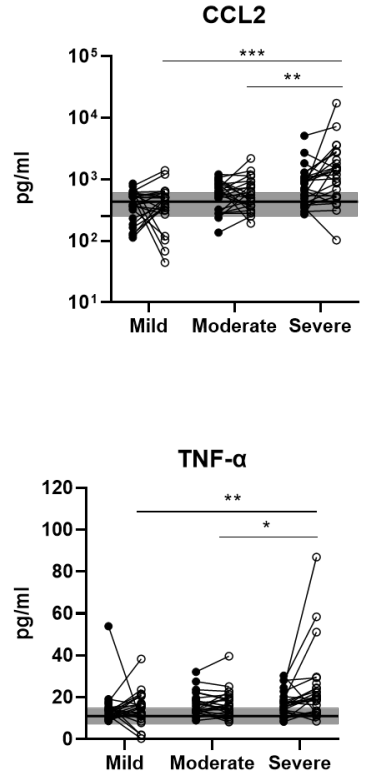
Granzyme B

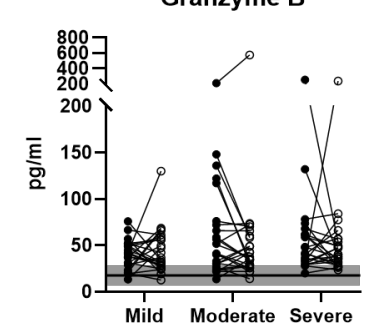

Mild Moderate Severe
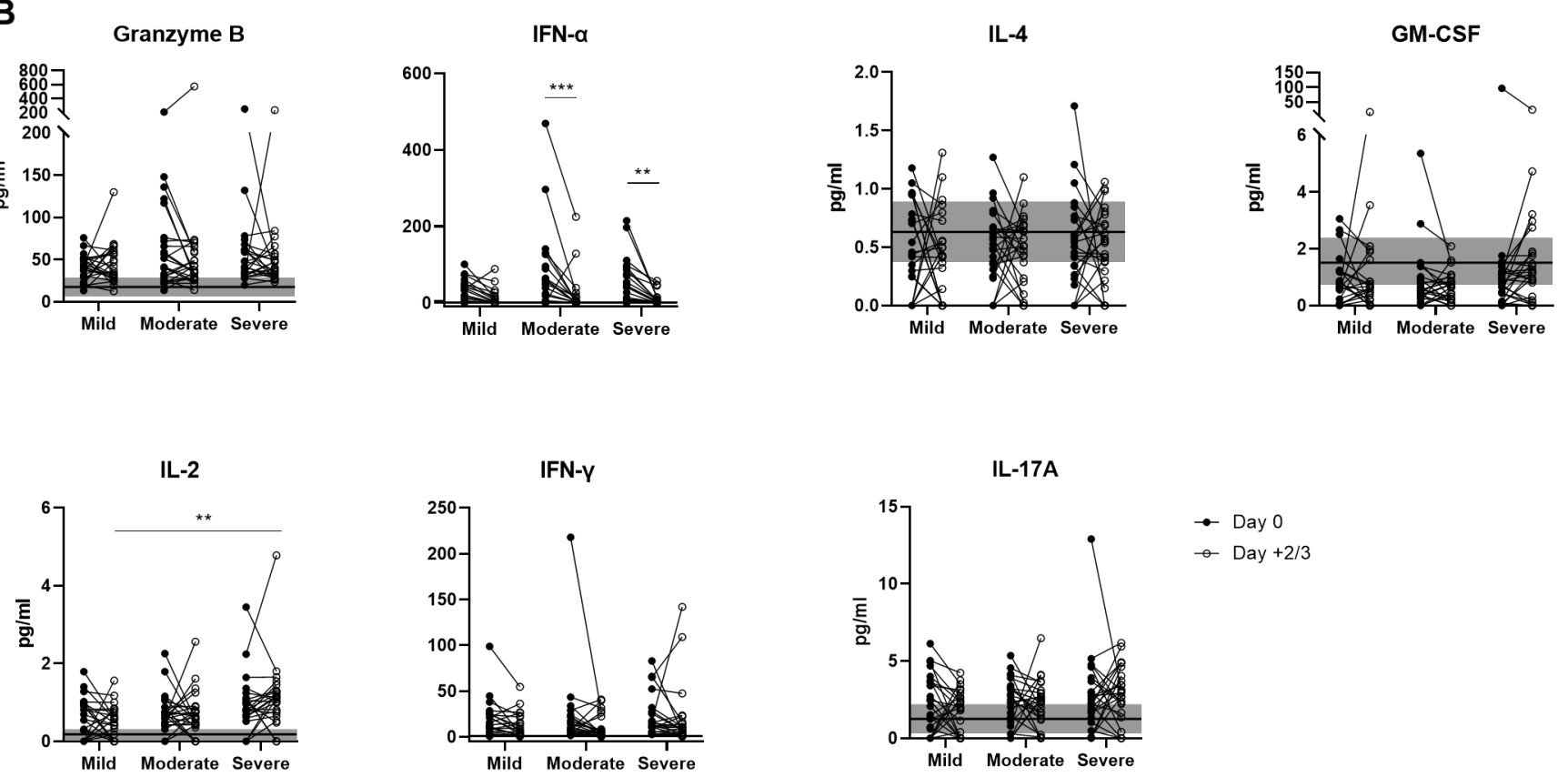

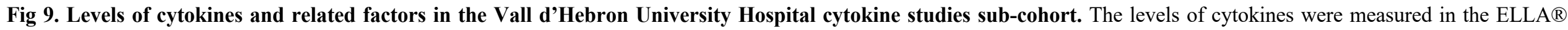

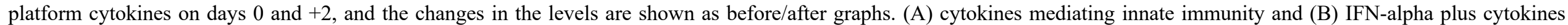
mediating adaptive immunity. 
medRxiv preprint doi: https://doi.org/10.1101/2022.01.29.22270016; this version posted February 2, 2022. The copyright holder for this preprint (which was not certified by peer review) is the author/funder, who has granted medRxiv a license to display the preprint in perpetuity.

All rights reserved. No reuse allowed without permission.

The immune phenotype was analysed in 41 patients (Table 10S). There was a steep reduction in the size of all T-cell subsets, which was more marked for CD8 effector and memory cells, and an increase in activation markers that was similar to the pattern observed in other time-series analyses $[23,36]$, revealing a deep disturbance of the immune response in severely ill patients (see Expanded phenotype analysis in supplementary). Naïve $\mathrm{T}$ cells were found associated to higher mortality (Figs 10 and 11S).

A
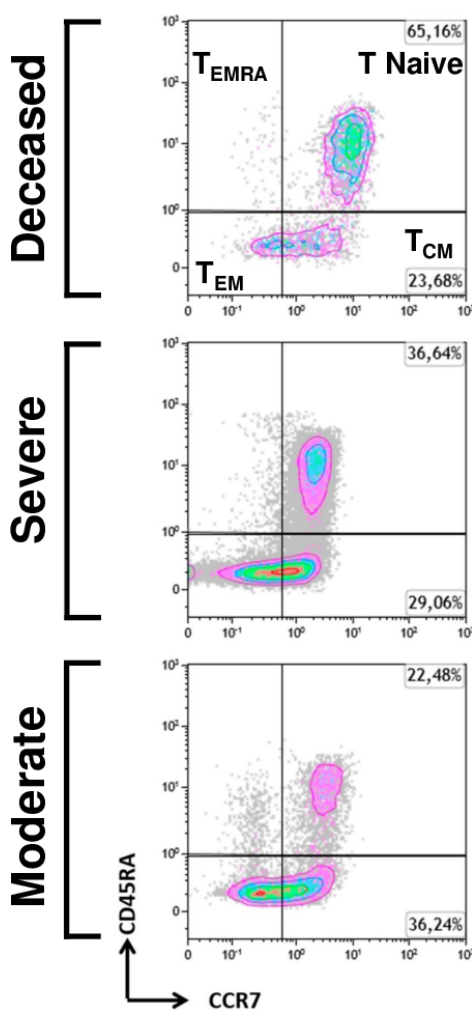

B
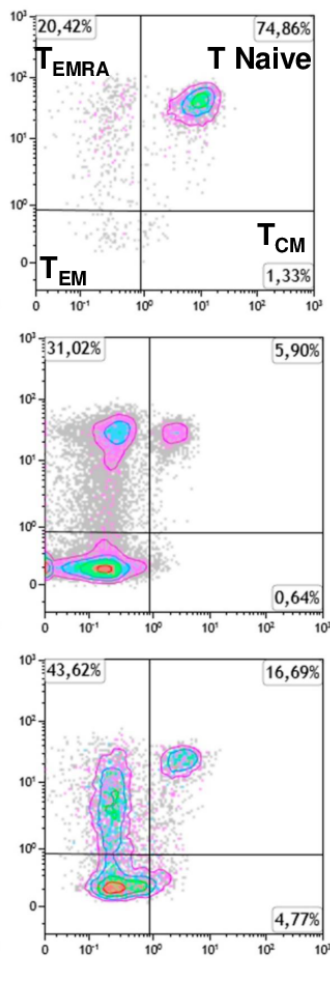

C
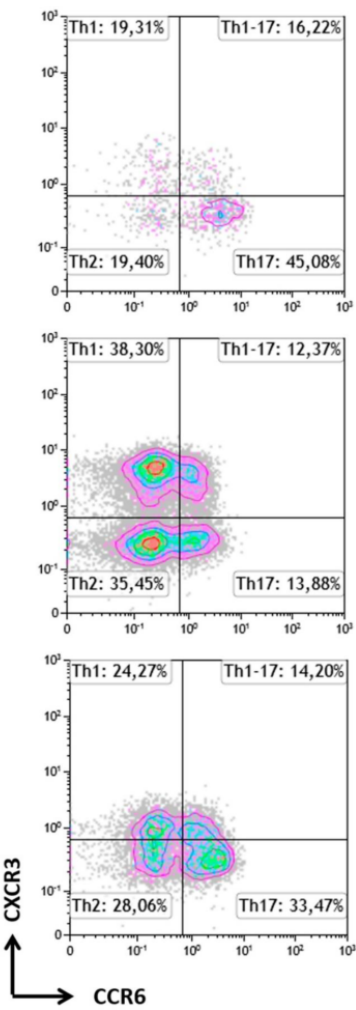

D
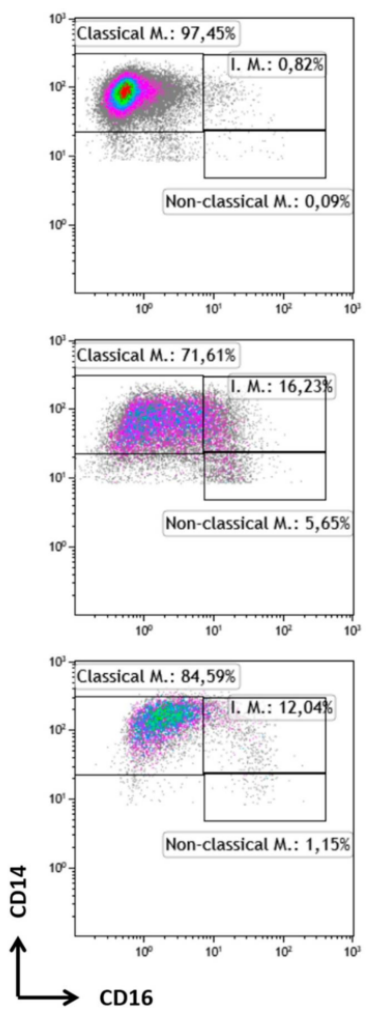

Fig 10. Representative flow cytometry plots from the Vall d'Hebron University Hospital cytokine studies subcohort. A, CD4 and B, CD8 T lymphocyte subpopulations distributed by differentiation phenotypes based on CD45RA and CCR7. C, Th-polarisation by CXCR3 and CCR6 expression. D, Monocyte subpopulations (classical intermediate monocytes [IM] and non-classical monocytes) in a comparison of patients belonging to the deceased, severe, and moderate patient categories.

\section{DISCUSSION}

The analyses revealed the limitations of currently used clinical laboratory tests used to assess the prognosis of patients with COVID-19 and tried to improve their interpretation by grouping them into categories that reflect the two main biological processes that are measured, i.e., inflammation and organ damage. As their limitations are due to redundancy, clinical management protocols could be simplified, but additional biomarkers with independent predictive power are urgently needed. This study highlights the lack of tests, for early prediction of the specific immune response to SARS-CoV-2. Such tests could provide critical non-redundant information required for prediction and clinical management. The results of the pilot study using a selection of robust immunological techniques derived from other areas of clinical immunology, suggest that better tests can be identified through systematic investigation.

As well as this central message, other notable findings are: 1) The three cohorts confirmed the strong association of: $\mathrm{SpO}_{2} / \mathrm{FiO}_{2}$, neutrophilia, lymphopenia, APRs, coagulation factors, kidney function and the AST/ALT ratio with survival and predicting disease severity. 2) There was a high 
medRxiv preprint doi: https://doi.org/10.1101/2022.01.29.22270016; this version posted February 2,2022 . The copyright holder for this preprint (which was not certified by peer review) is the author/funder, who has granted medRxiv a license to display the preprint in

All rights reserved. No reuse allowed without permission.

level of collinearity (redundancy) among the different variables, which explains the limited predictive ability of current tests. 3) After reducing redundancy, the best combination of variables was age, comorbidity index, $\mathrm{SpO}_{2} / \mathrm{FiO}_{2}$, NLR, CRP, AST/ALT ratio, fibrinogen, and GFR. 4) The classification of biomarkers into IFRB and ODRBs helped with their interpretation and revealed that ODBRs are better predictors of survival than severity, and that IFRBs are better predictors of severity than survival. 5) For the clinician at the bedside, laboratory ODBRs changes may be less conspicuous than IFRBs but they may deserve more attention.

There are several limitations to this study, including its retrospective nature. Another limitation is the absence of information regarding two key factors: the SARS-CoV-2 viral load and markers of the adaptive immune response. The SARS-CoV-2 detection techniques used during this period were not quantitative, and the variability of sampling efficiency reduces their value, even with current improved measurement methods. Serological markers need 7-21 days to become detectable and are not helpful as a tool to predict the prognosis of the patients during the initial medical assessment [37]. Finally, the effect of treatment on mortality, which changed continuously during the first wave, was not analysed in this study. We did not strictly follow the transparent reporting of a multivariable prediction model for individual prognosis or diagnosis recommendations, as generating a prediction mode was not an objective, but most requirements were fulfilled [38].

The analyses presented here are intended for improved interpretation of available biomarkers, but no algorithm is proposed. Most algorithms with good predictive power include parameters, such as oxygen requirements and imaging data, that reflect organ damage in patients that are already on the path to severe disease [13-21,38]. The ideal algorithm/biomarker should be able to identify patients at risk before organ damage occurs. Our results suggest that this is difficult with current tests because inflammation and organ damage biomarkers are strongly correlated at the time the patients reach the emergency department. If, as postulated, the main determinant of severity is a pre-existing latent pro-inflammatory state that leads to a late and inefficient adaptive immune response, biomarkers of this basal inflammation and inefficient response should be identifiable; if the generation of specific cytotoxic $\mathrm{T}$ lymphocytes is the main defence mechanism against an acute respiratory infection to a novel virus such as SARS-CoV-2, the early monitoring of these cells would help to predict the patient outcome [1,23,27,28,39-41]. These are the two obvious approaches to generate better biomarkers and the corresponding tests. Reliable early biomarkers would reduce the rate of hospitalization and as new treatments that are becoming available require early administration, generation of such biomarkers is urgent and should be feasible.

\section{Data sharing}

The supplementary material contains detailed information on the statistical analysis but deidentified data tables will shared on request after approval of a proposal, with a signed data access agreement.

\section{Supporting information}

Sequence of statistical Biomarkers Analyses, text

Table 1S, Patients excluded from HUVH cohort.

Table 2S. Monoclonal Antibodies used in in the flowcytometric phenotypic analysis

Table 3S. Distribution of comorbidities among the severity categories and demographics and hospitalization data in the HUVH cohort.

Table 4S. Demographics and hospitalization data by severity categories of the HUVH cohort.

Table 5S. Pairwise comparison of variables for maximal severity in four categories.

Table 6S. Median values of laboratory variables and the proportion out of the normal range and relation with mortality.

Table 7S. ROC curve analysis, age stratified.

Table 8S. Random Forest model applied to HUVH cohort.

Table 9S. Random Forest Model; comparison exploratory and combination of the three cohorts.

Table 10S. Patients included in immunological studies, cytokines and mononuclear cell phenotype by flowcytometry 
medRxiv preprint doi: https://doi.org/10.1101/2022.01.29.22270016; this version posted February 2,2022 . The copyright holder for this preprint (which was not certified by peer review) is the author/funder, who has granted medRxiv a license to display the preprint in All rights reserved. No reuse allowed without permission.

\section{Tables in xlsx format}

Correlation of variables $r$ values.xlsx

Correlation of variables $p$ values.xlsx

Repeated Multiple Logistic regression binary severity.xlsx

Repeated Multiple logistic regression decease.xlsx

Multiple logistic regression for follow up.xlsx

\section{Figures}

Fig 1S. Sequence of statistical analyses and summary of conclusions from every step.

Fig 2S. Heatmap summarizing pairwise comparison; p values scale refers to non-parametric tests (Mann-Whitney and Kruskal-Wallis).

Fig 3S. Principal component analysis of the main variables, exitus is equivalent to decease

Fig 4S. Correlograms of the main variables for patients under (A) and over (B) 65 years of age.

Fig 5S. Representative Kaplan-Meyer survival curves clinicodemographic biomarkers (ODRB) and inflammation related biomarkers (IFRB).

Fig 6S. Heatmap summarizing pairwise comparison of the survivors vs deceased in the three hospital cohorts; $p$ values scale refer non-parametric comparisons (Mann-Whitney and Kruskal-Wallis.

Fig 7S. PCA analysis representation of the three hospitals cohorts, indicating similar main vectors, with local differences. Fig 8S. Heatmap summarizing the reduction of mean Gini index in the Random Forest model that reflects the importance of each variable in the predictive model.

Fig 10S. Performance of cytokines as clinical laboratory test in ROC curve analysis

Fig 11S. Summary of flowcytometry analyses of peripheral blood mononuclear cells.

\section{Acknowledgments}

Hospital Vall d'Hebron Group for the study of COVID-19 immune profile:

Artur Llobell Uriel MD, Romina Dieli MD, PhD and Roger Colobran PhD, Immunology Division Gemma Codina MD, PhD and Tomás Pumarola MD, PhD, Microbiology Division

Roser Ferrer PhD and Vicente Cortina BSc, Biochemistry Division

Magda Campins MD, PhD, Epidemiology and Public Health Division

Isabel Ruiz MD, Nuria Fernández MD, Esteban Ribera MD and Joan Roig MD, Infectious Diseases Division

Ricardo Ferrer MD and Adolfo Ruiz-Sanmartín MD, Intensive Care Medicine Division

Albert Selva MD, PhD and Moisés Labrador MD, PhD, Division Internal Medicine.

María José Soler Romeo MD PhD, Nephrology Division

Jaume Ferrer MD, PhD, Eva Polverino MD, PhD and Antonio Álvarez MD, PhD, Pneumology

Division

María Queralt Gorgas PhD and Marta Miarons PhD, Clinical Pharmacy Division

Pere Soler-Palacín, MD, PhD and Andrea Martin, MD, Pediatrics Division

Anna Suy MD, Obstetrics and Gynecology Division

Maria Jose Buzon PhD and Meritxell Genesca PhD, Infectious Disease Research Group

We would like to thank all the patients who participated in this study. We thank all the physicians, medical students, study nurses, and trial coordinators from the participating centres. The authors thank all the patients and health staff of the Hospitals Vall d'Hebron, Bellvitge, and Germans Trias i Pujol and of the associated hospitals mentioned in the text who endured and did their best to overcome the first wave of COVID-19 in Barcelona, an experience that none of us would ever forget. The authors are grateful to Dr Isabel Novoa Garcia and Ms Sheyla Pascual Martin for their invaluable help in organizing and maintain the COVID-19 collection in the Bio-Bank; to Mr Àlex 
medRxiv preprint doi: https://doi.org/10.1101/2022.01.29.22270016; this version posted February 2,2022 . The copyright holder for this preprint (which was not certified by peer review) is the author/funder, who has granted medRxiv a license to display the preprint in

All rights reserved. No reuse allowed without permission.

Pérez Rodríguez, Ms Jessica Muñoz, Ms Cinta Rabaza Martí, and Ms Aina Aguiló Cucurull, the technical staff of the immunology laboratory who collected and organized the COVID-19 patient samples; and to Ms Adelaida Parada Ramos, the secretary of the Immunology Division, who helped retrieve the electronic medical records and discharge notes in regard to this study for review by the medical personnel for this study.

\section{References}

1 Abers MS, Delmonte OM, Ricotta EE, et al. An immune-based biomarker signature is associated with mortality in COVID-19 patients. JCI Insight 2021;6:m1985. doi:10.1172/jci.insight.144455

2 Zhou F, Yu T, Du R, et al. Clinical course and risk factors for mortality of adult inpatients with COVID-19 in Wuhan, China : a retrospective cohort study. The Lancet 2020;6736:1-9. doi:10.1016/S0140-6736(20)30566-3

3 Chams N, Chams S, Badran R, et al. COVID-19: A Multidisciplinary Review. Frontiers in Public Health 2020;8:1-20. doi:10.3389/fpubh.2020.00383

4 Ghayda RA, Lee J, Lee JY, et al. Correlations of clinical and laboratory characteristics of covid-19: A systematic review and meta-analysis. International Journal of Environmental Research and Public Health 2020;17:1-15. doi:10.3390/ijerph17145026

5 Coma Redon E, Mora N, Prats-Uribe A, et al. Excess cases of influenza and the coronavirus epidemic in Catalonia: a time-series analysis of primary-care electronic medical records covering over 6 million people. BMJ Open 2020;10:e039369. doi:10.1136/bmjopen-2020039369

6 Guallar MP, Meiriño R, Donat-Vargas C, et al. Inoculum at the time of SARS-CoV-2 exposure and risk of disease severity. International journal of infectious diseases : IJID : official publication of the International Society for Infectious Diseases 2020;97:290-2. doi:10.1016/j.ijid.2020.06.035

7 Marks M, Millat-Martinez P, Ouchi D, et al. Transmission of COVID-19 in 282 clusters in Catalonia, Spain: a cohort study. The Lancet Infectious Diseases 2021;21:629-36. doi:10.1016/S1473-3099(20)30985-3

8 Korber B, Fischer WM, Gnanakaran S, et al. Tracking Changes in SARS-CoV-2 Spike: Evidence that D614G Increases Infectivity of the COVID-19 Virus. Cell 2020;182:812827.e19. doi:10.1016/j.cell.2020.06.043

9 Meyerholz DK, Perlman S. Does common cold coronavirus infection protect against severe SARS-CoV-2 disease? Journal of Clinical Investigation 2021;131. doi:10.1172/JCI144807

10 Zhang Q, Bastard P, Liu Z, et al. Inborn errors of type I IFN immunity in patients with lifethreatening COVID-19. Science (New York, NY) 2020;370:eabd4570. doi:10.1126/science.abd4570

11 Ellinghaus D, Degenhardt F, Bujanda L, et al. Genomewide Association Study of Severe Covid-19 with Respiratory Failure. New England Journal of Medicine 2020;383:1522-34. doi:10.1101/2020.10.06.20205864

12 COVID-19 Host Genetics Initiative. Mapping the human genetic architecture of COVID-19. Nature 2021;600:472-7. doi:10.1038/s41586-021-03767-x

13 Ambale-Venkatesh B, Quinaglia T, Shabani M, et al. Prediction of Mortality in hospitalized COVID-19 patients in a statewide health network. medRxiv : the preprint server for health sciences Published Online First: 19 February 2021. doi:10.1101/2021.02.17.21251758

14 Galván-Román JM, Rodríguez-García SC, Roy-Vallejo E, et al. IL-6 serum levels predict severity and response to tocilizumab in COVID-19: An observational study. Journal of Allergy and Clinical Immunology 2021;147:72-80.e8. doi:10.1016/j.jaci.2020.09.018 
medRxiv preprint doi: https://doi.org/10.1101/2022.01.29.22270016; this version posted February 2,2022 . The copyright holder for this preprint (which was not certified by peer review) is the author/funder, who has granted medRxiv a license to display the preprint in

All rights reserved. No reuse allowed without permission.

15 Gupta RK, Marks M, Samuels THA, et al. Systematic evaluation and external validation of 22 prognostic models among hospitalised adults with COVID-19: an observational cohort study. The European respiratory journal 2020;56:2003498. doi:10.1183/13993003.034982020

16 Jehi L, Ji X, Milinovich A, et al. Development and validation of a model for individualized prediction of hospitalization risk in 4,536 patients with COVID-19. PLOS ONE 2020;15:e0237419. doi:10.1371/journal.pone.0237419

17 Knight SR, Ho A, Pius R, et al. Risk stratification of patients admitted to hospital with covid19 using the ISARIC WHO Clinical Characterisation Protocol: development and validation of the 4C Mortality Score. BMJ 2020;2:m3339. doi:10.1136/bmj.m3339

18 Marcolino MS, Pires MC, Ramos LEF, et al. ABC2-SPH risk score for in-hospital mortality in COVID-19 patients: development, external validation and comparison with other available scores. International Journal of Infectious Diseases 2021;110:281-308. doi:10.1016/j.ijid.2021.07.049

19 Riveiro-Barciela M, Labrador-Horrillo M, Camps-Relats L, et al. Simple predictive models identify patients with COVID-19 pneumonia and poor prognosis. PLoS ONE 2020;15. doi:10.1371/journal.pone.0244627

20 Smith GB, Prytherch DR, Meredith P, et al. The ability of the National Early Warning Score (NEWS) to discriminate patients at risk of early cardiac arrest, unanticipated intensive care unit admission, and death. Resuscitation 2013;84:465-70.

doi:10.1016/j.resuscitation.2012.12.016

21 Wynants L, Van Calster B, Collins GS, et al. Prediction models for diagnosis and prognosis of covid-19: systematic review and critical appraisal. BMJ 2020;369:m1328. doi:10.1136/bmj.m1328

22 Mathew D, Giles JR, Baxter AE, et al. Deep immune profiling of COVID-19 patients reveals distinct immunotypes with therapeutic implications. Science 2020;369. doi: $10.1126 /$ science.abc 8511

23 Lucas C, Wong P, Klein J, et al. Longitudinal analyses reveal immunological misfiring in severe COVID-19. Nature 2020;584:463-9. doi:10.1038/s41586-020-2588-y

24 Wilk AJ, Rustagi A, Zhao NQ, et al. A single-cell atlas of the peripheral immune response in patients with severe COVID-19. Nature Medicine 2020;26:1070-6. doi:10.1038/s41591-0200944-y

25 Kuri-Cervantes L, Pampena MB, Meng W, et al. Comprehensive mapping of immune perturbations associated with severe COVID-19. Science Immunology 2020;5. doi:10.1126/sciimmunol.abd7114

26 Mann ER, Menon M, Knight SB, et al. Longitudinal immune profiling reveals key myeloid signatures associated with COVID-19. Science Immunology 2020;5:eabd6197. doi:10.1126/sciimmunol.abd6197

27 Arunachalam PS, Wimmers F, Mok CKP, et al. Systems biological assessment of immunity to mild versus severe COVID-19 infection in humans. Science 2020;369:1210-20. doi:10.1126/SCIENCE.ABC6261

28 Mueller YM, Schrama TJ, Ruijten R, et al. Immunophenotyping and machine learning identify distinct immunotypes that predict COVID-19 clinical severity. medRxiv : the preprint server for health sciences Published Online First: 2021. doi:10.1101/2021.05.07.21256531

29 Marshall JC, Murthy S, Diaz J, et al. A minimal common outcome measure set for COVID19 clinical research. The Lancet Infectious Diseases 2020;20:e192-7. doi:10.1016/S14733099(20)30483-7

30 Levey AS, Stevens LA, Schmid CH, et al. A new equation to estimate glomerular filtration rate. Annals of internal medicine 2009;150:604-12. doi:10.7326/0003-4819-150-9200905050-00006 
medRxiv preprint doi: https://doi.org/10.1101/2022.01.29.22270016; this version posted February 2,2022 . The copyright holder for this preprint (which was not certified by peer review) is the author/funder, who has granted medRxiv a license to display the preprint in All rights reserved. No reuse allowed without permission.

31 Maecker HT, McCoy JP, Nussenblatt R. Standardizing immunophenotyping for the Human Immunology Project. Nature Reviews Immunology. 2012;12:191-200. doi:10.1038/nri3158

32 Garcia-Prat M, Álvarez-Sierra D, Aguiló-Cucurull A, et al. Extended immunophenotyping reference values in a healthy pediatric population. Cytometry Part B, Clinical cytometry 2019;96:223-33. doi:10.1002/cyto.b.21728

33 Barcelona demography, June 2020. https://www.ine.es/jaxiT3/Datos.htm?t=2861

34 Sempere A, Salvador F, Monforte A, et al. Covid-19 clinical profile in latin american migrants living in spain: Does the geographical origin matter? Journal of Clinical Medicine 2021;10:1-9. doi:10.3390/jcm10225213

35 Ferrer R, Báguena M, Balcells J, et al. Planning for the assistance of critically ill patients in a Pandemic Situation: The experience of Vall d'Hebron University Hospital. Enfermedades infecciosas y microbiologia clinica (English ed) 2020;110:697-700. doi:10.1016/j.eimc.2020.08.007

36 Chen Z, John Wherry E. T cell responses in patients with COVID-19. Nature reviews Immunology 2020;20:529-36. doi:10.1038/s41577-020-0402-6

37 Röltgen K, Powell AE, Wirz OF, et al. Defining the features and duration of antibody responses to SARS-CoV-2 infection associated with disease severity and outcome. Science Immunology 2020;5:eabe0240. doi:10.1126/sciimmunol.abe0240

38 Collins GS, Reitsma JB, Altman DG, et al. Transparent reporting of a multivariable prediction model for individual prognosis or diagnosis (TRIPOD): The TRIPOD statement. Annals of Internal Medicine 2015;162:55-63. doi:10.7326/M14-0697

39 Hadjadj J, Yatim N, Barnabei L, et al. Impaired type I interferon activity and inflammatory responses in severe COVID-19 patients. Science 2020;369:718-24. doi:10.1126/science.abc6027

40 Lucas C, Klein J, Sundaram ME, et al. Delayed production of neutralizing antibodies correlates with fatal COVID-19. Nature medicine 2021;27:1178-86. doi:10.1038/s41591021-01355-0

41 Sette A, Crotty S. Adaptive immunity to SARS-CoV-2 and COVID-19. Cell 2021;184:86180. doi:10.1016/j.cell.2021.01.007 


\section{SUPPLEMENTARY MATERIAL}

\section{SEQUENCE OF STATISTICAL BIOMARKERS ANALYSES}

The statistical analysis sequence and main conclusions are summarised in figure 1S. The main stages were exploratory, in depth and complementary analyses.

\section{Exploratory Analysis}

22 of 29 available variables were found strongly associated to 28-day outcome by pairwise comparison (table 2, and figure 3). Despite these strong associations, Multiple Logistic Regression, Random Forest Model and Principal Component (PCA) analysis showed limited prediction power as only around half of decease/severe cases were correctly classified in the multiple logistic regression and random forest classification tables and separation was poor in PCA (tables 3 and $8 \mathrm{~S}$ and figure $3 \mathrm{~S}$ ). To explain this limitation, multiple mutual correlation analysis was carried out (figure 4) and conclusions were confirmed by repeated logistic regression, see sections below "Complexity reduction and the weight of age" and "Repeated multiple Logistic regression...".

\section{In Depth Analyses}

Multiple correlations

In the global correlogram, lymphocytes, monocytes and eosinophils constitute a cluster of variables that correlated positively with each other ( $\mathrm{r}=0 \cdot 42$ to $\mathrm{r}=0 \cdot 30$, see figure 4$)$, while neutrophils, basophils and platelets form another cluster ( $\mathrm{r}=0 \cdot 4$ to $\mathrm{r}=0 \cdot 38$ ); each cluster kept a negative correlation with the other (lymphocytes with neutrophils $\% \mathrm{r}=$ -0.95). These reciprocal changes in neutrophil and lymphocyte clusters are also seen across the severity categories; Acute Phase Reactants (APRs) correlated among themselves ( $\mathrm{r}=0.71$ and $\mathrm{r}=0.46$ for IL- 6 with CRP and with Ferritin respectively) with coagulation factors ( $\mathrm{r}=0 \cdot 67, \mathrm{r}=0 \cdot 42, \mathrm{r}=0.35$ for IL-6, with fibrinogen, D-dimer and prothrombin time (INR) respectively) and with neutrophils $\%$, (IL-6 r $=0 \cdot 6, \mathrm{CRP} \mathrm{r}=0 \cdot 6$ ). This may reflect the central position of CRP in the network of interactions typically occurring in infection diseases and systemic inflammation in which IL-1, IL-6 and TNF-alpha all act synergistically on the liver increasing the production of acute phase proteins and coagulation factors. ${ }^{1}$ Age correlated strongly with kidney function tests $(\mathrm{r}=0 \cdot 6, \mathrm{r}=0 \cdot 32$ and $\mathrm{r}=-0 \cdot 6$ for urea, creatinine and GFR respectively), moderately with AST/ALT ratio $(\mathrm{r}=0 \cdot 40)$ and weakly with $\mathrm{SpO} 2 / \mathrm{FiO} 2(\mathrm{r}=0 \cdot 32)$. All above correlations were significant, (tables format excel $r$ and $p$ values of correlogram xlsx format). The relative weight of age in different age intervals was investigated by comparing the correlograms of patients over and under 65 years which showed that they are maintained (figure $4 \mathrm{~S}<65$ years vs $>65$ years correlation heatmaps). These networks of correlations explain the compound effect of age on the clinical laboratory variables and indicated that the limited prediction of power of biomarker combinations is due to redundancy. This conclusion was supported by the VIF indexes of many variables in the multiple logistic regression analysis, see below the sections "Repeated multiple logistical regression to confirm redundancy and identification minimal set of variables".

\section{Complexity reduction and the weight of age}

The above analysis and the understanding of the biological interrelations of the variables led to reduce the complexity of the analysis by combining variables of physio pathologically related families that were statistically correlated in: 1) Blood including Haemoglobin (Hb), Blood White Cell Count (WBC) and differential counts in \% and number, Neutrophil to Lymphocyte Ratio (NLR) and platelets; 2) Acute Phase Reactants including CReactive Protein (CRP), IL-6 and Ferritin; 3) Coagulation including D-dimer, fibrinogen, prothrombin time (INR); 4) Liver tests including Bilirubin direct and total, AST, ALT and AST/ALT ratio); and 5) Kidney function tests including urea, creatinine and glomerular filtration rate (GFR). As these groups of variables were found to behave similarly as predictors of survival and of severity and they are known to participate in common pathophysiological networks, we further combined them in Clinical Demographic (CD) variables, InFlammation Related Biomarkers (IFRB) that include the blood, APRs and coagulation and in Organ Damage Related biomarkers (ODRB) that include liver and kidney tests plus $\mathrm{SpO} 2 / \mathrm{FiO} 2$, as a biomarker of lung damage.

In the pairwise comparisons for survival/decease the lowest $\mathrm{p}$ values among CDs were for age and comorbidities e.g., exact $\mathrm{p}=7 \cdot 26 \times 10^{-81}$ and $2 \cdot 3 \times 10^{-38}$ respectively (table 2 ). Among ODRBs the lowest $\mathrm{p}$ values were GFR $2 \cdot 37 \times 10^{-101}$, AST/ALT ratio $6 \cdot 06 \times 10^{-31}$, while among IFRBs lowest $p$ values were IL-6, $10^{-55}$; CRP 5.99 $\times 10^{-43}$; and NLR $0 \cdot 34 \times 10^{-41}$ 
The analyses of variables in patients split into four maximal severity categories (Kruskal-Wallis test) showed that in severe vs deceased, ODRB (GFR and AST/ALT ratio) kept a high differential association ( $\mathrm{p}$ values $10^{-112}-10^{-11}$ ) while the association with IFRBs, APR and WBC differential counts was weaker i.e., only Hb, platelets and coagulation factors were significantly associated to outcome. Age and comorbidities are differentially associated to severity categories as outcome with $\mathrm{p}$ values of $2 \cdot 8 \times 10^{-53}$ and $10^{-10}$ respectively but in the comparison of moderate vs severe, age association was not significant and the significancy of the associations is low for ODRB while is high for IFRBs (table $4 \mathrm{~S}$ and figure $2 \mathrm{~S}$ ).

The univariate logistic regression analysis of the 19 main biomarkers adjusted by age confirmed that the association of 16 of 19 variables including ODRB and IFRB, with survival and severity respectively is only partially linked to age. The corresponding age corrected $\mathrm{Z}$ values followed the ranking IL-6>CRP $>\mathrm{SpO} 2 / \mathrm{FiO} 2>$ neutrophiles \% $>$ NLR $>$ Monocytes $\%>$ Neutrophils $n>$ GFR $>$ lymphocytes $\%$ for survival/decease and IL-6> CRP $>$ neutrophiles $\% \mathrm{SpO} 2 / \mathrm{FiO} 2>>$ NLR $>$ lymphocytes $\%>$ Monocytes $\%$ for severity where GFR is displaced to position 11 th in the ranking (table 4).

Kaplan-Mayer survival curve analysis using Youden indexes from laboratory test performance ROC curves as cutoff (see next section Performance of variables by ROC curves...) was applied to assess the relation of each biomarker with survival within the $28 \mathrm{~d}$ period (figures 5B and 5S). Age had the highest hazard ratio $(32 \cdot 8)$, followed by GFR (9.3), urea (6·3), IL-6 (5·9), D-dimer (4·7), comorbidities (4·7), AST/ALT (4·3), CRP (4·3), $\mathrm{SpO} 2 / \mathrm{FiO} 2(2 \cdot 8)$ and differential WBC $\%(2 \cdot 8-2 \cdot 6)$ while platelets, ferritin and sex gave low or no-significant hazard ratios.

Performance of variables by ROC curve analysis as applied to clinical laboratory tests ROC curves were generated to assess biomarker predictive power in the clinical context. For survival/decease as outcome, GFR, IL-6, AST/ALT, and SpO2/FiO2 showed the best curves, AUCs (CI): 0,80 (0.77-0.83), $0 \cdot 77(0 \cdot 73-$ $0.81), 0.73(0.69-0.77)$ and $0.73(0.70-0.78)$ respectively, followed by the other APRs and blood variables. Age, treated as a variable for comparison, gave an AUC of $0 \cdot 87(0 \cdot 85-0 \cdot 89)$ better than any of other variables; comorbidities gave an AUC $0.75(0.72-0.78)$ (table 5 and figure 5A). For non-severe vs severe as outcome, the larger AUC corresponded to: IL-6, $0 \cdot 78(0 \cdot 75-0 \cdot 80)$ followed by SpO2/FiO2, $0 \cdot 77(0 \cdot 74-0 \cdot 81)$, CRP, $0 \cdot 75(0 \cdot 71-$ $0.77)$, NLR $0.71(0.68-0.73)$, GFR $0.69(0.65-0.71)$ and age $0.67(0.64-0.70)$. The comparison of the ROC curves to predict severity with those to predict survival shows that ODRBs are better predictor of survival/decease and IFRBs of severity/non-severe with the exception of $\mathrm{SpO} 2 / \mathrm{FiO} 2$ that is a very good predictor of both outcomes (table 5). To reduce the effect of age better assess the effect of the other variables, patients were stratified by age intervals (40-55, 55-65, 66-75, 76-85 and $>85$ years old); the variable giving the larger AUC across all age group was $\mathrm{SpO} 2 / \mathrm{FiO} 2(0 \cdot 72$ to 0.79$)$ except in over 85 year-old patients in which IL-6 had the larger AUC $(0 \cdot 79)$; in this stratified analysis tests measuring IFRBs variables were found to be better tests than ODRBs probably because there is higher collinearity of ODRB with age, as suggested by the reduction of their prediction power when stratified by age (table 7S).

Repeated multiple logistical regression to identify of the minimal set of variables, and redundancy confirmation Repeated multiple logistic regression analyses of variables for outcomes decease and severity were carried out to confirm their redundancy, calculating VIF scores of collinearities to identify the combinations giving with the best prediction scores. The exploratory analysis had already indicated some redundancies, and the number of variables was reduced to 19 which included age, sex, comorbidity index, Hb, neutrophil, lymphocytes, monocyte, and eosinophils \% and number (n), NLR, platelets, CRP, IL-6, D-dimer, ferritin, fibrinogen, prothrombin time INR, $\mathrm{SpO} 2 / \mathrm{FiO} 2, \mathrm{AST} / \mathrm{ALT}$ ratio and GFR. Notice that when $\mathrm{SpO} 2 / \mathrm{FiO} 2$ was included, the number of observations was reduced to 411 , as $\mathrm{SpO} 2 / \mathrm{FiO} 2$ was available in only $52 \%$ of these patients. The scores generated for each variable were odd ratios (OR), Z scores, p values, VIF, area under the ROC curve (AUC, CI) at 50\% cut-off, Positive Predictive Value (PPV, predicting either decease or severity) and Negative Predictive Value (NPV, predicting survival or non-severity) and the \% of correctly classified patients for the outcome decease or severity (tables logistic regression in xlsx format).

For survival/decease prediction with 19 variables, scores were AUC $0 \cdot 95$, PPP $75 \cdot 7$, NPP $94 \cdot 4$ and $54 \cdot 4 \%$ of deceased patients correctly classified $(n=411)$; if age, comorbidities, and sex were excluded, values were AUC $0 \cdot 84$, PPP $76 \cdot 6$, NPP $80 \cdot 6$ and $58.2 \%$ correctly classified $(n=411)$. When $\mathrm{SpO} 2 / \mathrm{FiO} 2$, was excluded from the biomarkers the prediction scores were AUC $0 \cdot 86$, PPP 68.9 , NPP 92.9 and correct classification of decease cases was reduced to 
$22 \cdot 7 \%$, however these variables correctly classified $99 \%$ of the patients who survived as deduced by the PPP and NPP ( $\mathrm{n}=994)$. Age, comorbidity, and sex by themselves would give an AUC of 0.89, PPP 56.7, NPP 88.5 and $36 \cdot 5 \%$ deceased correctly classified $(n=1,579)$ with sex not modifying the scores. Therefore, while, if additive, the prediction of demographics and biomarkers would give $90.7 \%$ of correctly classified decease cases, only $58.2 \%$ of cases were actually correctly classified. A reduced set of variables to predict survival/decease was generated by repeated analyses progressively excluding redundant variables thus reducing the VIF scores of collinearities; the reduced set including eight variables: age, comorbidity index, SpO2/FiO2, NLR, CRP, fibrinogen, AST/ALT ratio and GFR gave AUC $0 \cdot 94$, PPP $83 \cdot 3$, NPP $94 \cdot 1$, and $65 \cdot 8$ of deceased patients were correctly classified $(\mathrm{n}=502)$. The same analysis with 19 variables applied to non-severity/severity outcome gave AUC $0 \cdot 85$, PPP $74 \cdot 7 \%$, NPP $79 \cdot 2$ and $54 \cdot 6$ of severe were correctly classified $(n=411)$. If age and comorbidities were excluded, scores were AUC $0 \cdot 84$, PPP $76 \cdot 6 \%$ NPP $80 \cdot 6$, and $58.2 \%$ of severe cases correctly classified. When $\mathrm{SpO} 2 / \mathrm{FiO} 2$, was excluded, the prediction scores were AUC $0 \cdot 81$, PPP $65 \cdot 3$, NPP $81 \cdot 0$ and correct classification of severe cases was reduced to $36 \cdot 2 \%(\mathrm{n}=994)$. The reduced set of eight variables gave AUC of $0 \cdot 86$, PPP 81,5, NPP $80 \cdot 3$ and correctly classified $64,1 \%$ of the severe cases $(n=502)$.

\section{Time course and biomarkers}

The predictive value of laboratory variables was expected to evolve during the disease course but because of the retrospective nature of this study, data at regular intervals for every patient were not available. However, as we had data from 7,586 additional follow up samples corresponding 1,079 of the 1,579 patients, we plotted them to generate an approximation of the evolution of the variables along the 28-days follow-up period. The curves representing means \pm CI values for each variable for survivors and deceased maintained a clear separation during the initial 10 days and only overlapped at the end of the $28 \mathrm{~d}$ period. Of note, NLR curves were more clearly separated between days 5 and 20, while IL-6 values overlapped after day 4-5; CRP, lymphocyte, and neutrophil \% curves remained separated over most of the period; the eosinophil curve shows a remarkable increase in survivors but only after day 10. GFR curves were clearly separated from the beginning, but the mean values differ little from the normal range. From this analysis it cannot be deduced whether IFRBs precede ODRB or vice versa. (figure 6 LOWESS main)

\section{Additional Analyses: Comparison of the exploratory with validation cohorts}

The patient populations in the three hospitals were not perfectly matched for demographics nor mortality (table 6). The mortality rate was higher in HUB (25.7\% vs. $16 \cdot 1 \%$ and $12 \cdot 3 \%$ in HUVH and HUGTP, respectively). This may be explained by their higher age, 65 (5374) as compared to HUVH 62 (50-75) and in HUGTP 62 (52-71) (table 6). There are also differences in the median laboratory variables that indicates that this cohort includes more critically ill patients. These differences however made these almost contemporary cohorts adequate for comparing the relative predictive power of clinical laboratory test with demographics and clinical variables in a real-life situation.

The pairwise univariate analysis of laboratory variables association with $28 \mathrm{~d}$ outcome of the HUB and HUGTP data sets were conducted similarly as for the HUVH data set. The significant association was confirmed for seven blood variables, three APRs (CRP, IL-6, and ferritin), and the D-dimer (table 6 and figure 6S). The only index of renal function that was available in the three hospitals, urea, was clearly validated, and this supports the findings from the HUVH data of creatinine and GFR as having strong prognostic value after adjustment for age.

Multiple logistic regression analysis that was adjusted for age showed that the ranking of the odds ratios of clinical laboratory variables associated with mortality was similar in the three centres. The APRs, IL-6, CRP, ferritin, and Ddimer occupy the top positions of the ranking, followed by neutrophils and, in the other side, lymphocytes, monocytes, and eosinophils (figure 7).

The PCA of 17 clinical laboratory variables show an almost complete overlap that support identical basic physiopathology of the disease, regardless of the differences in the patient population (figure 7S).

The Random Forest model was applied to the common variables of the three cohorts and the reduction of the mean Gini index in the exploratory HUVH cohort and in the combination of the three cohorts were calculated. Table 9S and figure $8 \mathrm{~S}$ show the similar rankings of the variables in the different analyses.

The clinical laboratory test performance as assessed by the AUC from ROC curves from the three hospitals, when subjected to unbiased clustering, showed the central role of APRs and kidney function; the AST/ALT ratio and GFR, available only from the HUVH cohort, showed the larger AUC, together but AUC of cytokines from the immunological studies, see below, section expanded immunological biomarkers (figure. 8 and table 7). 


\section{Additional Analyses: Pilot study of Immunological tests}

\section{Cytokine profile}

Cytokines were measured in 74 patients, who were representative of the HUVH cohort's moderate and severe disease categories (age 53 [44-64] years) (see table 10S Immunological studies patient). The ELLA platform to measure cytokines has been in use in the HUVH immunology laboratory for six years to monitor cytokines in transplantation and sepsis projects and has proved very robust. Samples were collected on days 0 and +2 . The levels of cytokines IL-6, TNF- $\alpha$, IL-10, IL-2, CXCL10, and CCL2 as well as the receptor antagonist of IL-1 (IL-1RA) reached significantly higher values in the severe patients and tended to increase over time. The remaining cytokines and SCD163 did not show significant differences in relation to time and severity categories. On day 0 , the IFN- $\alpha$ decreased, but increased in two mild cases; this may be interpreted as indicating the end of an initial peak in most patients. The IL 12p70 level seemed to follow a similar pattern, but the data did not show significant differences (figure $9 \mathrm{~A} \& \mathrm{~B}$ ).

The comparison of correlograms of cytokines at days 0 and 2 did not show significant changes in the mutual correlations, probably because the interval was too short. However, greater differences were seen between the moderate and severe of the four categories of patients, with a loss of the correlation with IFN- $\alpha$ probably attributable to its quick drop in severely ill patients. We also observe a moderate increase in the correlations around IL-17 (figure 9S).

Predictive power of cytokines and sCD163 were compared for both survival and severity as outcome. For 7 of the 20 cytokines, the survival predictive power as measured by the AUC of the ROC curves at day 0 was significant and followed the order CXCL10 > ILRA $>$ IL-6 $>$ CCL $2>$ IL10 $>$ IL-15 > IL-7 > TNF- $\alpha>$ IFN- $\alpha$. On day +2, the predictive power order for IL-6, CCL2, IL-15, TNF- $\alpha$, and IL-7 and significant for eight of them. The prediction power for non-severity vs severity categories followed the order CXCL10 > IL-6 > IL1-RA > IL-15 at day 0 and IL6, CCL2, IL-2 at day 2 of the 10 largest AUCs were statistically significant. The ROC curves for the main clinical laboratory biomarkers were also calculated for this group and in the comparison showed smaller AUCs than these cytokines (table 5 and figure 10S).

\section{Blood extended phenotyping}

Of the 41 patients, 5, 27, 6, and 3 were in the mild, moderate, severe, and deceased severity categories, respectively. The median age was lower than that of the HUVU cohort, although the M/F proportion, DFSO, and LOS were similar (table 10S immunology cohort). As adapted for this project, the HIPC protocol generated 163 variables corresponding to 42 lymphocytes, monocytes, and neutrophil subsets.

In pairwise comparison for decease and severity outcomes, 12 lymphocyte subsets were significantly associated with the 28-day decease according to a ranking as follows: naïve T lymphocytes (n) $>$ Th2 (n) $>$ total T lymphocytes $>$ CD8 T lymphocytes (n) > CD8 TCM (n) > CD8 TEM (n)> CD4 T lymphocytes (n) > CD4EM (n) > non-classical monocytes. Remarkably, for this subgroup, the significance was similar to that of CRP, IL-6, and D-dimer. Interestingly, the CD4 TEM and CD8 TEM populations showed a continuous decrease with the disease severity, whereas the naïve populations showed a surge in the most severe cases (probably, due to the mobilization of naïve cells which did not contribute to improved outcome (figure 10).

In the correlogram between laboratory biomarkers and cell phonotypes there is a negative correlation of APRs and T-cell populations except for Th1- and Th17-activated T cells. There is, therefore, an inverse correlation between inflammation and the T-cell subsets that drive the adaptive immune response; there is a strong negative correlation of age with CD8-naïve T cells, which is critical for the immune response to the virus; these changes reveal the deep dysregulation of lymphocyte biology in COVD-19 patients (figure 11S), The positive correlations between APR and $\mathrm{B}$ cells could be interpreted as resulting from an accelerated recruitment of naïve B cells to the switching stage; furthermore, there is a steeper reduction in non-classical monocytes and a reduction in their DR expression. This fits well with the high mortality rate seen among patients with $<2 \%$ monocytes and with the lack of changes in the sCD163 (see the section titled Cytokines), which is a marker of M2 macrophages. The ROC curves of CD3+CD62L (n) naïve T cells had an AUC of $0 \cdot 74$, with a sensitivity and specificity of $66 \cdot 7 \%$ and $72 \%$, respectively, for severity (table 5).

References:

1 Jones BE, Maerz MD, Buckner JH. IL-6: a cytokine at the crossroads of autoimmunity. Curr. Opin. Immunol. 2018; 55: 9-14. 
Table 1S. Patients excluded from HUVH cohort.

\begin{tabular}{|c|c|c|c|c|}
\hline Groups & $\begin{array}{c}\text { Number of } \\
\text { patients }\end{array}$ & $\begin{array}{c}\text { Sex } \\
\text { (male/female ratio) }\end{array}$ & $\begin{array}{c}\text { Age } \\
\text { median (IQR) }\end{array}$ & $\begin{array}{c}\text { 28-day } \\
\text { mortality }(\%)\end{array}$ \\
\hline Nosocomial & 57 & $57.9 \%$ & $67(60-75)$ & $36 \cdot 8 \%$ \\
\hline Severe oncological disease & 35 & $65 \cdot 7 \%$ & $66(58-74 \cdot 25)$ & $34 \cdot 3 \%$ \\
\hline Pregnancy & 15 & NA & $76(76-76)$ & $0 \cdot 0 \%$ \\
\hline Transplanted & 13 & $84 \cdot 6 \%$ & $53(51-55)$ & $46 \cdot 2 \%$ \\
\hline $\begin{array}{l}\text { Severe haematological } \\
\text { disease }\end{array}$ & 11 & $36 \cdot 4 \%$ & $37(30 \cdot 75-44 \cdot 25)$ & $36 \cdot 4 \%$ \\
\hline Paediatric & 11 & $36 \cdot 4 \%$ & $75(74 \cdot 5-75 \cdot 5)$ & $0 \cdot 0 \%$ \\
\hline Autoimmune disease & 7 & $28 \cdot 6 \%$ & $65(56 \cdot 5-71)$ & $14 \cdot 3 \%$ \\
\hline Referred for ECMO & 7 & $71 \cdot 4 \%$ & $61(59 \cdot 5-69)$ & $0 \cdot 0 \%$ \\
\hline Primary immunodeficiency & 1 & $0 \cdot 0 \%$ & 44 (NA) & $0 \cdot 0 \%$ \\
\hline Other severe disease & 1 & $0 \cdot 0 \%$ & 49 (NA) & $0 \cdot 0 \%$ \\
\hline Total & 158 & & & $27.8 \%$ \\
\hline
\end{tabular}

Patients who were excluded from the HUVH cohort and their pathology.ECMO, ExtraCorporeal Membrane Oxygenation; NA, Not Applicable. 
Table 2S. Monoclonal Antibodies used in in the flowcytometric phenotypic analysis

\begin{tabular}{|c|c|c|}
\hline & ISOTYPE & CLONE \\
\hline \multicolumn{3}{|l|}{ General lymphocyte populations } \\
\hline $\begin{array}{l}\text { CD45-FITC/CD8-PE/CD4-ECD/CD3- } \\
\text { PC5 }\end{array}$ & $\begin{array}{c}\text { IgG2b / IgG1 / IgG1 / IgG1 } \\
\text { mouse }\end{array}$ & B3821F4A/SFCI12T4D11/SFCI21Thy2D3/UCHT1 \\
\hline $\begin{array}{l}\text { CD45-FITC/CD56-PE/CD19- } \\
\text { ECD/CD3-PC5 }\end{array}$ & $\begin{array}{c}\operatorname{IgG} 2 \mathrm{~b} / \mathrm{IgG} 1 / \mathrm{IgG} 1 / \mathrm{IgG} 1 \\
\text { mouse }\end{array}$ & B3821F4A/SFCI12T4D11/SFCI21Thy2D3/UCHT1 \\
\hline \multicolumn{3}{|l|}{ T- Lymphocyte populations } \\
\hline CXCR3/CD183 AF488 & IgG1 mouse & G025H7 \\
\hline CCR7/CD197 PE & IgG2a mouse & G043H7 \\
\hline CD45RA ECD & IgG1 mouse & ALB11 \\
\hline CCR6/CD196 PC7 & IgG2a mouse & B-R35 \\
\hline CD4 APC & IgG1 mouse & 13B8.2 \\
\hline CD8 APC700 & IgG1 mouse & SFCI21Thy2D3 (T8) \\
\hline CD3 APC750 & IgG1 mouse & UCHT1 \\
\hline HLADR PB & IgG1 mouse & Immu-357 \\
\hline CD45 KRO & IgG1 mouse & J.33 \\
\hline \multicolumn{3}{|l|}{ Recent thymic emigrants } \\
\hline CD31 FITC & IgG1 mouse & $5.6 \mathrm{E}$ \\
\hline CD62L PE & IgG1 mouse & DREG56 \\
\hline CD3 ECD & IgG1 mouse & UCHT1 \\
\hline CD27 PC7 & IgG1 mouse & 1A4CD27 \\
\hline CD4 APC & IgG1 mouse & 13B8.2 \\
\hline CD45RA PB & IgG1 mouse & 2H4LDH11LDB9 (2H4) \\
\hline CD45 KRO & IgG1 mouse & J.33 \\
\hline \multicolumn{3}{|l|}{ T-regulatory cells } \\
\hline CD45RO FITC & IgG2a mouse & UCHL1 \\
\hline CD25 PE & IgG2a mouse & B1.49.9 \\
\hline CD3 ECD & IgG1 mouse & UCHT1 \\
\hline CCR4/ CD194 PC7 & IgG1 mouse & $1 \mathrm{G} 1$ \\
\hline CD4 APC & IgG1 mouse & 13B8.2 \\
\hline CD127 APC750 & IgG1 mouse & R34.34 \\
\hline HLADR PB & IgG1 mouse & Immu-357 \\
\hline CD45 KRO & IgG1 mouse & J.33 \\
\hline \multicolumn{3}{|l|}{ DC/Monocytes/NK } \\
\hline CD16 FITC & IgG1 mouse & $3 \mathrm{G} 8$ \\
\hline CD11c PE & IgG1 mouse & BU15 \\
\hline CD3 ECD & IgG1 mouse & UCHT1 \\
\hline CD19 ECD & IgG1 mouse & J3-119 \\
\hline CD20 ECD & IgG2a mouse & B9E9(HRC20) \\
\hline CD56 PC7 & IgG1 mouse & N901 (NKH-1) \\
\hline CD123 APC & IgG1 mouse & SSDCLY107D2 \\
\hline CD14 APC750 & IgG1 mouse & RMO52 \\
\hline HLADR PB & IgG1 mouse & Immu-357 \\
\hline \multicolumn{3}{|l|}{ B Lymphocytes } \\
\hline IgD FITC & IgG2a mouse & IA6-2 \\
\hline CD21 PE & IgG1 mouse & BL13 \\
\hline
\end{tabular}




\begin{tabular}{|l|c|c|}
\hline CD19 ECD & IgG1 mouse & J3.119 \\
\hline CD27 PC7 & IgG1 mouse & 1A4CD27 \\
\hline CD24 APC & IgG1 mouse & ALB9 \\
\hline CD38 APC750 & IgG1 mouse & SA-DA4 4 \\
\hline IgM PB & IgG1 mouse & J.33 \\
\hline CD45 RO & IgG1 mouse & \\
\hline
\end{tabular}

DC, dendritic cells; NK, Natural Killer. 
Table 3S. Distribution of comorbidities among the severity categories and demographics and hospitalization data in the HUVH cohort

\begin{tabular}{|c|c|c|c|c|c|c|c|c|c|c|c|c|}
\hline Comorbidities & n (\%) & $\begin{array}{c}\text { Age } \\
\text { (mean) }\end{array}$ & Male & Female & $\mathbf{M} / \mathbf{F} \%$ & $\begin{array}{c}\text { DFSO (days) } \\
{[\text { mean } \pm \text { SD] }}\end{array}$ & $\begin{array}{c}\text { LOS (days) } \\
{[\text { mean } \pm \text { SD] }}\end{array}$ & $\begin{array}{c}\text { Mortality } \\
\text { (\%) }\end{array}$ & $\begin{array}{c}\text { Mild } \\
\text { (n) }\end{array}$ & $\begin{array}{l}\text { Moderate } \\
\text { (n) }\end{array}$ & $\begin{array}{c}\text { Severe } \\
\text { (n) }\end{array}$ & $\begin{array}{l}\text { Deceased } \\
\text { (n) }\end{array}$ \\
\hline $\mathbf{0}$ & $546(34 \cdot 6 \%)$ & $51 \cdot 6$ & 305 & 241 & 0.56 & $7 \cdot 8 \pm 4 \cdot 4$ & $14 \cdot 9 \pm 22 \cdot 4$ & $2 \cdot 9 \%$ & 40 & 400 & 89 & 16 \\
\hline 1 & $431(27 \cdot 3 \%)$ & $61 \cdot 6$ & 240 & 191 & $0 \cdot 56$ & $8 \cdot 1 \pm 5 \cdot 4$ & $17 \cdot 1 \pm 24 \cdot 0$ & $12 \cdot 8 \%$ & 15 & 273 & 88 & 55 \\
\hline 2 & $303(19 \cdot 2 \%)$ & $71 \cdot 1$ & 165 & 138 & $0 \cdot 54$ & $6 \cdot 7 \pm 4 \cdot 7$ & $17 \cdot 6 \pm 23 \cdot 5$ & $28 \cdot 4 \%$ & 9 & 162 & 46 & 86 \\
\hline 3 & $186(11 \cdot 8 \%)$ & $71 \cdot 2$ & 101 & 85 & $0 \cdot 54$ & $6 \cdot 3 \pm 4 \cdot 6$ & $24 \cdot 2 \pm 30 \cdot 5$ & $28 \cdot 5 \%$ & 5 & 93 & 35 & 53 \\
\hline 4 & $88(5 \cdot 6 \%)$ & $72 \cdot 1$ & 52 & 36 & 0.59 & $5 \cdot 2 \pm 3 \cdot 9$ & $20 \cdot 2 \pm 26 \cdot 4$ & $39 \cdot 8 \%$ & 2 & 31 & 20 & 35 \\
\hline $5-7$ & $25(1 \cdot 6 \%)$ & $73 \cdot 7$ & 17 & 8 & $0 \cdot 59$ & $5 \cdot 20 \pm 3 \cdot 8$ & $33 \cdot 9 \pm 32 \cdot 9$ & $40 \cdot 0 \%$ & 0 & 6 & 4 & 10 \\
\hline
\end{tabular}

FSO, days from symptom onset; LOS, length of stay; n, number. For comorbidities considered, see text 
Table 4S. Demographics and hospitalization data by severity categories of the HUVH cohort.

\begin{tabular}{|c|c|c|c|c|c|c|c|c|c|c|c|}
\hline $\begin{array}{c}\text { Severity among } \\
\text { patients } \\
(\mathrm{n}=1579)\end{array}$ & Mild & Moderate & Severe & Deceased & $\begin{array}{l}\text { Mild } \\
\text { vs. Moderate } \\
\text { (Adj. p- } \\
\text { values) }\end{array}$ & $\begin{array}{c}\text { Mild } \\
\text { vs. Severe } \\
\text { (Adj. p- } \\
\text { values) }\end{array}$ & $\begin{array}{c}\text { Mild } \\
\text { vs. Deceased } \\
\text { (Adj. p- } \\
\text { values) }\end{array}$ & $\begin{array}{c}\text { Moderate } \\
\text { vs. Severe } \\
\text { (Adj. p- } \\
\text { values) }\end{array}$ & $\begin{array}{c}\text { Moderate } \\
\text { vs. Deceased } \\
\text { (Adj. p- } \\
\text { values) }\end{array}$ & $\begin{array}{l}\text { Severe } \\
\text { vs. Deceased } \\
\text { (Adj. p- } \\
\text { values) }\end{array}$ & $\begin{array}{c}\text { Multiple } \\
\text { comparison } \\
\text { (Adj. p- } \\
\text { values) }\end{array}$ \\
\hline Patients & $71(4.5 \%)$ & 969 (61.4\%) & $284(18.0 \%)$ & $255(16.1 \%)$ & & & & & & & \\
\hline $\begin{array}{l}\text { Age } \\
\text { median (IQR) }\end{array}$ & $47(36-69)$ & $58(48-72)$ & $55(51-68)$ & $82(74-87)$ & $7.55 \mathrm{E}-04$ & $7.50 \mathrm{E}-03$ & 4.94E-36 & $3.80 \mathrm{E}-01$ & $1.65 \mathrm{E}-72$ & $2.28 \mathrm{E}-53$ & $<0.001$ \\
\hline $\begin{array}{l}\text { Female } \\
\mathrm{n}(\%)\end{array}$ & $44(62.0 \%)$ & $446(46.1 \%)$ & $101(35.6 \%)$ & $107(39.6 \%)$ & $1.32 \mathrm{E}-02$ & 7.60E-05 & $3.00 \mathrm{E}-03$ & $1.73 \mathrm{E}-03$ & 2.6E-01 & $1.3 \mathrm{E}-01$ & $<0.001$ \\
\hline $\begin{array}{l}\text { DFSO } \\
\text { median (IQR) }\end{array}$ & $8(5-10)$ & $7(5-10)$ & $7(4-9)$ & $5(2-7)$ & $5.10 \mathrm{E}-01$ & 4.69E-02 & 7.42E-08 & $6.83 \mathrm{E}-03$ & $9.50 \mathrm{E}-20$ & 1.09E-07 & $<0.001$ \\
\hline $\begin{array}{l}\text { LOS } \\
\text { median (IQR) }\end{array}$ & $2.0(2-2)$ & $5(2-11)$ & $35(17-59)$ & $7(4-11)$ & $1.53 \mathrm{E}-06$ & $8.74 \mathrm{E}-41$ & $1.57 \mathrm{E}-08$ & $7.93 \mathrm{E}-69$ & $1.73 \mathrm{E}-02$ & $5.35 \mathrm{E}-32$ & $<0.001$ \\
\hline $\begin{array}{l}\text { Disease duration } \\
\text { median (IQR) }\end{array}$ & $10(8-16)$ & $13(9-21)$ & $41(25-66)$ & $12(9-18)$ & $1.01 \mathrm{E}-02$ & $1.92 \mathrm{E}-24$ & $5.96 \mathrm{E}-01$ & $2.44 \mathrm{E}-53$ & 4.95E-04 & $5.30 \mathrm{E}-50$ & $<0.001$ \\
\hline $\begin{array}{l}\text { Composite Morbidity } \\
(\text { mean } \pm \text { SD })\end{array}$ & $0(0-1)$ & $1(0-2)$ & $1(0-2)$ & $2(1)$ & $2.00 \mathrm{E}-02$ & $2.00 \mathrm{E}-04$ & $<1.0 \mathrm{E}-10$ & 9.9E-04 & $1.00 \mathrm{E}-10$ & $1.00 \mathrm{E}-10$ & $<0.001$ \\
\hline
\end{tabular}

Statistical comparisons include univariate comparisons, using Kruskal-Wallis with the two-stage step-up method of Benjamini and Hochsberg for the adjustment of the false-discovery rate. IQR, 25-75 interquartile range; DFSO, days from symptom onset; LOS, length of stay. 
Table 4S. Demographics and hospitalization data by severity categories of the HUVH cohort

\begin{tabular}{|c|c|c|c|c|c|c|c|c|c|c|c|}
\hline $\begin{array}{l}\text { Severity among } \\
\text { patients } \\
(\mathrm{n}=1579)\end{array}$ & Mild & Moderate & Severe & Deceased & $\begin{array}{c}\text { Mild } \\
\text { vs. Moderate } \\
\text { (Adj. p- } \\
\text { values) } \\
\end{array}$ & $\begin{array}{c}\text { Mild } \\
\text { vs. Severe } \\
\text { (Adj. p- } \\
\text { values) } \\
\end{array}$ & $\begin{array}{c}\text { Mild } \\
\text { vs. Deceased } \\
\text { (Adj. p- } \\
\text { values) }\end{array}$ & $\begin{array}{c}\text { Moderate } \\
\text { vs. Severe } \\
\text { (Adj. p- } \\
\text { values) }\end{array}$ & $\begin{array}{c}\text { Moderate } \\
\text { vs. Deceased } \\
\text { (Adj. p- } \\
\text { values) }\end{array}$ & $\begin{array}{c}\text { Severe } \\
\text { vs. Deceased } \\
\text { (Adj. p- } \\
\text { values) } \\
\end{array}$ & $\begin{array}{c}\text { Multiple } \\
\text { comparison } \\
\text { (Adj. p- } \\
\text { values) }\end{array}$ \\
\hline Patients & $71(4 \cdot 5 \%)$ & $969(61 \cdot 4 \%)$ & $284(18 \cdot 0 \%)$ & $255(16 \cdot 1 \%)$ & & & & & & & \\
\hline $\begin{array}{l}\text { Age } \\
\text { median (IQR) }\end{array}$ & $47(36-69)$ & $58(48-72)$ & $55(51-68)$ & $82(74-87)$ & $7 \cdot 55 \mathrm{E}-04$ & $7 \cdot 50 \mathrm{E}-03$ & 4.94E-36 & 3·80E-01 & $1 \cdot 65 \mathrm{E}-72$ & $2 \cdot 28 \mathrm{E}-53$ & $<0 \cdot 001$ \\
\hline $\begin{array}{l}\text { Female } \\
\mathrm{n}(\%)\end{array}$ & $44(62 \cdot 0 \%)$ & $446(46 \cdot 1 \%)$ & $101(35 \cdot 6 \%)$ & $107(39 \cdot 6 \%)$ & $1 \cdot 32 \mathrm{E}-02$ & $7 \cdot 60 \mathrm{E}-05$ & 3.00E-03 & $1 \cdot 73 \mathrm{E}-03$ & $2 \cdot 6 \mathrm{E}-01$ & $1 \cdot 3 \mathrm{E}-01$ & $<0 \cdot 001$ \\
\hline $\begin{array}{l}\text { DFSO } \\
\text { median (IQR) }\end{array}$ & $8(5-10)$ & $7(5-10)$ & $7(4-9)$ & $5(2-7)$ & $5 \cdot 10 \mathrm{E}-01$ & $4 \cdot 69 \mathrm{E}-02$ & 7·42E-08 & $6 \cdot 83 \mathrm{E}-03$ & $9 \cdot 50 \mathrm{E}-20$ & 1.09E-07 & $<0 \cdot 001$ \\
\hline $\begin{array}{l}\text { LOS } \\
\text { median (IQR) }\end{array}$ & $2 \cdot 0(2-2)$ & $5(2-11)$ & $35(17-59)$ & $7(4-11)$ & 1.53E-06 & $8 \cdot 74 \mathrm{E}-41$ & 1.57E- 08 & 7·93E-69 & 1.73E-02 & $5 \cdot 35 \mathrm{E}-32$ & $<0 \cdot 001$ \\
\hline $\begin{array}{l}\text { Disease duration } \\
\text { median (IQR) }\end{array}$ & $10(8-16)$ & $13(9-21)$ & $41(25-66)$ & $12(9-18)$ & 1.01E-02 & $1 \cdot 92 \mathrm{E}-24$ & $5 \cdot 96 \mathrm{E}-01$ & $2 \cdot 44 \mathrm{E}-53$ & 4.95E-04 & $5 \cdot 30 \mathrm{E}-50$ & $<0 \cdot 001$ \\
\hline $\begin{array}{l}\text { Composite Morbidity } \\
(\text { mean } \pm \text { SD) }\end{array}$ & $0(0-1)$ & $1(0-2)$ & $1(0-2)$ & $2(1)$ & $2 \cdot 00 \mathrm{E}-02$ & 2.00E-04 & $<1 \cdot 0 \mathrm{E}-10$ & $9 \cdot 9 \mathrm{E}-04$ & 1.00E-10 & 1.00E-10 & $<0 \cdot 001$ \\
\hline
\end{tabular}

Statistical comparisons include univariate comparisons, using Kruskal-Wallis with the two-stage step-up method of Benjamini and Hochsberg for the adjustment of the false-discovery rate. IQR, 25-75 interquartile range; DFSO, days from symptom onset; LOS, length of stay. 
Table 5S. Pairwise comparison of variables for maximal severity in four categories

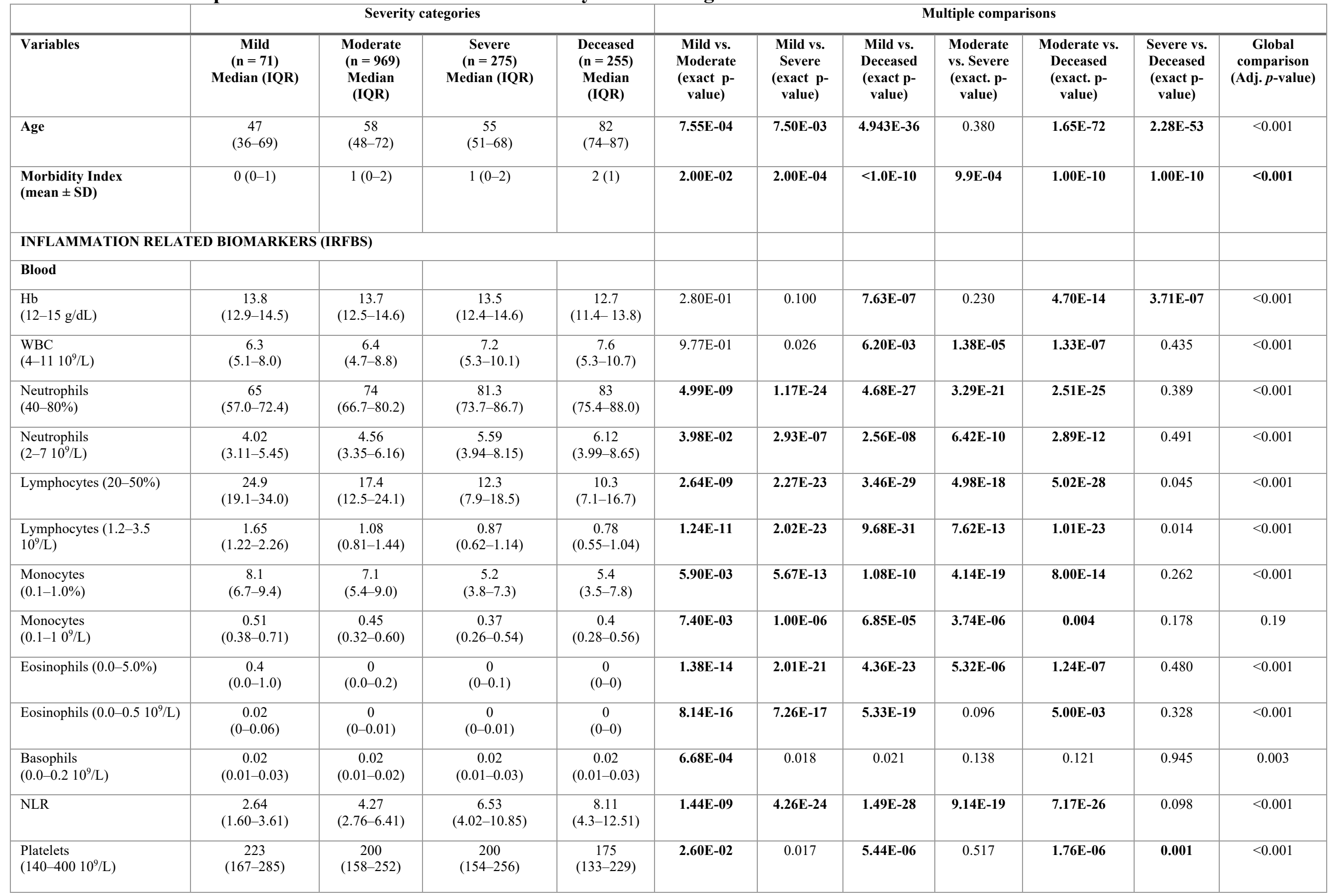




\begin{tabular}{|c|c|c|c|c|c|c|c|c|c|c|c|}
\hline \multicolumn{12}{|c|}{ Clinical Chemistry \& Immunology } \\
\hline \multicolumn{12}{|c|}{ APR and related parameters } \\
\hline $\begin{array}{l}\text { CRP } \\
(0.03-0.5 \mathrm{mg} / \mathrm{dL})\end{array}$ & $\begin{array}{c}1.49 \\
(0 \cdot 50-4 \cdot 62)\end{array}$ & $\begin{array}{c}7 \cdot 46 \\
(3 \cdot 18-13 \cdot 16)\end{array}$ & $\begin{array}{c}15 \cdot 53 \\
(7 \cdot 91-22 \cdot 43)\end{array}$ & $\begin{array}{c}17 \cdot 21 \\
(9 \cdot 76-25 \cdot 08)\end{array}$ & 2.05E-12 & $1 \cdot 73 E-30$ & $2 \cdot 64 E-33$ & $9 \cdot 42 \mathrm{E}-21$ & $7 \cdot 09 E-23$ & $0 \cdot 116$ & $<0 \cdot 001$ \\
\hline $\begin{array}{l}\text { IL-6 } \\
(0 \cdot 0-4 \cdot 3 \mathrm{pg} / \mathrm{mL})\end{array}$ & $\begin{array}{c}10 \\
(4-25)\end{array}$ & $\begin{array}{c}37 \\
(21-63)\end{array}$ & $\begin{array}{c}80 \\
(47-127)\end{array}$ & $\begin{array}{c}90 \\
(55-163)\end{array}$ & 8.92E-13 & $5 \cdot 41 \mathrm{E}-35$ & $7 \cdot 07 E-38$ & 2.09E-27 & $1 \cdot 21 \mathrm{E}-28$ & $0 \cdot 092$ & $<0 \cdot 001$ \\
\hline $\begin{array}{l}\text { Ferritin } \\
(25-400 \mathrm{ng} / \mathrm{mL})\end{array}$ & $\begin{array}{c}247 \\
(104 \cdot 5-441)\end{array}$ & $\begin{array}{c}501 \\
(269-935)\end{array}$ & $\begin{array}{c}795 \\
(474-1478)\end{array}$ & $\begin{array}{c}671 \\
(334-1217)\end{array}$ & $3 \cdot 67 E-08$ & 2.12E-17 & $3 \cdot 10 \mathrm{E}-10$ & $2 \cdot 23 E-10$ & 0.007 & $0 \cdot 045$ & $<0 \cdot 001$ \\
\hline $\begin{array}{l}\text { LDH } \\
(0-248 \mathrm{UI} / \mathrm{L})\end{array}$ & $\begin{array}{c}243 \\
(209-284)\end{array}$ & $\begin{array}{c}318 \\
(267-391)\end{array}$ & $\begin{array}{c}434 \\
(330-564)\end{array}$ & $\begin{array}{c}429 \\
(342-523)\end{array}$ & $3 \cdot 11 E-11$ & $3 \cdot 43 E-29$ & 2-32E-24 & $6 \cdot 30 \mathrm{E}-21$ & $4 \cdot 48 E-13$ & $0 \cdot 902$ & $<0 \cdot 001$ \\
\hline $\begin{array}{l}\text { Triglycerides } \\
(43-200 \mathrm{mg} / \mathrm{dL})\end{array}$ & $\begin{array}{c}121 \\
(89 \cdot 7-159 \cdot 5)\end{array}$ & $\begin{array}{c}120 \\
(91-158 \cdot 5)\end{array}$ & $\begin{array}{c}122 \cdot 5 \\
(93 \cdot 5-172 \cdot 8)\end{array}$ & $\begin{array}{c}126 \cdot 5 \\
(93 \cdot 5-158 \cdot 8)\end{array}$ & 0.953 & $0 \cdot 723$ & $0 \cdot 681$ & $0 \cdot 533$ & $0 \cdot 558$ & $0 \cdot 897$ & $0 \cdot 882$ \\
\hline \multicolumn{12}{|l|}{ Coagulation factors } \\
\hline Fibrinogen $(2 \cdot 39-6 \cdot 1 \mathrm{~g} / \mathrm{L})$ & $\begin{array}{c}4 \cdot 37 \\
(4 \cdot 00-4 \cdot 83)\end{array}$ & $\begin{array}{c}5 \cdot 12 \\
(4 \cdot 48-5 \cdot 92)\end{array}$ & $\begin{array}{c}5 \cdot 45 \\
(4 \cdot 73-6 \cdot 28)\end{array}$ & $\begin{array}{c}4 \cdot 94 \\
(4 \cdot 23-5 \cdot 90)\end{array}$ & $2 \cdot 96 \mathrm{E}-09$ & $1 \cdot 26 \mathrm{E}-13$ & $8 \cdot 47 E-06$ & $2 \cdot 04 \mathrm{E}-04$ & $7 \cdot 95 \mathrm{E}-02$ & $1 \cdot 48 \mathrm{E}-05$ & $<0 \cdot 001$ \\
\hline $\begin{array}{l}\text { D dimer } \\
(0-243 \mathrm{ng} / \mathrm{mL})\end{array}$ & $\begin{array}{c}168 \\
(115-284)\end{array}$ & $\begin{array}{c}241 \\
(160-401)\end{array}$ & $\begin{array}{c}303 \\
(192-549)\end{array}$ & $\begin{array}{c}477 \\
(292 \cdot 5-861)\end{array}$ & $9 \cdot 90 \mathrm{E}-04$ & $3 \cdot 24 \mathrm{E}-08$ & $3 \cdot 58 \mathrm{E}-17$ & $3 \cdot 78 \mathrm{E}-06$ & $4 \cdot 93 \mathrm{E}-20$ & 1.38E-05 & $<0 \cdot 001$ \\
\hline $\begin{array}{l}\text { Prothrombin time INR } \\
(0 \cdot 7-1 \cdot 3)\end{array}$ & $\begin{array}{c}1 \cdot 03 \\
(0 \cdot 99-1 \cdot 11)\end{array}$ & $\begin{array}{c}1 \cdot 1 \\
(1 \cdot 03-1 \cdot 17)\end{array}$ & $\begin{array}{c}1 \cdot 11 \\
(1 \cdot 03-1 \cdot 20)\end{array}$ & $\begin{array}{c}1 \cdot 14 \\
(1 \cdot 05-1 \cdot 30)\end{array}$ & $4 \cdot 17 \mathrm{E}-05$ & 2.89E-05 & 2-33E-10 & $0 \cdot 423$ & $1 \cdot 38 \mathrm{E}-06$ & $0 \cdot 001$ & $<0 \cdot 001$ \\
\hline \multicolumn{12}{|c|}{ ORGAN DAMAGE RELATED BIOMARKERS (ODBR) } \\
\hline \multicolumn{12}{|l|}{ Liver function test } \\
\hline $\begin{array}{l}\text { AST } \\
(12-50 \mathrm{IU} / \mathrm{L})\end{array}$ & $\begin{array}{c}27 \\
(22-38)\end{array}$ & $\begin{array}{c}38 \\
(29-56)\end{array}$ & $\begin{array}{c}47 \\
(35-71)\end{array}$ & $\begin{array}{c}45 \\
(31-68)\end{array}$ & 2.20E-07 & $3 \cdot 27 E-14$ & 6•19E-11 & $5 \cdot 45 \mathrm{E}-08$ & $6 \cdot 48 \mathrm{E}-04$ & $0 \cdot 117$ & $<0 \cdot 001$ \\
\hline $\begin{array}{l}\text { ALT } \\
(19-50 \mathrm{IU} / \mathrm{L})\end{array}$ & $\begin{array}{c}22 \\
(13-42)\end{array}$ & $\begin{array}{c}29 \\
(19-51)\end{array}$ & $\begin{array}{c}34 \\
(22-54)\end{array}$ & $\begin{array}{c}22 \cdot 5 \\
(15-35)\end{array}$ & $1 \cdot 80 \mathrm{E}-03$ & 6.13E-05 & $0 \cdot 993$ & $0 \cdot 030$ & $3 \cdot 37 E-08$ & $7 \cdot 53 \mathrm{E}-10$ & $<0 \cdot 001$ \\
\hline $\begin{array}{l}\text { AST/ALT } \\
(0 \cdot 5-1)\end{array}$ & $\begin{array}{c}1 \cdot 30 \\
(0 \cdot 87-1 \cdot 69)\end{array}$ & $\begin{array}{c}1 \cdot 30 \\
(1 \cdot 00-1 \cdot 71)\end{array}$ & $\begin{array}{c}1 \cdot 47 \\
(1 \cdot 14-1 \cdot 86)\end{array}$ & $\begin{array}{c}1 \cdot 92 \\
(1 \cdot 43-2 \cdot 60)\end{array}$ & $0 \cdot 427$ & $0 \cdot 008$ & $2 \cdot 14 \mathrm{E}-12$ & $2 \cdot 00 E-04$ & $8 \cdot 10 E-33$ & $1 \cdot 37 E-11$ & $<0 \cdot 001$ \\
\hline $\begin{array}{l}\text { Direct bilirubin } \\
(0 \cdot 1-0.57 \mathrm{mg} / \mathrm{dL})\end{array}$ & $\begin{array}{c}0 \cdot 25 \\
(0 \cdot 22-0 \cdot 32)\end{array}$ & $\begin{array}{c}0 \cdot 3 \\
(0 \cdot 24-0 \cdot 37)\end{array}$ & $\begin{array}{c}0 \cdot 31 \\
(0 \cdot 25-0 \cdot 42)\end{array}$ & $\begin{array}{c}0 \cdot 35 \\
(0 \cdot 27-0 \cdot 46)\end{array}$ & $4 \cdot 76 \mathrm{E}-04$ & 1.39E-05 & $7 \cdot 14 E-08$ & $0 \cdot 033$ & $1 \cdot 27 \mathrm{E}-04$ & $0 \cdot 067$ & $<0 \cdot 001$ \\
\hline $\begin{array}{l}\text { Total bilirubin } \\
(0 \cdot 3-1 \cdot 2 \mathrm{mg} / \mathrm{dL})\end{array}$ & $\begin{array}{c}0 \cdot 49 \\
(0 \cdot 4-0 \cdot 61)\end{array}$ & $\begin{array}{c}0 \cdot 57 \\
(0 \cdot 45-0 \cdot 74)\end{array}$ & $\begin{array}{c}0 \cdot 57 \\
(0 \cdot 42-0 \cdot 775)\end{array}$ & $\begin{array}{c}0 \cdot 62 \\
(0 \cdot 47-0 \cdot 85)\end{array}$ & $4 \cdot 50 \mathrm{E}-03$ & $0 \cdot 017$ & 2.28E-04 & $0 \cdot 726$ & $4 \cdot 16 E-02$ & $0 \cdot 048$ & $0 \cdot 002$ \\
\hline \multicolumn{12}{|l|}{ Kidney function test } \\
\hline $\begin{array}{l}\text { Creatinine } \\
(0 \cdot 67-1 \cdot 17 \mathrm{mg} / \mathrm{dL})\end{array}$ & $\begin{array}{c}0 \cdot 72 \\
(0 \cdot 59-0 \cdot 86)\end{array}$ & $\begin{array}{c}0 \cdot 78 \\
(0 \cdot 64-0 \cdot 93)\end{array}$ & $\begin{array}{c}0 \cdot 85 \\
(0 \cdot 70-1 \cdot 02)\end{array}$ & $\begin{array}{c}1 \cdot 01 \\
(0 \cdot 78-1 \cdot 36)\end{array}$ & $0 \cdot 030$ & $1 \cdot 82 \mathrm{E}-05$ & $6 \cdot 43 E-14$ & $1 \cdot 02 \mathrm{E}-05$ & $1 \cdot 12 \mathrm{E}-24$ & 6-32E-07 & $<0 \cdot 001$ \\
\hline $\begin{array}{l}\text { GFR } \\
\left(>75 \mathrm{~mL} / 1.73 \mathrm{~m}^{2}\right)\end{array}$ & $\begin{array}{c}90 \\
(90-90)\end{array}$ & $\begin{array}{c}90 \\
(88 \cdot-90)\end{array}$ & $\begin{array}{c}90 \\
(79-90)\end{array}$ & $\begin{array}{c}57 \\
(36-79)\end{array}$ & $0 \cdot 206$ & $5 \cdot 75 \mathrm{E}-04$ & $3 \cdot 06 E-65$ & $2 \cdot 36 E-06$ & $1 \cdot 42 E-196$ & $1 \cdot 5 \mathrm{E}-112$ & $<0 \cdot 001$ \\
\hline
\end{tabular}


AST, Aspartic Amino Transferase; ALT, Alanine Amino Transferase; CRP; C Reactive Protein; GFR, Glomerular Filtration Rate; Hb, Hemoglobin; NLR, Neutrophil Lymphocyte Ratio; WBC, White Blood cell Count. 
Table 6S. Median values of laboratory variables and the proportion out of the normal range and relation with mortality

\begin{tabular}{|c|c|c|c|c|c|c|}
\hline & $\mathbf{n}$ & Median (IQR) & $\begin{array}{c}\text { ONR } \\
\text { n (\%) }\end{array}$ & $\begin{array}{c}\text { Mortality } \\
\text { n (\%) }\end{array}$ & $p$-value & OR \\
\hline \multicolumn{7}{|l|}{ Blood } \\
\hline $\mathrm{Hb}$ & 1550 & $13 \cdot 5(12 \cdot 3-14 \cdot 5)$ & $590(38 \cdot 06 \%)$ & $107(18 \cdot 1 \%)$ & n.s. & \\
\hline$<12$ & & & 272 & $83(30 \cdot 5 \%)$ & $3 \cdot 00 \mathrm{E}-10$ & $2 \cdot 77$ \\
\hline$>15$ & & & 246 & $21(8 \cdot 5 \%)$ & $1 \cdot 16 \mathrm{E}-04$ & $2 \cdot 38$ \\
\hline Leukocytes & 1550 & $6 \cdot 6(5 \cdot 08-8 \cdot 76)$ & $344(22 \cdot 19 \%)$ & $86(25 \cdot 0 \%)$ & $5 \cdot 63 \mathrm{E}-06$ & $2 \cdot 00$ \\
\hline$<4 \cdot 0 \mathrm{e} 3$ & & & 166 & $28(16 \cdot 9 \%)$ & n.s. & \\
\hline$>11 \cdot 0 \mathrm{e} 3$ & & & 178 & $58(32 \cdot 6 \%)$ & $2 \cdot 30 \mathrm{E}-08$ & $2 \cdot 83$ \\
\hline Neutrophils, \% & 1550 & $76 \cdot 1(68-83 \cdot 2)$ & $550(35 \cdot 48 \%)$ & $153(27 \cdot 8 \%)$ & $1 \cdot 00 \mathrm{E}-10$ & \\
\hline$<40 \%$ & & & 9 & $1(11 \cdot 1 \%)$ & n.s. & \\
\hline$>80 \%$ & & & 541 & $152(28 \cdot 1 \%)$ & $1 \cdot 00 \mathrm{E}-10$ & $3 \cdot 33$ \\
\hline Top $10 \%$ cutoff & & & 156 & $58(37 \cdot 2 \%)$ & $1 \cdot 00 \mathrm{E}-10$ & $3 \cdot 53$ \\
\hline Bottom $10 \%$ cutoff & & & 157 & $15(9 \cdot 6 \%)$ & $1 \cdot 24 \mathrm{E}-02$ & $2 \cdot 00$ \\
\hline Neutrophils, $\mathrm{n}$ & 1550 & $4 \cdot 9(3 \cdot 5-6 \cdot 8)$ & $415(26 \cdot 77 \%)$ & $114(27 \cdot 5 \%)$ & $1 \cdot 00 \mathrm{E}-10$ & $2 \cdot 61$ \\
\hline$<2 \cdot 0 \mathrm{e} 3$ & & & 43 & $8(18 \cdot 6 \%)$ & n.s. & \\
\hline$>7.0 \mathrm{e} 3$ & & & 372 & $106(28 \cdot 5 \%)$ & $1 \cdot 0 \mathrm{E}-10$ & $2 \cdot 69$ \\
\hline Top $10 \%$ cutoff, $88 \cdot 4 \%$ & & & 156 & $58(37 \cdot 2 \%)$ & $1 \cdot 0 \mathrm{E}-10$ & $3 \cdot 53$ \\
\hline Top $5 \%$ cutoff, $90 \cdot 6$ & & & 77 & $36(46 \cdot 8 \%)$ & $2 \cdot 0 \mathrm{E}-10$ & $4 \cdot 95$ \\
\hline Lymphocytes, \% & 1550 & $16 \cdot 0(10 \cdot 5-23 \cdot 0)$ & $1031(66 \cdot 52 \%)$ & $211(20 \cdot 5 \%)$ & $3 \cdot 7 \mathrm{E}-09$ & $2 \cdot 58$ \\
\hline$<20 \%$ & & & 1022 & $210(20 \cdot 5 \%)$ & $2 \cdot 8 \mathrm{E}-09$ & $2 \cdot 5 \mathrm{c}$ \\
\hline$>50 \%$ & & & 9 & $1(11 \cdot 1 \%)$ & n.s. & \\
\hline Bottom $10 \%$ & & & 157 & $54(34 \cdot 4 \%)$ & n.s. & \\
\hline Bottom 5\% & & & 77 & $34(44 \cdot 2 \%)$ & $2 \cdot 58 \mathrm{E}-02$ & $1 \cdot 61$ \\
\hline Lymphocytes, $\mathrm{n}$ & 1550 & $1 \cdot 0(0 \cdot 7-1 \cdot 4)$ & $993(64 \cdot 06 \%)$ & $207(20 \cdot 8 \%)$ & $1 \cdot 1 \mathrm{E}-09$ & $2 \cdot 61$ \\
\hline$<1 \cdot 2 \mathrm{e} 3$ & & & 985 & $206(20 \cdot 9 \%)$ & $8 \cdot 00 \mathrm{E}-10$ & $2 \cdot 61$ \\
\hline$>3 \cdot 5 \mathrm{e} 3$ & & & 8 & $1(12 \cdot 5 \%)$ & n.s. & \\
\hline Bottom $10 \%$ & & & 163 & $60(36 \cdot 8 \%)$ & $1 \cdot 00 \mathrm{E}-10$ & $3 \cdot 50$ \\
\hline Bottom 5\% & & & 87 & $32(36 \cdot 8 \%)$ & $3 \cdot 95 \mathrm{E}-06$ & $3 \cdot 18$ \\
\hline Monocytes, $\%$ & 1551 & $6 \cdot 7(4 \cdot 8-8 \cdot 8)$ & $184(11 \cdot 86 \%)$ & $37(20 \cdot 1 \%)$ & n.s. & \\
\hline$<2 \%$ & & & 25 & $12(48 \cdot 0 \%)$ & $2 \cdot 39 \mathrm{E}-04$ & $4 \cdot 80$ \\
\hline$>11 \%$ & & & 159 & $25(15 \cdot 7 \%)$ & n.s. & \\
\hline$<0.1$ e 3 & & & 1 & $1(100 \cdot 0 \%)$ & n.s. & \\
\hline$>1 \cdot 0 \mathrm{e} 3$ & & & 67 & $16(23 \cdot 9 \%)$ & $\mathrm{n} \cdot \mathrm{s} \cdot$ & \\
\hline Eosinophils, $\%$ and $n$ & 1551 & $0 \cdot 0(0-0 \cdot 3)$ & $16(1 \cdot 03 \%)$ & $2(12 \cdot 5 \%)$ & n.s. & \\
\hline$>5 \%$ & & & 11 & $1(9 \cdot 1 \%)$ & n.s. & \\
\hline$>0.05 \mathrm{e} 3$ & & & 5 & $1(20 \cdot 0 \%)$ & n.s. & \\
\hline Basophils, $\mathrm{n}$ & 1551 & $0 \cdot 0(0-0)$ & 1 & $1(100 \cdot 0 \%)$ & n.s. & \\
\hline
\end{tabular}




\begin{tabular}{|c|c|c|c|c|c|c|}
\hline$>0.02 \mathrm{e} 3$ & & $0.02(0.01-0.03)$ & 1 & $1(100 \cdot 0 \%)$ & n.s. & \\
\hline Platelets & 1550 & & 311 & $83(26 \cdot 7 \%)$ & $3 \cdot 96 \mathrm{E}-04$ & $2 \cdot 21$ \\
\hline$<140 \mathrm{e} 3$ & & & 251 & $72(28 \cdot 7 \%)$ & $1 \cdot 46 \mathrm{E}-04$ & $2 \cdot 41$ \\
\hline$>400 \mathrm{e} 3$ & & & 60 & $11(18 \cdot 3 \%)$ & n.s. & \\
\hline \multicolumn{7}{|l|}{ APR and related parameters } \\
\hline CRP (N 0.03-0.5 mg/dL) & 1226 & $8 \cdot 9(3 \cdot 8-16 \cdot 6)$ & $1219(99 \cdot 43 \%)$ & $146(11 \cdot 98 \%)$ & n.s. & \\
\hline Top decile cutoff, 20 & & & 122 & $37(30 \cdot 33 \%)$ & $6 \cdot 40 \mathrm{E}-09$ & $3 \cdot 93$ \\
\hline Top 5\% cutoff, 30 & & & 62 & $24(38 \cdot 71 \%)$ & $2 \cdot 44 \mathrm{E}-08$ & $5 \cdot 35$ \\
\hline IL-6 $(0.0-4.3 \mathrm{pg} / \mathrm{mL})$ & 1259 & $45 \cdot 0(24-80)$ & $1029(81 \cdot 73 \%)$ & $146(14 \cdot 19 \%)$ & $1 \cdot 07 \mathrm{E}-02$ & Infinity \\
\hline Top decile cutoff, 140 & & & 125 & $47(37 \cdot 60 \%)$ & $1 \cdot 00 \mathrm{E}-10$ & $6 \cdot 30$ \\
\hline Top 5\% cutoff, $30219 \cdot 5$ & & & 62 & $24(38 \cdot 71 \%)$ & $1 \cdot 24 \mathrm{E}-08$ & $5 \cdot 57$ \\
\hline Ferritin $(25-400 \mathrm{ng} / \mathrm{mL})$ & 1128 & $539 \cdot 0(283 \cdot 5-1011)$ & $732(64 \cdot 89 \%)$ & $77(10 \cdot 52 \%)$ & n.s. & \\
\hline Top decile cutoff, 1667 & & & 108 & $12(11 \cdot 11 \%)$ & n.s. & \\
\hline Top 5\% cutoff, 2279 & & & 57 & $10(17 \cdot 54 \%)$ & n.s. & \\
\hline Triglycerides $(43-200 \mathrm{mg} / \mathrm{dL})$ & 620 & $121 \cdot 0(92-161)$ & $78(12 \cdot 58 \%)$ & $6(7 \cdot 69 \%)$ & n.s. & \\
\hline Top $10 \%$ cutoff, $224 \mathrm{mg} / \mathrm{dL}$ & & & 63 & $4(6 \cdot 35 \%)$ & n.s. & \\
\hline Top $5 \%$ cutoff, $269 \mathrm{mg} / \mathrm{dL}$ & & & 50 & $1(2 \cdot 00 \%)$ & n.s. & \\
\hline LDH $(0-248 \mathrm{UI} / \mathrm{L})$ & 1128 & $336 \cdot 0(271-421)$ & $935(82 \cdot 89 \%)$ & $98(10 \cdot 48 \%)$ & $0 \cdot 04$ & 1.94 \\
\hline Top 5\% cutoff, $661 \mathrm{UI} / \mathrm{L}$ & & & 56 & $14(25.00 \%)$ & 4·9E-04 & $3 \cdot 43$ \\
\hline \multicolumn{7}{|l|}{ Coagulation parameters } \\
\hline Fibrinogen $(2 \cdot 39-6 \cdot 1 \mathrm{~g} / \mathrm{L})$ & 1440 & $5 \cdot 1(4 \cdot 43-5 \cdot 95)$ & $311(21 \cdot 60 \%)$ & $48(15 \cdot 43 \%)$ & n.s. & \\
\hline$>6.1$ & & & 310 & $48(15 \cdot 48 \%)$ & n.s. & \\
\hline$<2.4$ & & & 2 & $0(0 \cdot 00 \%)$ & n.s. & \\
\hline Top decile cutoff, $6 \cdot 7$ & & & 146 & $28(19 \cdot 18 \%)$ & n.s. & \\
\hline Top $5 \%$ cutoff, $7 \cdot 22$ & & & 72 & $13(18 \cdot 06 \%)$ & n.s. & \\
\hline Bottom $5 \%$ cutoff, 1.68 & & & 73 & $18(24 \cdot 66 \%)$ & $0 \cdot 0495$ & \\
\hline D-dimer $(0-243 \mathrm{ng} / \mathrm{mL})$ & 1248 & $253 \cdot 0(168-463)$ & $683(54 \cdot 73 \%)$ & $121(17 \cdot 72 \%)$ & $1 \cdot 0 \mathrm{E}-10$ & $4 \cdot 65$ \\
\hline Top decile cutoff, $1074 \mathrm{ng} / \mathrm{mL}$ & & & 124 & $28(22 \cdot 58 \%)$ & $3 \cdot 1 \mathrm{E}-04$ & $2 \cdot 49$ \\
\hline Top $5 \%$ cutoff, $2352 \mathrm{ng} / \mathrm{mL}$ & & & 62 & $17(27 \cdot 42 \%)$ & 4.0E-04 & $3 \cdot 10$ \\
\hline Prothrombin time, INR $(0 \cdot 7-1 \cdot 3)$ & 1445 & $1 \cdot 1(1 \cdot 03-1 \cdot 19)$ & $148(10 \cdot 24 \%)$ & $57(38 \cdot 51 \%)$ & 1.0E-09 & $3 \cdot 99$ \\
\hline Top decile cutoff, $1 \cdot 31$ & & & 148 & $57(38 \cdot 51 \%)$ & $1 \cdot 0 \mathrm{E}-10$ & $3 \cdot 99$ \\
\hline Top $5 \%$ cutoff, $1 \cdot 51$ & & & 72 & $30(41 \cdot 67 \%)$ & $9 \cdot 3 \mathrm{E}-08$ & $4 \cdot 12$ \\
\hline Bottom 5\% & & & 84 & $12(14 \cdot 29 \%)$ & n.s. & \\
\hline \multicolumn{7}{|l|}{ Liver function test } \\
\hline AST (12-50 IU/L) & 1560 & $40 \cdot 0(30-60)$ & $532(34 \cdot 10 \%)$ & $109(20 \cdot 49 \%)$ & $4 \cdot 1 \mathrm{E}-03$ & $1 \cdot 50$ \\
\hline Top decile cutoff, $92 \mathrm{IU} / \mathrm{L}$ & & & 156 & $39(25 \cdot 00 \%)$ & $4 \cdot 6 \mathrm{E}-03$ & $1 \cdot 78$ \\
\hline Top $5 \%$ cutoff, 116 & & & 79 & $17(21 \cdot 52 \%)$ & n.s. & \\
\hline $\operatorname{ALT}(19-50 \mathrm{IU} / \mathrm{L})$ & 1563 & $28 \cdot 0(1911-50)$ & $370(23 \cdot 67 \%)$ & $41(11 \cdot 08 \%)$ & $1 \cdot 1 \mathrm{E}-03$ & $0 \cdot 56$ \\
\hline
\end{tabular}




\begin{tabular}{|c|c|c|c|c|c|c|}
\hline Top decile cutoff, $75 \mathrm{UI} / \mathrm{dL}$ & & & 162 & $18(11 \cdot 11 \%)$ & $3 \cdot 3 \mathrm{E}-02$ & 0.56 \\
\hline Top 5\% cutoff, 106 IU/L & & & 80 & $5(6 \cdot 25 \%)$ & $8 \cdot 2 \mathrm{E}-03$ & $0 \cdot 32$ \\
\hline AST/ALT & 1560 & $1 \cdot 4(1 \cdot 05-1 \cdot 8)$ & $1213(77 \cdot 76 \%)$ & & & \\
\hline Top decile cutoff, $2 \cdot 4$ & & & 155 & $74(47 \cdot 74 \%)$ & & \\
\hline Bilirubin, $\mathrm{T}(0 \cdot 3-1 \cdot 2 \mathrm{mg} / \mathrm{dL})$ & 1022 & $0 \cdot 6(0 \cdot 45-0 \cdot 74)$ & $46(4 \cdot 50 \%)$ & $12(26 \cdot 09 \%)$ & n.s. & \\
\hline Top decile cutoff, $0.95 \mathrm{mg} / \mathrm{dL}$ & & & 103 & $22(21 \cdot 36 \%)$ & $5 \cdot 7 \mathrm{E}-04$ & $2 \cdot 63$ \\
\hline Top $5 \%$ cutoff & & & 51 & $11(21 \cdot 57 \%)$ & $1 \cdot 7 \mathrm{E}-02$ & $2 \cdot 48$ \\
\hline Bilirubin, D $(0 \cdot 1-0 \cdot 57 \mathrm{mg} / \mathrm{dL})$ & 982 & $0 \cdot 3(0 \cdot 24-0 \cdot 38)$ & $49(4 \cdot 99 \%)$ & $10(20 \cdot 41 \%)$ & $2 \cdot 0 \mathrm{E}-02$ & $2 \cdot 63$ \\
\hline Top decile cutoff, $0 \cdot 64 \mathrm{mg} / \mathrm{dL}$ & & & 98 & $20(20 \cdot 41 \%)$ & $4 \cdot 0 \mathrm{E}-04$ & $2 \cdot 85$ \\
\hline Top 5\% cutoff & & & 49 & $10(20 \cdot 41 \%)$ & $2 \cdot 0 \mathrm{E}-02$ & $2 \cdot 63$ \\
\hline \multicolumn{7}{|l|}{ Kidney function test } \\
\hline Urea $(17-42 \mathrm{mg} / \mathrm{dL})$ & 1291 & $35 \cdot 0(3551)$ & $627(48 \cdot 57 \%)$ & $169(26 \cdot 95 \%)$ & $1 \cdot 0 \mathrm{E}-10$ & $4 \cdot 01$ \\
\hline Top decyl cutoff, $78 \mathrm{mg} / \mathrm{dL}$ & & & 132 & $78(59 \cdot 09 \%)$ & $1 \cdot 0 \mathrm{E}-10$ & $9 \cdot 94$ \\
\hline Top $5 \%$ cutoff, $103 \mathrm{mg} / \mathrm{dL}$ & & & 66 & $41(62 \cdot 12 \%)$ & $1 \cdot 0 \mathrm{E}-10$ & $9 \cdot 28$ \\
\hline Bottom $5 \%$ cutoff, $5 \mathrm{mg} / \mathrm{dL}$ & & & 72 & $3(4 \cdot 17 \%)$ & $1 \cdot 1 \mathrm{E}-03$ & $5 \cdot 12$ \\
\hline Creatinine,,$>1 \cdot 17$ & 1576 & & $270(17 \cdot 13 \%)$ & $107(39 \cdot 63 \%)$ & $1 \cdot 6 \mathrm{E}-26$ & $5 \cdot 34$ \\
\hline Creatinine, top decile cutoff, $1 \cdot 42$ & & & 157 & $74(47 \cdot 13 \%)$ & $4 \cdot 2 \mathrm{E}-23$ & $6 \cdot 35$ \\
\hline GFR $<75$ & 1573 & & $499(31 \cdot 7 \%)$ & $326(65 \cdot 33 \%)$ & $4 \cdot 4 \mathrm{E}-39$ & $6 \cdot 42$ \\
\hline Bottom $10 \%,<42 \cdot 7 \mathrm{~mL}$ & & & 154 & $83(53 \cdot 90 \%)$ & $6 \cdot 5 \mathrm{E}-31$ & $8 \cdot 53$ \\
\hline
\end{tabular}

Clinical laboratory variables and the 28-day decease outcome. Mortality among patients who had abnormal and extreme deviations in the laboratory values. The WBC count was at the above upper limit of normal (ULN) in $22.2 \%$ of the patients, and the mortality rate of these patients was significantly higher (25.0\%) than that of the entire study cohort (16.1\%). In most patients, the platelet count was within the normal range; however, when values fell below the lower limit of normal (LLN), the mortality rate was $26.7 \%$, which was significantly higher than that of the HUVH cohort's. The CRP values were outside the normal range in all but one patient; the mortality rate was $30.3 \%$ among patients with values in the top $10 \%$ ( $>20 \mathrm{mg} / \mathrm{dL}$ ), which was significantly higher than the HUVH cohort's. The IL-6 values were above the ULN in $96.8 \%$ of cases; the mortality rate was $37.7 \%$ in the participants with the top $10 \%$ values $(>140 \mathrm{ng} / \mathrm{dL})$. LDH and Triglycerides were excluded from other analysis because the excessive and unbalance number or missing data. Comparisons by Fisher exact test,

APR, acute-phase reactants; AST, aspartate aminotransferase; ALT, alanine aminotransferase; CRP, C-reactive protein; DFSO, days from symptom onset; GFR, glomerular filtration rate; IL-6, Interleukin-6; Hb, hemoglobin; LDH, lactate dehydrogenase; LOS, length of stay; NLR, neutrophil-to-lymphocyte ratio; OR, Odd Ratio; ONR, out of the normal range. 
Table 7S. ROC curve analysis, age stratified

\begin{tabular}{|c|c|c|c|c|c|c|c|c|c|c|c|c|c|c|c|c|c|c|c|c|}
\hline Variable & $\begin{array}{l}\text { AUC 40-55 } \\
\text { years }\end{array}$ & $95 \%$ CI & $p$ & $\mathrm{n}$ & $\begin{array}{l}\text { AUC } \\
\text { 56-65 } \\
\text { years }\end{array}$ & $95 \%$ CI & $p$ & $\mathbf{n}$ & $\begin{array}{l}\text { AUC 66- } \\
75 \text { years }\end{array}$ & $95 \%$ CI & $p$ & $\mathrm{n}$ & $\begin{array}{l}\text { AUC 76- } \\
85 \text { years }\end{array}$ & $95 \%$ CI & $p$ & $\mathrm{n}$ & $\begin{array}{c}\text { AUC }>85 \\
\text { years }\end{array}$ & $95 \% \mathrm{CI}$ & $p$ & $\mathbf{n}$ \\
\hline Age & 0.63 & $0 \cdot 56-0 \cdot 68$ & $5 \cdot 68 \mathrm{E}-05$ & 417 & 0.58 & $0 \cdot 50-0 \cdot 66$ & $3 \cdot 72 \mathrm{E}-02$ & 281 & 0.53 & $0 \cdot 45-0.59$ & $4 \cdot 38 \mathrm{E}-01$ & 306 & 0.58 & $0 \cdot 50-0 \cdot 64$ & $3 \cdot 89 \mathrm{E}-02$ & 247 & 0.59 & $0 \cdot 56-0 \cdot 68$ & $8 \cdot 50 \mathrm{E}-03$ & 320 \\
\hline Comorbidity & 0.66 & $0 \cdot 60-0 \cdot 71$ & $2 \cdot 96 \mathrm{E}-07$ & 417 & 0.57 & $0.50-0.66$ & $8 \cdot 56 \mathrm{E}-02$ & 281 & 0.63 & $0 \cdot 56-0.68$ & $2 \cdot 33 \mathrm{E}-04$ & 306 & 0.59 & $0 \cdot 51-0.65$ & 1.91E-02 & 247 & 0.64 & $0 \cdot 60-0 \cdot 71$ & 3.63E- 05 & 320 \\
\hline $\mathrm{SpO} / \mathrm{FiO} 2$ & 0.76 & $0 \cdot 69-0 \cdot 82$ & $6 \cdot 85 \mathrm{E}-11$ & 223 & $0 \cdot 77$ & $0 \cdot 68-0 \cdot 85$ & $3 \cdot 70 \mathrm{E}-02$ & 132 & $0 \cdot 79$ & $0.71-0.86$ & $3 \cdot 82 \mathrm{E}-10$ & 159 & 0.72 & $0 \cdot 63-0 \cdot 80$ & $4 \cdot 37 \mathrm{E}-06$ & 146 & $0 \cdot 75$ & $0 \cdot 69-0 \cdot 82$ & $1 \cdot 20 \mathrm{E}-08$ & 184 \\
\hline $\mathrm{Hb}$ & 0.55 & $0 \cdot 48-0 \cdot 61$ & $1 \cdot 27 \mathrm{E}-01$ & 411 & 0.58 & $0 \cdot 49-0.65$ & $3 \cdot 05 \mathrm{E}-07$ & 286 & 0.54 & $0 \cdot 47-0 \cdot 60$ & $2 \cdot 73 \mathrm{E}-01$ & 304 & $0 \cdot 58$ & $0 \cdot 50-0 \cdot 64$ & $3 \cdot 98 \mathrm{E}-02$ & 247 & $0 \cdot 56$ & $0 \cdot 48-0 \cdot 61$ & $1 \cdot 14 \mathrm{E}-01$ & 315 \\
\hline NLR & $0 \cdot 72$ & $0 \cdot 66-0 \cdot 77$ & $3 \cdot 02 \mathrm{E}-12$ & 411 & 0.66 & $0 \cdot 58-0.73$ & $5 \cdot 53 \mathrm{E}-05$ & 277 & 0.69 & $0 \cdot 62-0 \cdot 75$ & 3. $63 \mathrm{E}-08$ & 304 & 0.65 & $0 \cdot 61-0 \cdot 75$ & $2 \cdot 72 \mathrm{E}-05$ & 247 & $0 \cdot 71$ & $0 \cdot 66-0 \cdot 77$ & $9 \cdot 76 \mathrm{E}-10$ & 315 \\
\hline Monocytes \% & 0.64 & $0 \cdot 57-0 \cdot 69$ & 1.81E-05 & 411 & 0.65 & $0 \cdot 57-0 \cdot 72$ & $1 \cdot 85 \mathrm{E}-04$ & 277 & 0.69 & $0.62-0 \cdot 75$ & $6 \cdot 28 \mathrm{E}-08$ & 304 & 0.69 & $0 \cdot 53-0.67$ & $3 \cdot 33 \mathrm{E}-07$ & 247 & 0.64 & $0 \cdot 57-0.69$ & $3 \cdot 82 \mathrm{E}-05$ & 315 \\
\hline Monocytes n & 0.58 & $0 \cdot 51-0 \cdot 64$ & $1 \cdot 22 \mathrm{E}-02$ & 411 & 0.56 & $0 \cdot 48-0 \cdot 63$ & 1.32E-01 & 277 & 0.54 & $0 \cdot 47-0 \cdot 61$ & $2 \cdot 00 \mathrm{E}-01$ & 304 & $0 \cdot 61$ & $0 \cdot 51-0.65$ & $3 \cdot 60 \mathrm{E}-03$ & 247 & $0 \cdot 59$ & $0 \cdot 51-0 \cdot 64$ & $7 \cdot 60 \mathrm{E}-03$ & 315 \\
\hline Eosinophils \% & 0.64 & $0 \cdot 58-0.69$ & 1.08E-05 & 411 & $0 \cdot 60$ & $0.52-0.67$ & 1.56E-02 & 277 & $0 \cdot 60$ & $0.53-0.65$ & $5 \cdot 80 \mathrm{E}-03$ & 304 & 0.59 & $0 \cdot 51-0.65$ & $1 \cdot 61 \mathrm{E}-02$ & 247 & 0.63 & $0 \cdot 58-0.69$ & 1.65E-04 & 315 \\
\hline CRP & $0 \cdot 72$ & $0 \cdot 66-0 \cdot 77$ & $1 \cdot 85 \mathrm{E}-10$ & 359 & $0 \cdot 73$ & $0 \cdot 65-0 \cdot 80$ & $2 \cdot 83 \mathrm{E}-07$ & 235 & 0.76 & $0 \cdot 69-0 \cdot 82$ & $2 \cdot 75 \mathrm{E}-11$ & 240 & 0.73 & $0 \cdot 64-0 \cdot 80$ & $6 \cdot 35 \mathrm{E}-07$ & 165 & $0 \cdot 73$ & $0 \cdot 66-0 \cdot 77$ & $1 \cdot 40 \mathrm{E}-09$ & 274 \\
\hline IL6 & 0.78 & $0 \cdot 72-0 \cdot 83$ & $1 \cdot 16 \mathrm{E}-16$ & 374 & 0.76 & $0 \cdot 68-0 \cdot 82$ & 3.32E-09 & 245 & $0 \cdot 78$ & $0 \cdot 72-0.84$ & $5 \cdot 27 \mathrm{E}-14$ & 253 & 0.72 & $0 \cdot 64-0 \cdot 80$ & $1 \cdot 24 \mathrm{E}-06$ & 159 & 0.79 & $0 \cdot 72-0 \cdot 83$ & $6 \cdot 24 \mathrm{E}-15$ & 287 \\
\hline Ferritin & 0.65 & $0 \cdot 58-0 \cdot 71$ & $3 \cdot 41 \mathrm{E}-05$ & 343 & 0.67 & $0 \cdot 58-0 \cdot 76$ & $2 \cdot 31 \mathrm{E}-04$ & 225 & 0.61 & $0 \cdot 53-0.68$ & $9 \cdot 30 \mathrm{E}-03$ & 214 & 0.61 & $0 \cdot 51-0 \cdot 70$ & $2 \cdot 43 \mathrm{E}-02$ & 145 & 0.65 & $0 \cdot 58-0 \cdot 71$ & 1.91E-04 & 260 \\
\hline D-dimer & 0.65 & $0 \cdot 59-0 \cdot 71$ & 1.03E-05 & 343 & 0.64 & $0 \cdot 55-0.71$ & $1 \cdot 40 \mathrm{E}-03$ & 245 & 0.62 & $0 \cdot 55-0.69$ & $1 \cdot 70 \mathrm{E}-03$ & 245 & 0.64 & $0 \cdot 55-0 \cdot 72$ & $1 \cdot 90 \mathrm{E}-03$ & 164 & 0.64 & $0 \cdot 59-0 \cdot 71$ & $2 \cdot 54 \mathrm{E}-04$ & 279 \\
\hline AST/ALT & 0.61 & $0.55-0.67$ & 3.90E-04 & 412 & 0.59 & $0 \cdot 51-0.66$ & $2 \cdot 12 \mathrm{E}-02$ & 280 & 0.64 & $0 \cdot 56-0 \cdot 70$ & 9.90E-05 & 298 & 0.61 & $0 \cdot 54-0.68$ & $2 \cdot 70 \mathrm{E}-03$ & 244 & 0.59 & $0.55-0.67$ & $1 \cdot 05 \mathrm{E}-02$ & 315 \\
\hline GFR & 0.63 & $0 \cdot 56-0.68$ & $5 \cdot 12 \mathrm{E}-05$ & 416 & 0.57 & $0 \cdot 49-0 \cdot 64$ & $8.09 \mathrm{E}-02$ & 281 & 0.65 & $0 \cdot 58-0.71$ & $1 \cdot 03 \mathrm{E}-05$ & 305 & 0.61 & $0.53-0.67$ & $4 \cdot 00 \mathrm{E}-03$ & 245 & 0.62 & $0 \cdot 56-0.68$ & $8 \cdot 87 \mathrm{E}-04$ & 319 \\
\hline
\end{tabular}

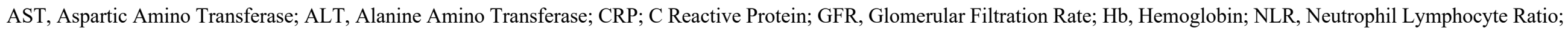
$\mathrm{NC}$, not calculated, $\mathrm{SpO} 2 / \mathrm{FiO} 2$, Oxygen saturation to fraction of inspired oxygen ratio; WBC, White Blood cell Count; CI, Confidence interval 5 to 95\%. 
Table 8S. Random Forest model applied to HUVH cohort

Random forest models

\begin{tabular}{|c|c|c|c|c|c|}
\hline \multicolumn{2}{|c|}{ Laboratory data model } & \multicolumn{2}{|c|}{ Clinical data model } & \multicolumn{2}{|c|}{ Laboratory and clinical data combined model } \\
\hline Variables & Mean Decrease Gini & Variables & Mean Decrease Gini & Variables & Mean Decrease Gini \\
\hline IL-6 & $12 \cdot 3$ & Age, years & $40 \cdot 5$ & Age & $13 \cdot 8$ \\
\hline CRP & $10 \cdot 4$ & Comorbidity Index & $11 \cdot 1$ & IL-6 & $9 \cdot 7$ \\
\hline GFR & $8 \cdot 5$ & Sex & $5 \cdot 6$ & CRP & $7 \cdot 1$ \\
\hline Neutrophils, \% & $7 \cdot 6$ & Cardiovascular conditions & $5 \cdot 2$ & GFR & $6 \cdot 4$ \\
\hline Urea & $7 \cdot 3$ & Obesity & $4 \cdot 1$ & Lymphocytes, $\mathrm{n}$ & $6 \cdot 3$ \\
\hline AST/ALT ratio & $7 \cdot 0$ & Chronic lung disease & $3 \cdot 5$ & Neutrophils, \% & $5 \cdot 5$ \\
\hline NLR & $6 \cdot 5$ & Diabetes & $3 \cdot 5$ & Urea & $5 \cdot 3$ \\
\hline Lymphocytes, $\mathrm{n}$ & $6 \cdot 5$ & Chronic neurological disease & $3 \cdot 2$ & Lymphocytes, $\%$ & $5 \cdot 2$ \\
\hline Fibrinogen & $6 \cdot 4$ & Chronic kidney disease & $2 \cdot 4$ & AST/ALT ratio & $5 \cdot 2$ \\
\hline Creatinine & $6 \cdot 2$ & Active non-terminal malignancy & $2 \cdot 3$ & NLR & $5 \cdot 2$ \\
\hline Lymphocytes, \% & $5 \cdot 9$ & Chronic liver disease & $1 \cdot 2$ & Creatinine & $4 \cdot 7$ \\
\hline Creatinine & $5 \cdot 7$ & & & D-dimer & $4 \cdot 6$ \\
\hline Platelets & $5 \cdot 3$ & & & Monocytes, \% & $4 \cdot 4$ \\
\hline Ferritin & $5 \cdot 2$ & & & Fibrinogen & $4 \cdot 4$ \\
\hline Monocytes, $\%$ & $5 \cdot 2$ & & & Ferritin & $4 \cdot 3$ \\
\hline AST & $5 \cdot 2$ & & & Platelets & $4 \cdot 0$ \\
\hline $\mathrm{Hb}$ & $5 \cdot 1$ & & & AST & $4 \cdot 0$ \\
\hline ALT & $5 \cdot 1$ & & & $\mathrm{Hb}$ & $3 \cdot 8$ \\
\hline Prothrombin time, INR & $4 \cdot 7$ & & & Monocytes, $\mathrm{n}$ & $3 \cdot 8$ \\
\hline Monocytes, $\mathrm{n}$ & $4 \cdot 5$ & & & Prothrombin time, INR & $3 \cdot 7$ \\
\hline WBC & $4 \cdot 3$ & & & ALT & $3 \cdot 6$ \\
\hline Neutrophils, $\mathrm{n}$ & $4 \cdot 2$ & & & Neutrophils, $\mathrm{n}$ & $3 \cdot 6$ \\
\hline Eosinophils, \% & $3 \cdot 2$ & & & WBC & $3 \cdot 3$ \\
\hline Eosinophils, $\mathrm{n}$ & $2 \cdot 4$ & & & Comorbidity Index & $2 \cdot 9$ \\
\hline & & & & Eosinophils, \% & $2 \cdot 8$ \\
\hline & & & & Eosinophils, $\mathrm{n}$ & $2 \cdot 6$ \\
\hline & & & & Cardiovascular conditions & $1 \cdot 6$ \\
\hline & & & & Obesity & $0 \cdot 9$ \\
\hline & & & & Chronic lung disease & $0 \cdot 7$ \\
\hline & & & & Chronic neurological disease & $0 \cdot 6$ \\
\hline
\end{tabular}




\begin{tabular}{|l|l|l|l|l|l|}
\hline & & & Sex & \multicolumn{1}{|c|}{$0 \cdot 8$} \\
\hline & & & & Active non-terminal malignancy & $0 \cdot 4$ \\
\hline & & & & Chronic kidney disease \\
\hline & & & Chronic liver disease & $0 \cdot 2$ \\
\hline
\end{tabular}

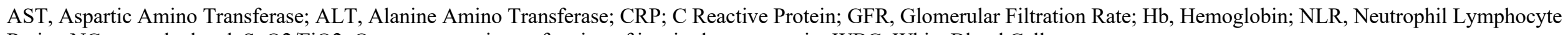
Ratio; NC, not calculated, $\mathrm{SpO} 2 / \mathrm{FiO} 2$, Oxygen saturation to fraction of inspired oxygen ratio; WBC, White Blood Cell count.

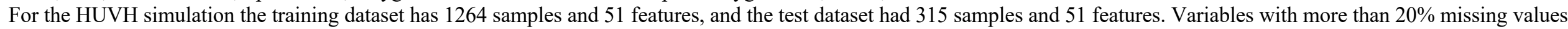
were removed, missing value imputation by median. The Mean Decrease Gini value indicates the importance of the variable in the outcome predicted in the model. 
Table 9S. Random Forest Model; comparison exploratory and combination of the three cohorts.

\begin{tabular}{|l|r|r|r|r|}
\hline & \multicolumn{4}{|c|}{ Mean Decrease Gini } \\
\hline Variables & HUVH cohort & Rank & Combined cohorts & Rank \\
\hline Urea & $16 \cdot 7$ & 1 & $31 \cdot 3$ & 2 \\
\hline IL-6 & $12 \cdot 8$ & 2 & $40 \cdot 3$ & 1 \\
\hline D·dimer & $11 \cdot 4$ & 3 & $27 \cdot 6$ & 3 \\
\hline CRP & $8 \cdot 4$ & 4 & $20 \cdot 6$ & 9 \\
\hline Hb & $7 \cdot 0$ & 5 & $22 \cdot 5$ & 6 \\
\hline ALT & $6 \cdot 3$ & 6 & $25 \cdot 2$ & 4 \\
\hline Platelets & $6 \cdot 2$ & 7 & $21 \cdot 2$ & 8 \\
\hline Neutrophils \% & $6 \cdot 0$ & 8 & $23 \cdot 5$ & 5 \\
\hline NLR & $5 \cdot 8$ & 9 & $22 \cdot 1$ & 7 \\
\hline Lymphocytes n & $5 \cdot 8$ & 10 & $20 \cdot 3$ & 10 \\
\hline Lymphocytes \% & $5 \cdot 6$ & 11 & $19 \cdot 3$ & 11 \\
\hline Ferritin & $5 \cdot 4$ & 12 & $17 \cdot 8$ & 13 \\
\hline Monocytes n & $4 \cdot 7$ & 13 & $14 \cdot 3$ & 16 \\
\hline Protrombin (INR) & $4 \cdot 6$ & 14 & $15 \cdot 7$ & 14 \\
\hline Monocytes \% & $4 \cdot 6$ & 15 & $18 \cdot 1$ & 12 \\
\hline Neutrophils n & $4 \cdot 4$ & 16 & $15 \cdot 6$ & 15 \\
\hline Eosinophils \% & $2 \cdot 7$ & 17 & $6 \cdot 5$ & 18 \\
\hline Basophils n & $2 \cdot 5$ & 18 & $7 \cdot 3$ & 17 \\
\hline Eosinophils n & $2 \cdot 3$ & 19 & 19 \\
\hline & & & & \\
\hline
\end{tabular}

CRP, C Reactive Protein; Hb, Hemoglobin; NLR, Neutrophil Lymphocyte Ratio; WBC, White Blood cell Count; n, number. For the three cohorts' simulation the training dataset had 2600 samples, and the test dataset 519 samples and 19 features. Variables with more than $20 \%$ missing values were removed, missing values imputation by median. The Mean Decrease Gini value indicates the importance of the variable in the outcome predicted in model. 
Table 10S. Patients included in immunological studies, cytokines and mononuclear cell phenotype by flowcytometry

\begin{tabular}{|c|c|c|c|c|c|}
\hline Patients & $\begin{array}{l}\text { HUVH cohort } \\
(\mathrm{n}=1579)\end{array}$ & $\begin{array}{l}\text { Cytokines sub-cohort } \\
(\mathrm{n}=74)\end{array}$ & $p$-value & $\begin{array}{l}\text { Phenotype sub-cohort } \\
\qquad(\mathrm{n}=\mathbf{4 1})\end{array}$ & $p$-value \\
\hline Age median (IQR) & $62(50-75)$ & $53(44-63)$ & $<0 \cdot 0001$ & $50(41-65)$ & $0 \cdot 012$ \\
\hline Female n (\%) & $698(44 \cdot 2 \%)$ & $36(48 \cdot 70 \%)$ & \multirow[t]{2}{*}{$0 \cdot 45$} & $15(30 \cdot 0 \%)$ & \multirow{2}{*}{0.34} \\
\hline Male n $(\%)$ & $880(55 \cdot 7 \%)$ & $38(51 \cdot 40 \%)$ & & $26(52 \cdot 0 \%)$ & \\
\hline \multicolumn{6}{|l|}{ Mortality } \\
\hline Overall n (\%) & $255(16 \cdot 1 \%)$ & $1(1 \cdot 40 \%)$ & $<0.001$ & $3(7 \cdot 3 \%)$ & $0 \cdot 18$ \\
\hline Female n (\%) & $107(15 \cdot 3 \%)$ & $0(0)$ & $<0 \cdot 01$ & $1(6 \cdot 7 \%)$ & $0 \cdot 48$ \\
\hline Male n (\%) & $148(16 \cdot 8 \%)$ & $1(2 \cdot 6 \%)$ & $<0 \cdot 05$ & $2(7 \cdot 7 \%)$ & $0 \cdot 29$ \\
\hline DFSO median (IQR) & $7(4-10)$ & $7(5-9)$ & $0 \cdot 73$ & $7(5-10)$ & $0 \cdot 09$ \\
\hline LOS median (IQR) & $6(2-19)$ & $11(6-37)$ & $<0 \cdot 001$ & $6(2-16)$ & $0 \cdot 97$ \\
\hline \multicolumn{6}{|l|}{ Severity } \\
\hline Mild n (\%) & $71(4 \cdot 40 \%)$ & $0(0 \cdot 0 \%)$ & \multirow[t]{4}{*}{$<0 \cdot 0001$} & $5(12 \cdot 2 \%)$ & \multirow{4}{*}{$0 \cdot 06$} \\
\hline Moderate n (\%) & $969(61 \cdot 50 \%)$ & $48(64 \cdot 9 \%)$ & & $27(65 \cdot 9 \%)$ & \\
\hline Severe $\mathrm{n}(\%)$ & $284(17 \cdot 40 \%)$ & $25(33 \cdot 8 \%)$ & & $6(14 \cdot 6 \%)$ & \\
\hline Deceased n (\%) & $255(16 \cdot 80 \%)$ & $1(1 \cdot 4 \%)$ & & $3(7 \cdot 3 \%)$ & \\
\hline \multicolumn{6}{|l|}{ Clinical presentation } \\
\hline Fever n (\%) & $1325(83 \cdot 9 \%)$ & $71(96 \cdot 0 \%)$ & $<0 \cdot 01$ & $36(87 \cdot 8 \%)$ & $0 \cdot 13$ \\
\hline \multicolumn{6}{|l|}{ Respiratory symptoms } \\
\hline Upper airways symptoms n (\%) & $94(5 \cdot 9 \%)$ & $4(5 \cdot 4 \%)$ & $0 \cdot 99$ & $3(7 \cdot 3 \%)$ & $0 \cdot 73$ \\
\hline Lower airway symptoms n (\%) & $1351(85 \cdot 5 \%)$ & $64(86 \cdot 5 \%)$ & $0 \cdot 99$ & $34(82 \cdot 9 \%)$ & $0 \cdot 65$ \\
\hline Pneumonia n (\%) & $1525(96 \cdot 5 \%)$ & $74(1)$ & $0 \cdot 17$ & $30(73 \cdot 2 \%)$ & $<0 \cdot 0001$ \\
\hline Digestive n (\%) & $492(31 \cdot 1 \%)$ & $28(37 \cdot 8 \%)$ & $0 \cdot 24$ & $15(36 \cdot 6 \%)$ & $0 \cdot 45$ \\
\hline \multicolumn{6}{|l|}{ Comorbidities } \\
\hline Cardiovascular \& hypertension n (\%) & $713(45 \cdot 1 \%)$ & $23(31 \cdot 1 \%)$ & $0 \cdot 02$ & $15(36 \cdot 6 \%)$ & $0 \cdot 34$ \\
\hline Chronic lung disease $\mathrm{n}(\%)$ & $278(17 \cdot 6 \%)$ & $10(13 \cdot 5 \%)$ & $0 \cdot 43$. & $3(7 \cdot 3 \%)$ & $0 \cdot 09$ \\
\hline Diabetes n (\%) & $293(18 \cdot 5 \%)$ & $8(10 \cdot 8 \%)$ & $0 \cdot 12$ & $11(26 \cdot 8 \%)$ & $0 \cdot 03$ \\
\hline Neurological disease $n(\%)$ & $227(14 \cdot 4 \%)$ & $5(6 \cdot 8 \%)$ & $0 \cdot 08$ & $3(7 \cdot 3 \%)$ & $0 \cdot 25$ \\
\hline Chronic renal disease $\mathrm{n}(\%)$ & $134(8 \cdot 5 \%)$ & $1(1 \cdot 4 \%)$ & $0 \cdot 02$ & $1(2 \cdot 4 \%)$ & $0 \cdot 25$ \\
\hline Active non-terminal malignancy $\mathrm{n}(\%)$ & $113(7 \cdot 2 \%)$ & $5(6 \cdot 8 \%)$ & $0 \cdot 99$ & $0(0 \cdot 0 \%)$ & $0 \cdot 11$ \\
\hline Obesity n (\%) & $261(16 \cdot 5 \%)$ & $24(32 \cdot 4 \%)$ & 1 & $2(4 \cdot 9 \%)$ & $0 \cdot 05$ \\
\hline Chronic liver disease $\mathrm{n}(\%)$ & $61(3 \cdot 9 \%)$ & $1(1 \cdot 4 \%)$ & $0 \cdot 52$ & $3(7 \cdot 3 \%)$ & $0 \cdot 21$ \\
\hline Comorbidity index $($ mean \pm SD) & $1 \cdot 32( \pm 1 \cdot 3)$ & $1( \pm 1 \cdot 3)$ & 0.03 & $0 \cdot 92(1 \cdot 14)$ & $0 \cdot 04$ \\
\hline
\end{tabular}




\begin{tabular}{|l|c|c|c|c|c|}
\hline Blood tests & $76 \cdot 1(68-83 \cdot 2)$ & $73 \cdot 9(68 \cdot 4-82 \cdot 3)$ & $0 \cdot 69$ & $79 \cdot 6(70 \cdot 6-84 \cdot 5)$ & $0 \cdot 25$ \\
\hline Neutrophils, \% median (IQR) & $4 \cdot 9(3 \cdot 5-6 \cdot 9)$ & $4 \cdot 7(3 \cdot 3-6 \cdot 3)$ & $0 \cdot 37$ & $5 \cdot 8(4 \cdot 1-7 \cdot 7)$ & $0 \cdot 17$ \\
\hline Neutrophils, n median (IQR) & $16(10 \cdot 5-23)$ & $17 \cdot 5(12 \cdot 8-17 \cdot 5)$ & $0 \cdot 14$ & $13(10 \cdot 5-20 \cdot 6)$ & $0 \cdot 32$ \\
\hline Lymphocytes, \% median (IQR) & $1 \cdot 0(0 \cdot 7-1 \cdot 4)$ & $1 \cdot 1(0 \cdot 83-1 \cdot 48)$ & $0 \cdot 23$ & $1 \cdot 02(0 \cdot 77-1 \cdot 02)$ & $0 \cdot 63$ \\
\hline Lymphocytes, n median (IQR) & $0 \cdot 4(0 \cdot 31-0 \cdot 6)$ & $0 \cdot 39(0 \cdot 29-0 \cdot 58)$ & $0 \cdot 34$ & $0 \cdot 44(0 \cdot 33-0 \cdot 63)$ & $0 \cdot 50$ \\
\hline Monocytes, n median (IQR) & $0(0-0 \cdot 3)$ & $0 \cdot 0(0 \cdot 0-0 \cdot 2)$ & $0 \cdot 45$ & $0 \cdot 10(0 \cdot 0-0 \cdot 45)$ & $0 \cdot 13$ \\
\hline Eosinophils, \% median (IQR) & $197(154-251)$ & $199(167-199)$ & $0 \cdot 46$ & $229(176-306)$ & $0 \cdot 007$ \\
\hline Platelets median (IQR) & & & & \\
\hline Clinical Chemistry \& Immunology & $8 \cdot 9(3 \cdot 8-16 \cdot 6)$ & $7 \cdot 8(4 \cdot 5-18)$ & $0 \cdot 93$ & $9 \cdot 9(6 \cdot 2-15)$ & $0 \cdot 97$ \\
\hline APR and related parameters & $45 \cdot 1(23 \cdot 80 \cdot 0)$ & $37(21-78)$ & $0 \cdot 24$ & $46(25-79)$ & $0 \cdot 86$ \\
\hline CRP median (IQR) & $539(282 \cdot 5-1011 \cdot 5)$ & $581(284-1,106)$ & $0 \cdot 44$ & $438(237-915)$ & $0 \cdot 63$ \\
\hline IL-6 median (IQR) & & & \\
\hline Ferritin median (IQR) & $263(168-463 \cdot 5)$ & $246(141-420)$ & $0 \cdot 23$ & $239(152-375)$ & $0 \cdot 25$ \\
\hline Coagulation & & & \\
\hline D-dimer median (IQR) & & & & \\
\hline
\end{tabular}

HUVH Cohort: clinical and demographic features of the sub-cohorts from cytokines and blood cell-phenotypic analysis. Univariate comparison using Mann-Whitney U test with adjusted p-values. DFSO, days from symptom onset; LOS, length of stay; NLR, neutrophil-to-lymphocyte ratio; CRP, C-reactive protein; AST, aspartate aminotransferase; ALT, alanine aminotransferase; eGFR, estimated glomerular filtration rate; IL-6, Interleukin-6; LDH, lactate dehydrogenase; Hb, hemoglobin. 


\section{Exploratory}

\begin{tabular}{|c|c|}
\hline $\begin{array}{l}\text { Descriptive: age, mortality, severity } \\
\text { and comorbidities distribution }\end{array}$ & ble to other conte \\
\hline $\begin{array}{l}\text { Pairwise comparison of all variables } \\
\text { comparing survivors with deceased } \\
\text { and max severity } 28 \mathrm{~d} \text { outcome }\end{array}$ & $\begin{array}{l}\text { The comparison of demographic, clinical and } \\
\text { laboratory variable show strong association of } 20 \\
\text { variables to outcomes }\end{array}$ \\
\hline $\begin{array}{l}\text { Logistic regression, Random Forest } \\
\text { simulation and principal component } \\
\text { analysis }\end{array}$ & $\begin{array}{l}\text { Confusion matrix classification tables shows } \\
\text { maximal predictive power for decase in the order } \\
\text { of } 50 \% \text {, no clear separations of groups in the PCA }\end{array}$ \\
\hline \multicolumn{2}{|l|}{ In depth analysis } \\
\hline Multiple correlations & $\begin{array}{l}\text { Global correlogram reveals cluster of varlables; } \\
\text { Categories proposed CDs, IFRBs and ODRBs. }\end{array}$ \\
\hline $\begin{array}{l}\text { Repeated Multiple logistic } \\
\text { regression, VIF scores }\end{array}$ & \\
\hline Weight of age as predictor & differe \\
\hline $\begin{array}{l}\text { Survival curves generated using } \\
\text { ROC Youden indexes as cut-off, } \\
\text { and also age stratified }\end{array}$ & $\begin{array}{l}\text { Hazard Ratios from survival curves dimensions } \\
\text { the weight of age in survival }\end{array}$ \\
\hline $\begin{array}{l}\text { Univariate logistic regression } \\
\text { corrected by age }\end{array}$ & $\begin{array}{l}\text { independent predictive power. Age has more } \\
\text { predictive power for decease than for severity }\end{array}$ \\
\hline Test performance & ROC curve analysis shows dominant effect o \\
\hline $\begin{array}{l}\text { Clinical laboratory performance } \\
\text { assessment by ROC curve analysis }\end{array}$ & $\begin{array}{l}\text { is constant, and in this context } \mathrm{SpO} / \mathrm{FiO} 2 \text { and } \\
\text { clinical laboratory test can make a decisive } \\
\text { contribution }\end{array}$ \\
\hline $\begin{array}{l}\text { LOWESS analysis of daily mean } \\
\text { variables for deceased and } \\
\text { survivors during the } 28 \text { days time } \\
\text { course }\end{array}$ & $\begin{array}{l}\text { Shows that differences are maintained during } \\
\text { most of the time course. Helps interpreting } \\
\text { laboratory results at different diseases stages }\end{array}$ \\
\hline
\end{tabular}

Additional analyses

\begin{tabular}{|c|c|}
\hline $\begin{array}{l}\text { Pairwise comparison of Clinico- } \\
\text { Demographic data from the three } \\
\text { cohorts, age adjusted logistic } \\
\text { regression and and biomarkers } \\
\text { performance assessed by ROC } \\
\text { curves }\end{array}$ & $\begin{array}{l}\text { Comparison of the three cohorts: similar results of } \\
\text { pairwise, univariate (age adjusted) and } \\
\text { multivariate; PCAs and random forest confirms } \\
\text { similar performance of predictive variables }\end{array}$ \\
\hline $\begin{array}{l}\text { Cytokine and flow cytometry } \\
\text { results, pairwise and performance } \\
\text { ROC curve analysis }\end{array}$ & $\begin{array}{l}\text { Promising performance (AUROCs), but } \\
\text { preliminary } \\
\text { Early efficient immune response required }\end{array}$ \\
\hline
\end{tabular}

Figure $1 \mathrm{~S}$

Figure 1S. Sequence of statistical analyses and summary of conclusions from every step, left column boxes type of analysis, right column boxes main conclusion. CD, Clinicodemographic; IFRB, Inflammatory Related Biomarkers; ODRB, Organ Damage Related Biomarkers. 


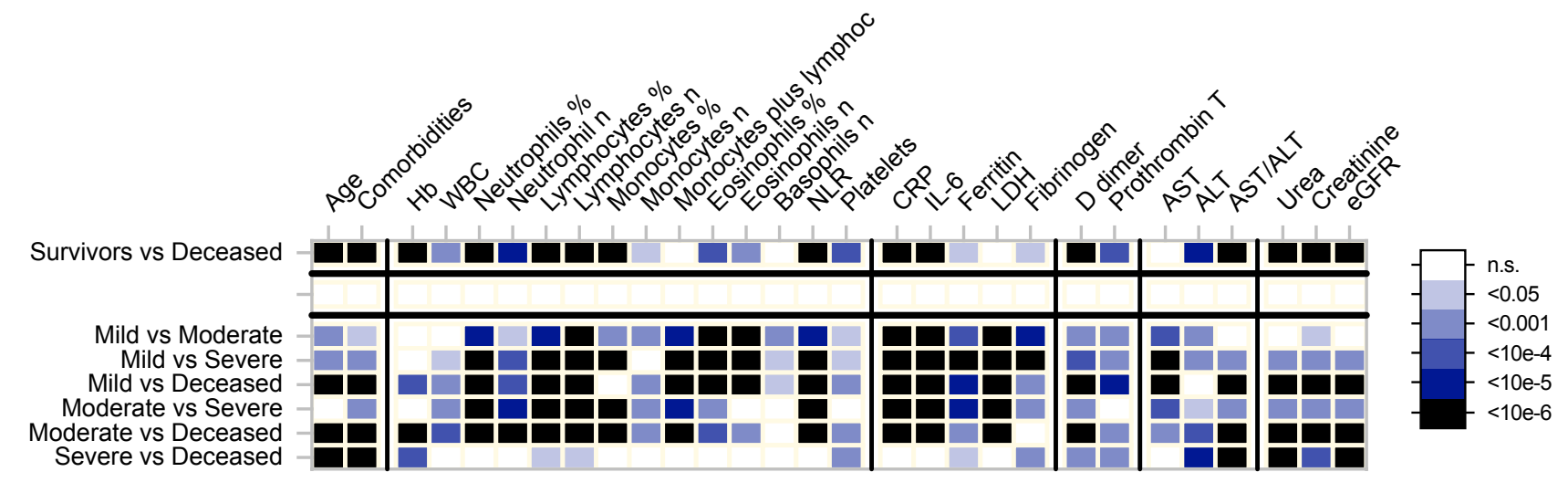

\section{Figure2S}

Figure 2S. Heatmap summarizing pairwise comparison; p values scale refers to non-parametric tests (Mann-Whitney and Kruskal-Wallis). 


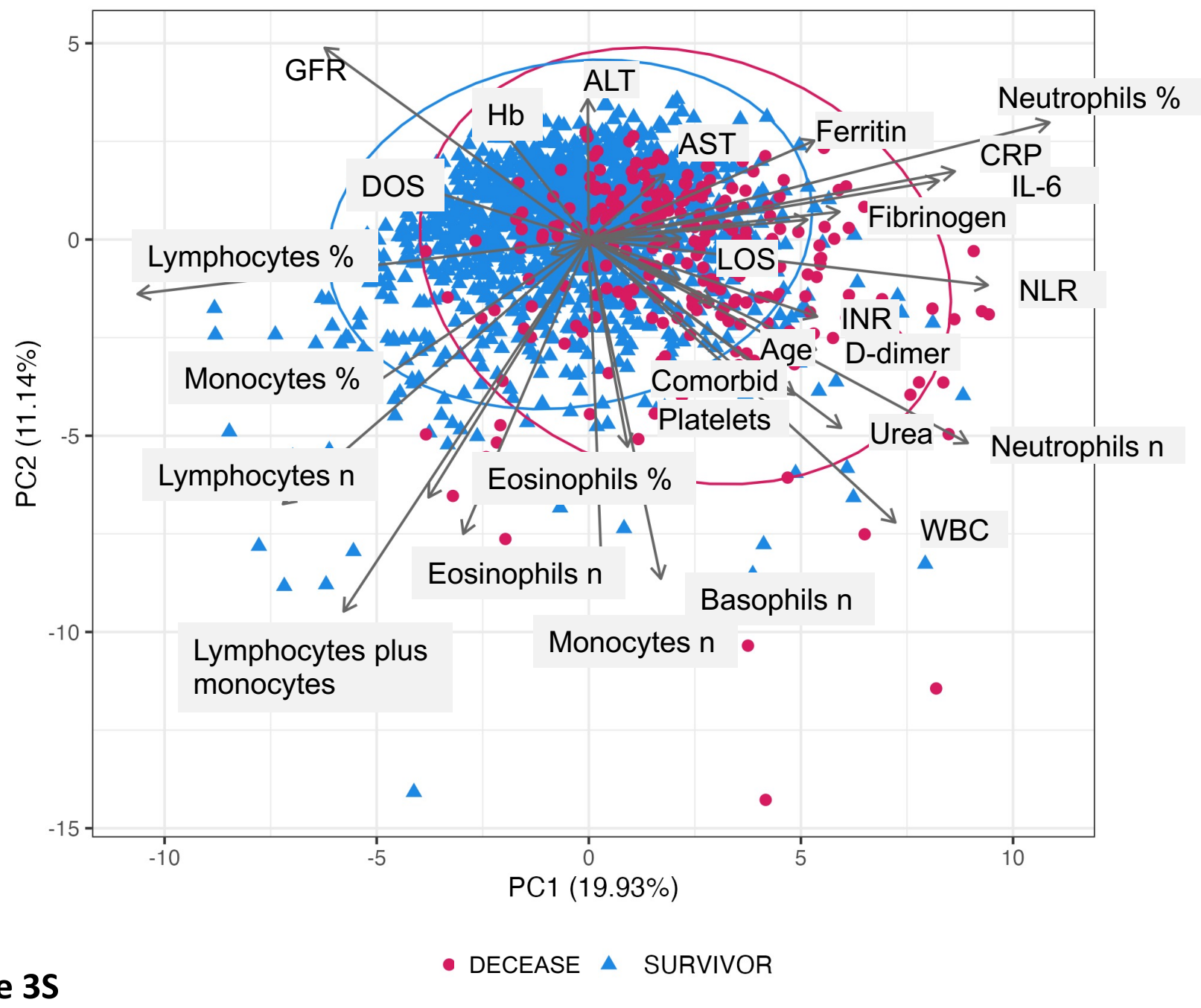

Figure 3S. Principal component analysis of the main variables, exitus is equivalent to decease. CRP, C-Reactive Protein; GFR, glomerular filtration rate; Hb, haemoglobin; LOS, length of stay at hospital; NLR, neutrophils to lymphocyte ratio; WBC, Whole Blood Count. The variables to the right of the plot contribute to decease, the variables to the left contribute to survival, the length of the vector and the angle is and indicator of the relative contribution to the outcome. Notice how lymphocyte $\%$ and $n$ and neutrophils $\%$ and $n$ pull to the opposite outcomes. 
A

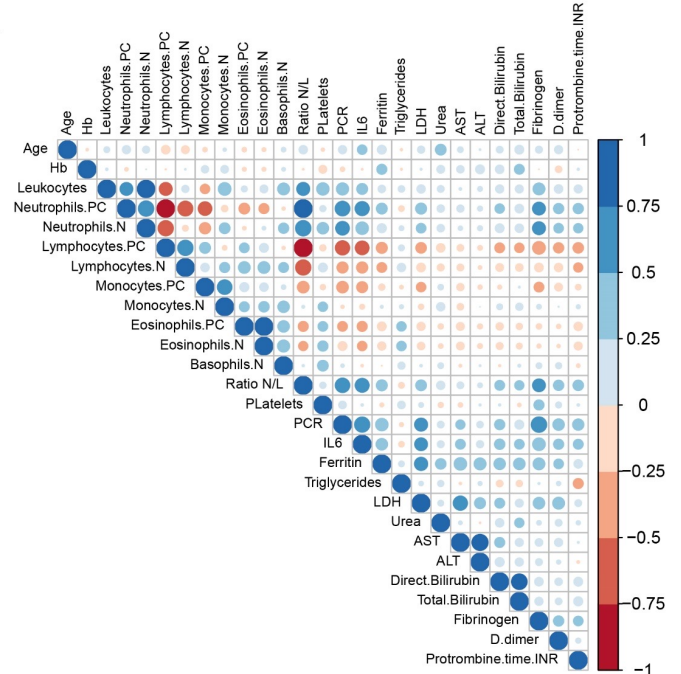

B

\section{Figure 4S}

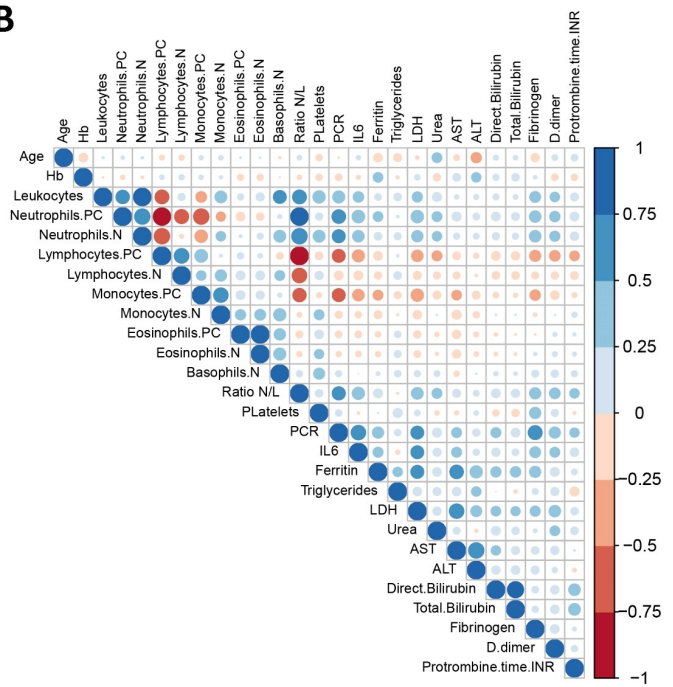

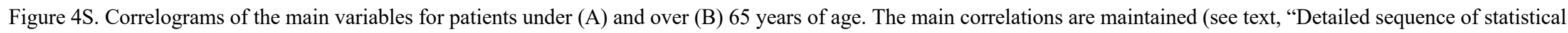

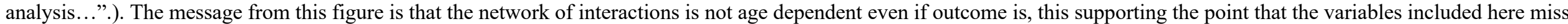
some crucial pathogenic factors. 


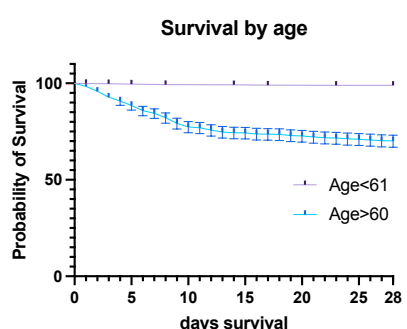

days surviva

Survival by GFR

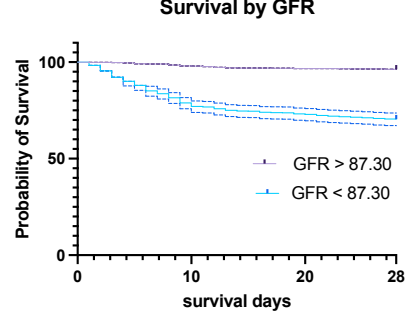

Survival by CRP

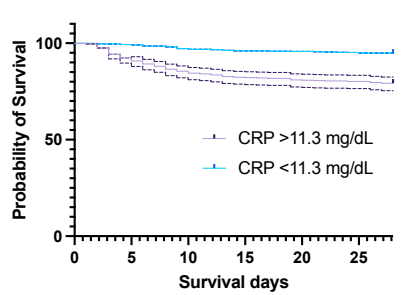

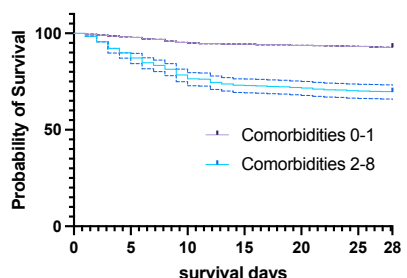

Survival by AST/ALT

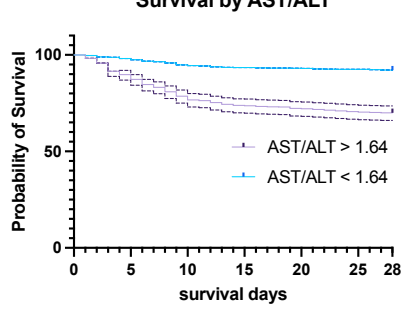

Survival by Ferritin

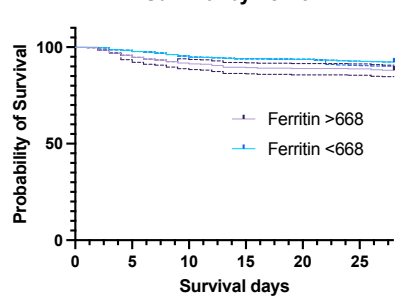

Survival of SpO2/FiO2

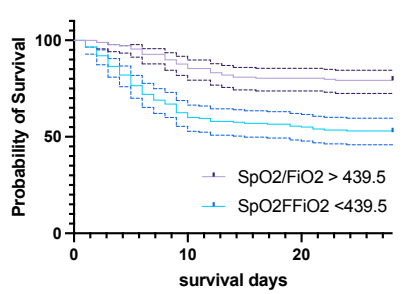

Survival by NLR

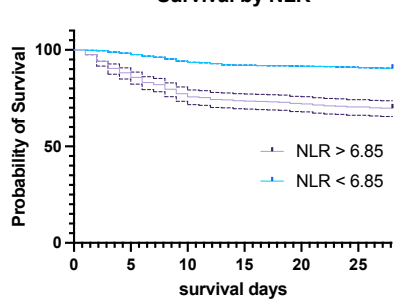

Survival by D-dimer

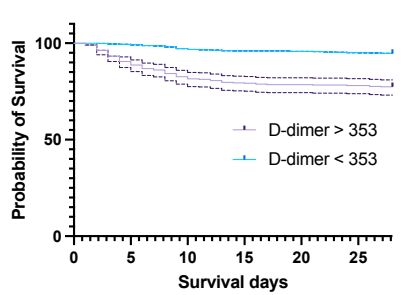

\section{Figure $5 S$}

Figure 5S. Representative Kaplan-Meyer survival curves clinicodemographic biomarkers (ODRB) and inflammation related biomarkers (IFRB). Cut off points determined by the Youden index in performance clinical laboratory type of ROC curves. The message from this figure is that ODRB are more closely associated to mortality, even if their variations were not wide and they may be easily missed during clinical management. 


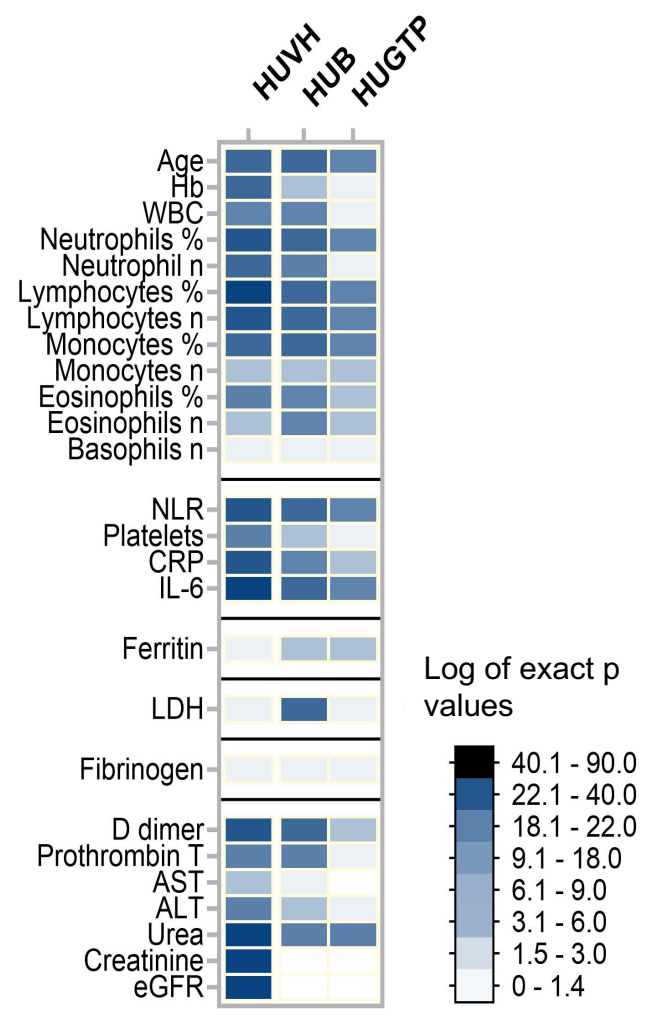

\section{Figure 6S}

Figure 6S. Heatmap summarizing pairwise comparison of the survivors vs deceased in the three hospital cohorts; p values scale refer non-parametric comparisons (Mann-Whitney and Kruskal-Wallis). In general $p$ values are not very informative of the weight of each independent variable in the outcome (dependent variable) but when differences are so large, that they are indicative of which variables are more closely associated to outcome, to be corroborated by the subsequent analyses. The heatmap makes visual those differences. 


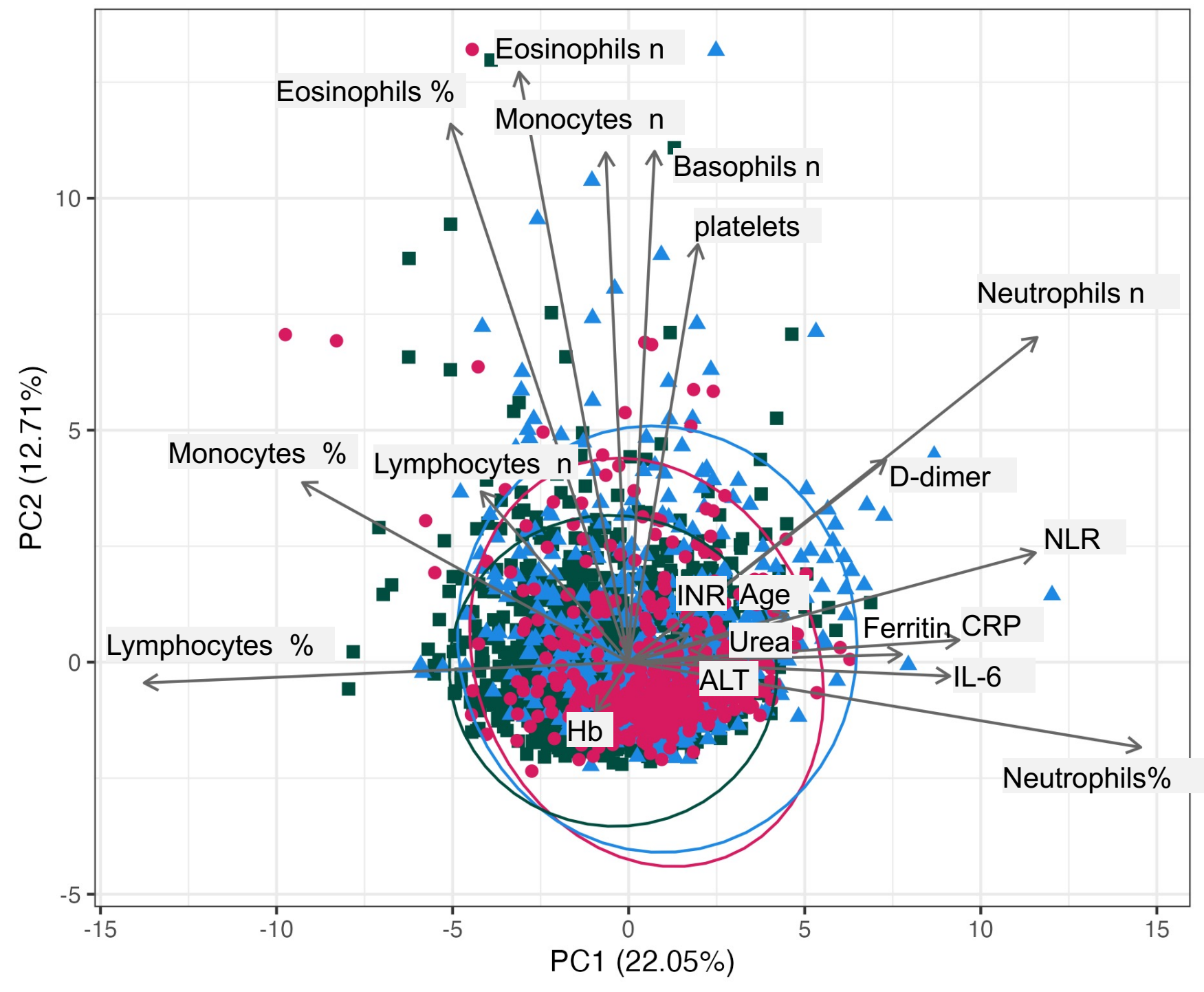

Figure 7S

- HUVH $\triangle$ HUB $\bullet$ HUGTP

Figure 7S. PCA analysis representation of the three hospitals cohorts, indicating similar main vectors, with local differences. The plot should be compared with plot figure 3S; . The variables to the right of the plot contribute to decease, the variables to the left contribute to survival, the length of the vector and the angle is and indicator of the relative contribution to the outcome. Notice how lymphocyte $\%$ and $\mathrm{n}$ and neutrophils $\%$ and $\mathrm{n}$ pull to the opposite outcomes 


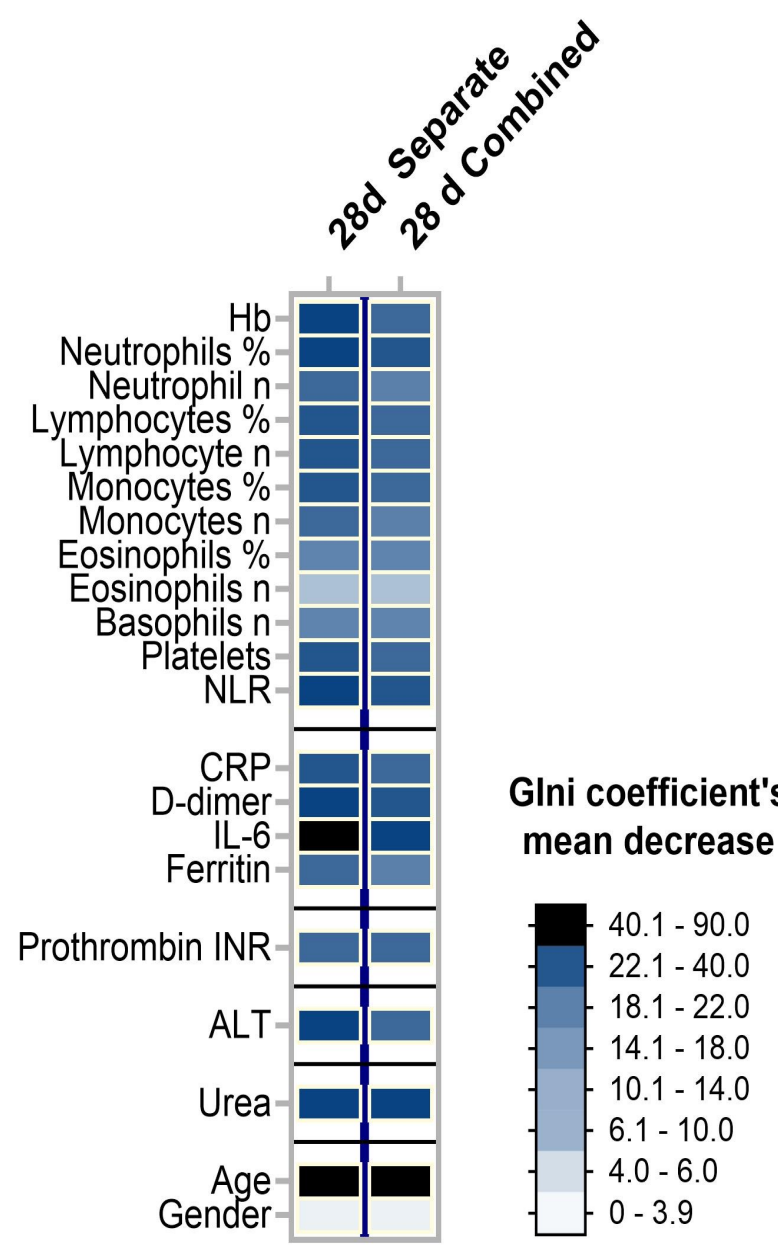

\section{Figure 8S}

Figure 8S. Heatmap summarizing the reduction of mean Gini index in the Random Forest model that reflects the importance of each variable in the predictive model. The left column represents the values when laboratory and age plus comorbidities models were run separately and the right column, when run combined; notice that in both, age is the dominant variable. 
A

\section{Cytokine correlogram}

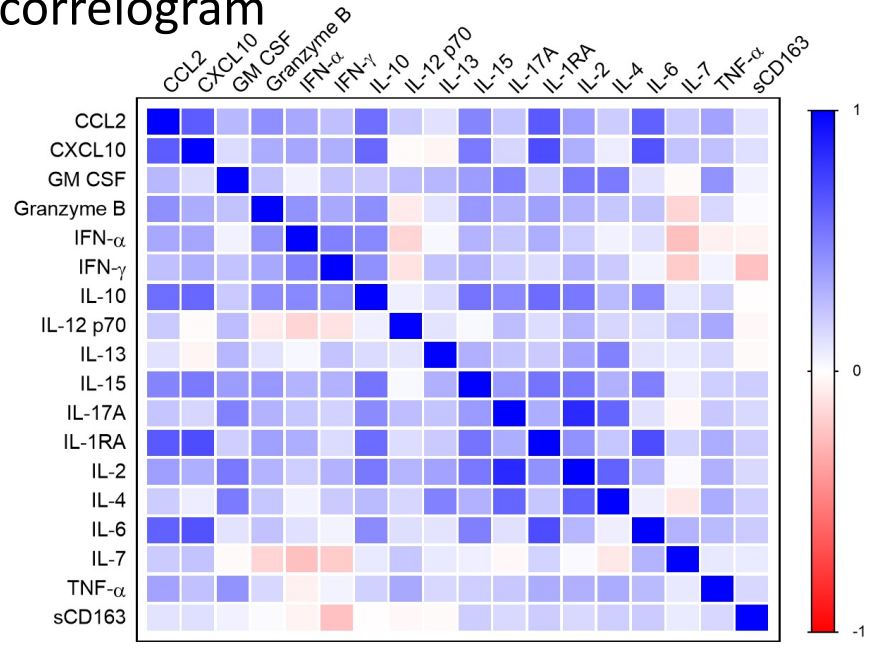

Day 2-3

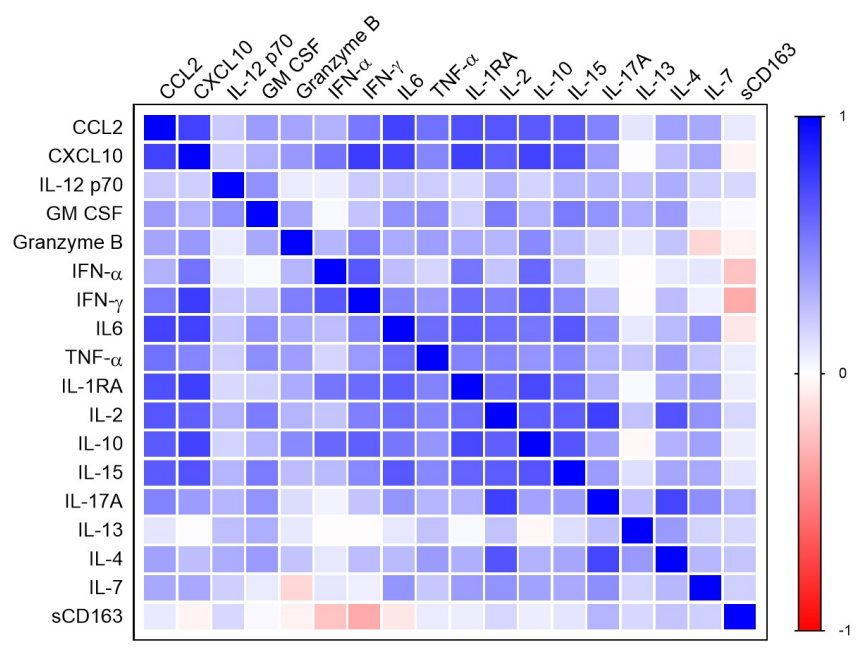

B

Non-severe

Figure 9S

Figure 9S. A, Comparison of correlograms among cytokines initial sample and two differences are observed (see supplementary text, subsection cytokines) but not striking, thus indicating that the interval was too short, an indication for future studies. 

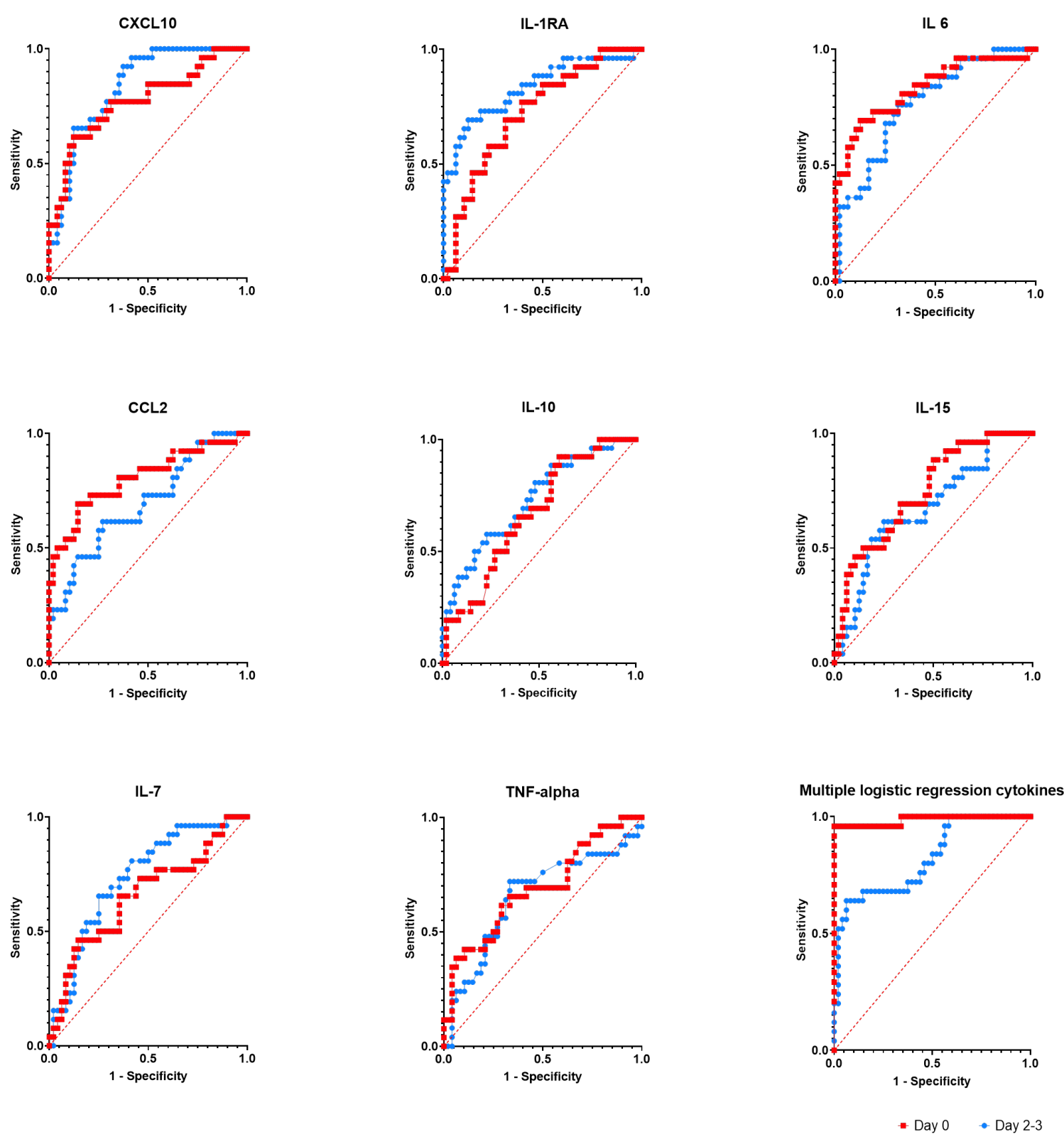

Figure 10S

Figure 10S. Performance of cytokines as clinical laboratory test in ROC curve analysis. For values see Table 6, but direct examination of the curves indicates that these variables may be useful for further studies. 
A

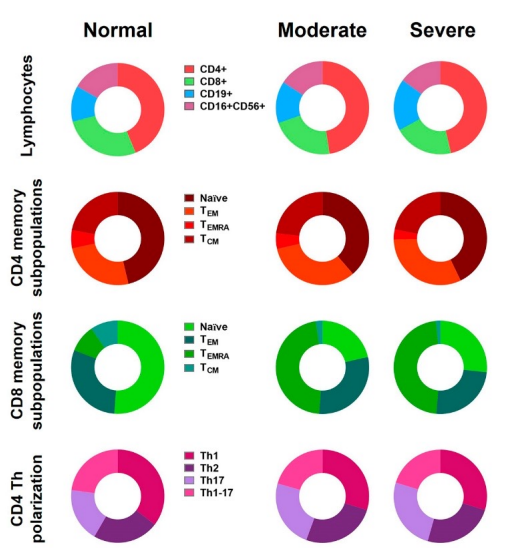

B

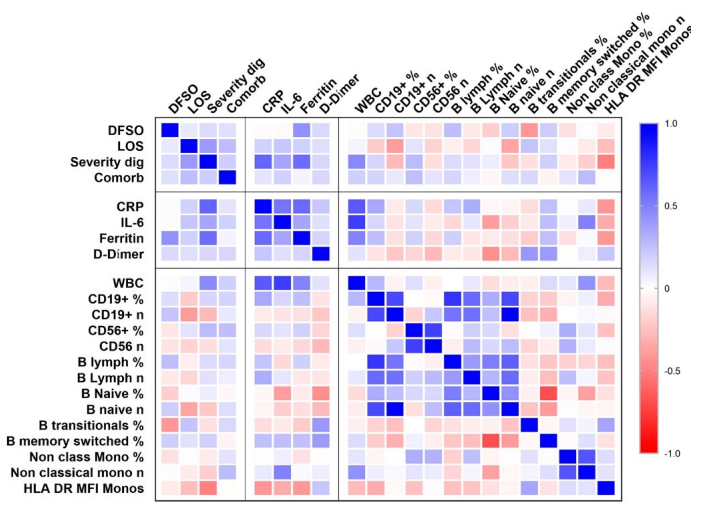

C

\section{Figure 11S}

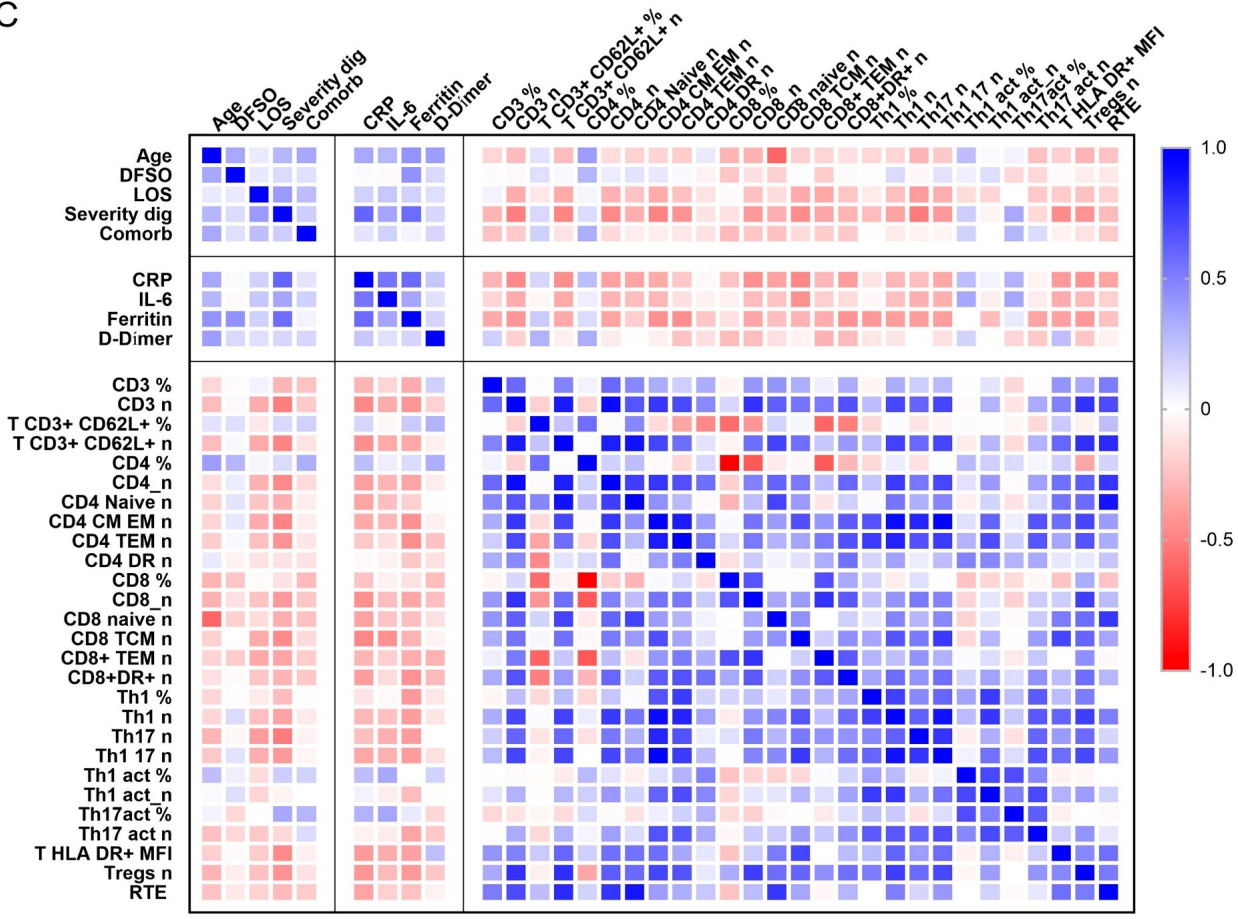

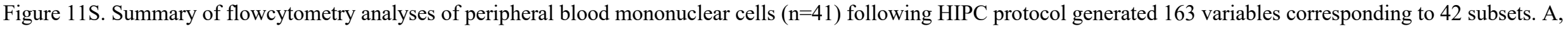

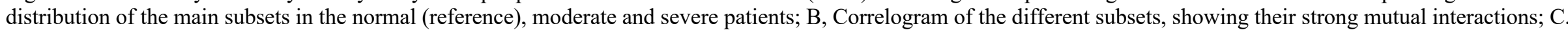

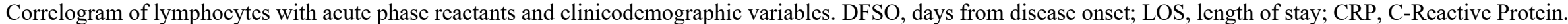

